\title{
(1)
}

UNIVERSIDAD PERUANA DE CIENCIAS APLICADAS

ESCUELA DE POSTGRADO

PROGRAMA DE MAESTRÍA EN DIRECCIÓN DE SISTEMAS Y

TECNOLOGÍAS DE LA INFORMACIÓN

\section{Propuesta de implementación de una arquitectura de negocio para optimizar los procesos de las áreas de producto y ventas para la agencia de viajes "viajes falabella"}

TRABAJO DE INVESTIGACIÓN

Para optar el grado académico de Maestro en Dirección de Sistemas y

Tecnologías de la Información

\begin{abstract}
AUTORES
Anton Calvay, Hernan Aaron (0000-0001-5523-235X)

Inga Ramirez, Rocio (0000-0001-8039-6612)

La Hoz Chavez, Efrain Eduardo (0000-0002-7094-570X)

ASESOR

Villalta Riega, Rosario Del Pilar (0000-0002-9546-7927)
\end{abstract}

Lima, Noviembre de 2017 


\section{TABLA DE CONTENIDO}

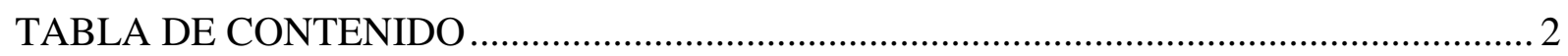

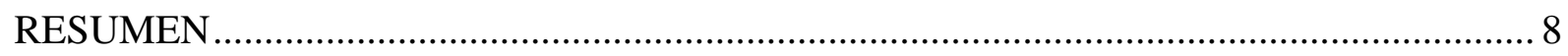

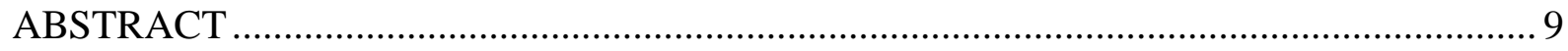

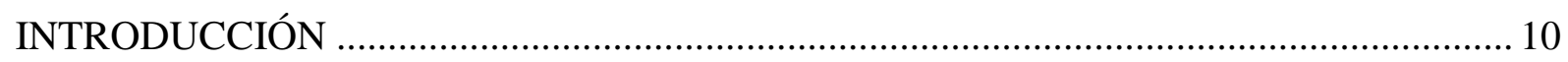

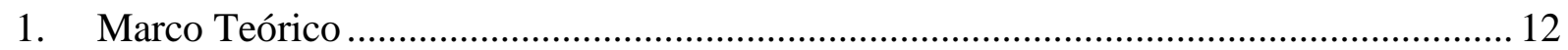

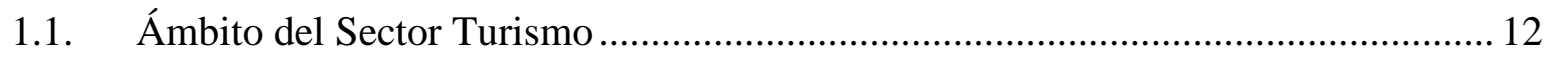

1.1.1. El Sector Turismo - Definiciones ............................................................. 12

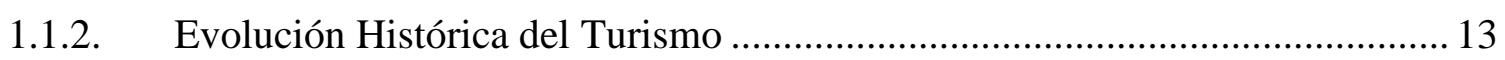

1.1.3. Evolución Histórica del Turismo en el Perú .................................................. 14

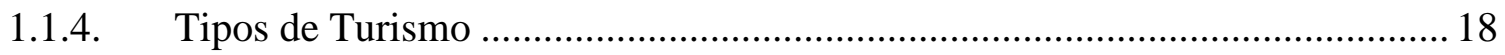

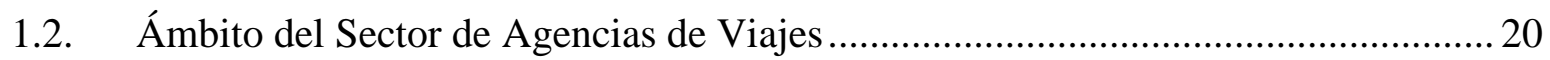

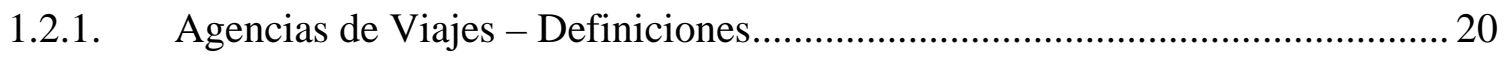

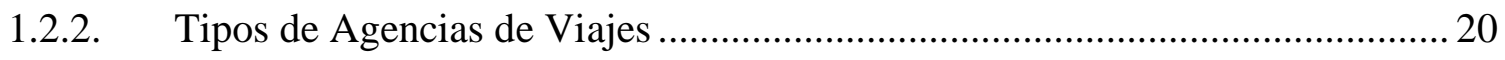

1.2.3. Tipo de Proveedores de Agencias de Viajes .................................................. 21

1.2.4. Cifras Estadísticas del Sector Turismo - Agencias de Viajes en el Perú.......... 21

1.2.5. Tendencias claves en las demandas de viajes y turismo ................................. 25

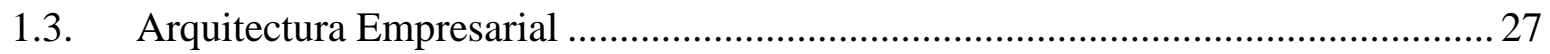

1.3.1. Definición de arquitectura empresarial ............................................................ 27

1.3.2. Metodologías de Arquitectura Empresarial.................................................... 28

1.3.3. Metodología de Selección del framework de Arquitectura Empresarial .......... 29

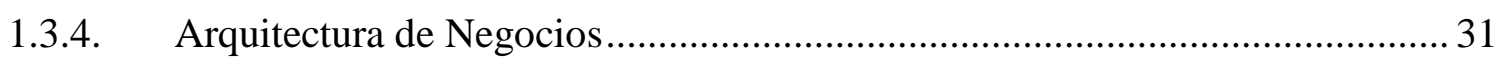

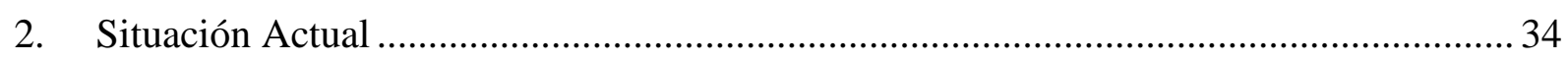

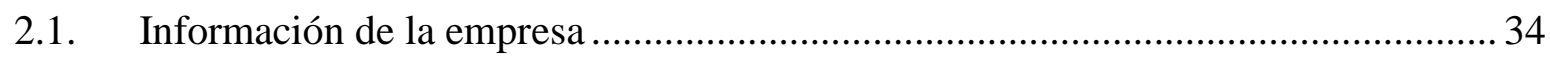

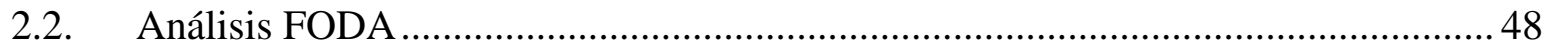

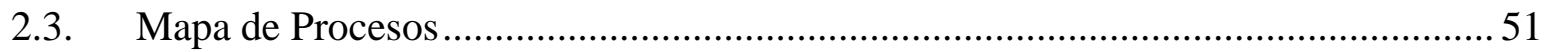

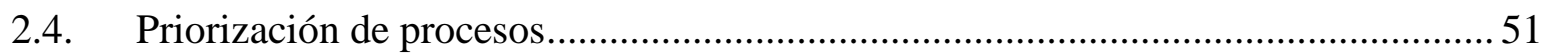

2.5. Descripción de Macroprocesos ........................................................................... 53

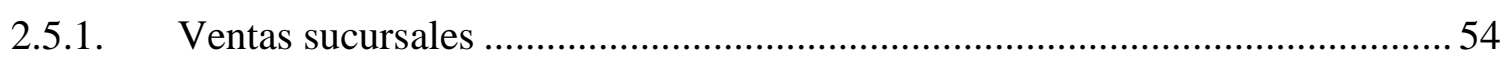




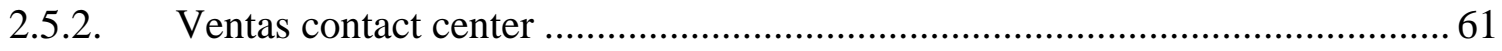

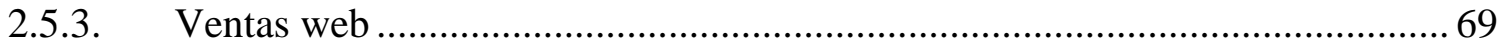

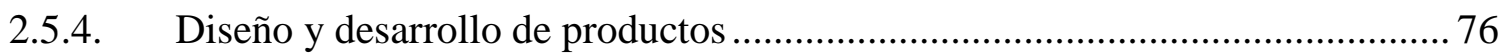

2.6. Situación actual de los procesos de Diseño de Productos y Ventas.......................... 80

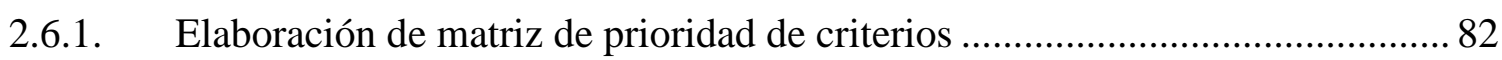

2.6.2. Elaboración de matriz de prioridad de indicadores .......................................... 83

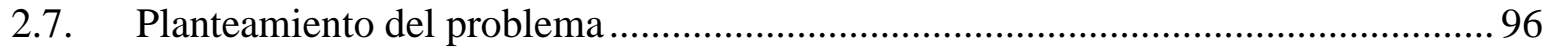

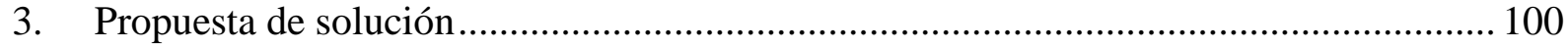

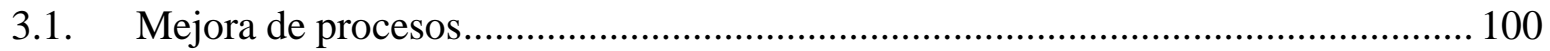

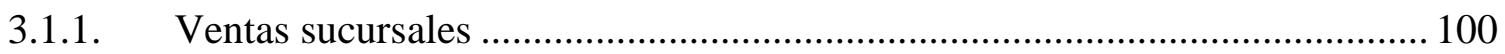

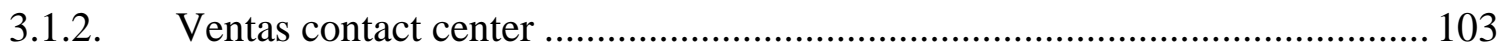

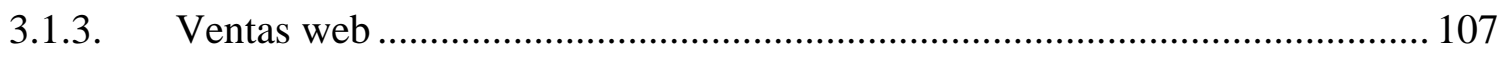

3.1.4. Diseño y desarrollo y de productos ............................................................... 111

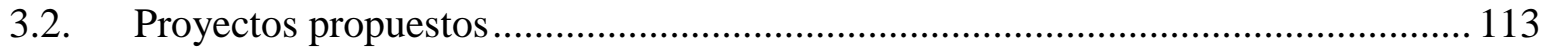

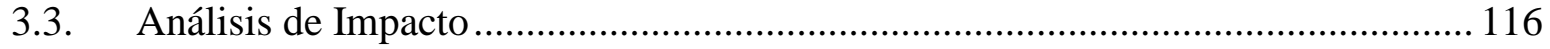

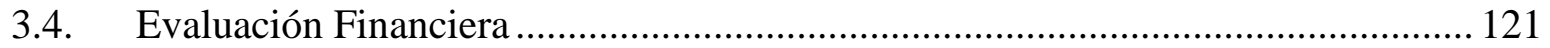

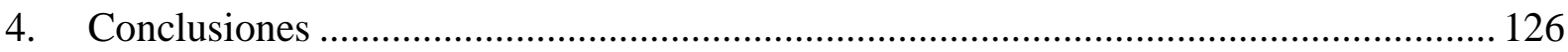

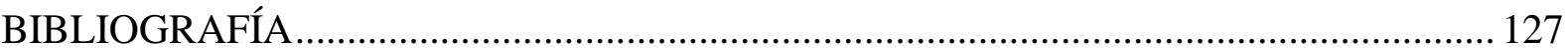


Gráfico 1. Balanza de Bienes y Servicios del sector turismo.................................................. 21

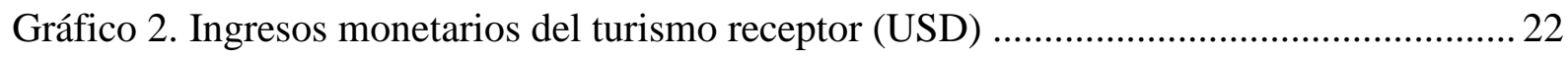

Gráfico 3. Market Share 2015 - 2016.................................................................................... 40

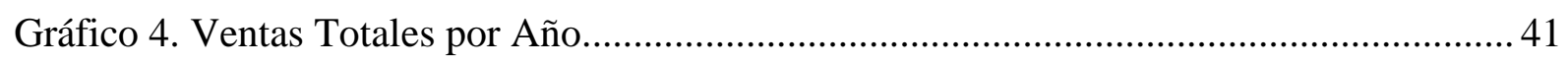

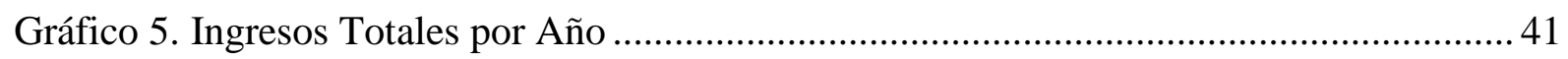

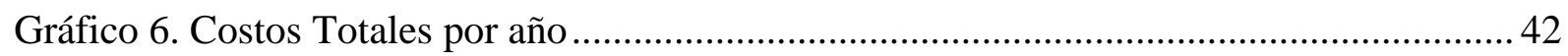

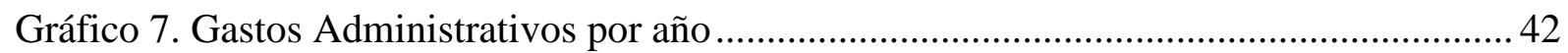

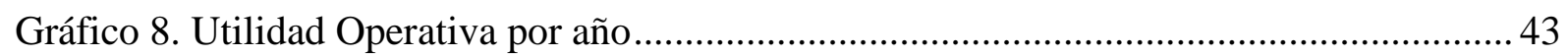

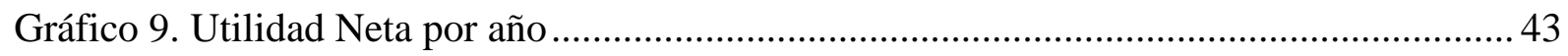

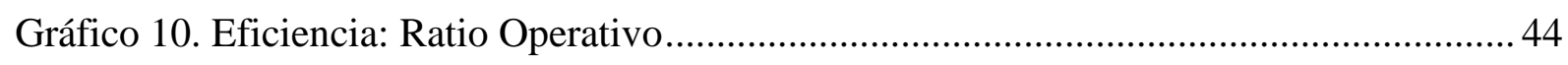

Gráfico 11. Eficiencia: GAV / Ventas ................................................................................ 44

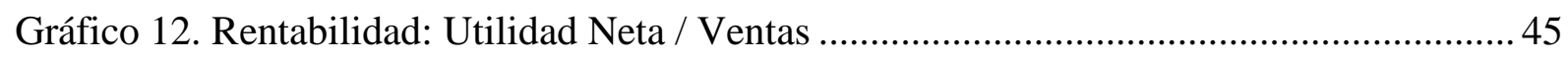

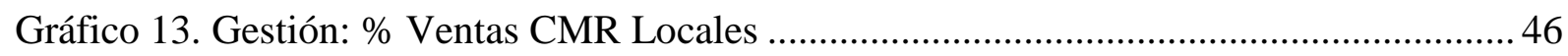

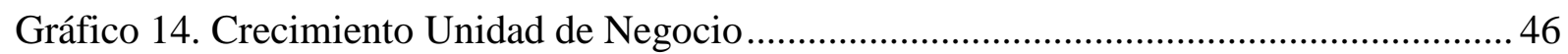

Gráfico 15. Análisis causa raíz del proceso Ventas sucursales ............................................ 57

Gráfico 16. Análisis causa raíz del proceso Ventas contact center ........................................ 64

Gráfico 17. Análisis causa raíz del proceso Ventas web....................................................... 72

Gráfico 18. Análisis causa raíz del proceso Diseño y desarrollo de productos ....................... 79

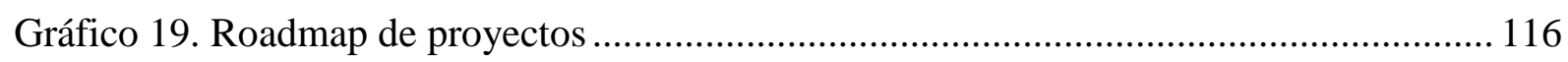


Tabla 1. Market Share 2015 - 2016. 40

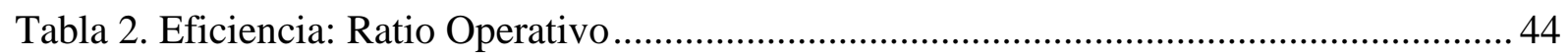

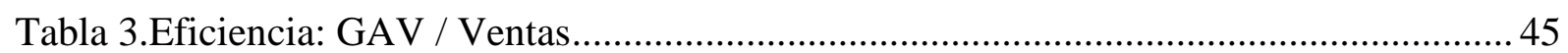

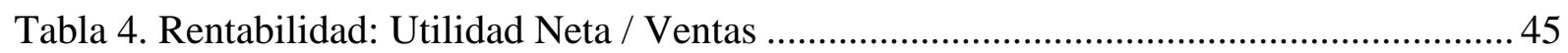

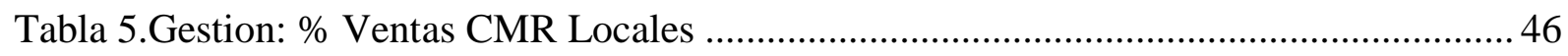

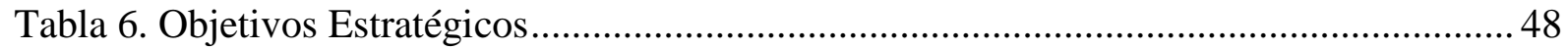

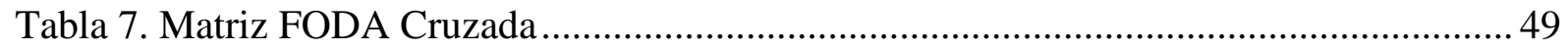

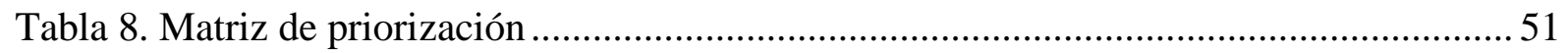

Tabla 9. Matriz de asignación de responsabilidades .................................................................. 52

Tabla 10. Caracterización AS-IS del proceso Ventas sucursales ............................................ 56

Tabla 11. Caracterización AS-IS del proceso Ventas sucursales ............................................ 58

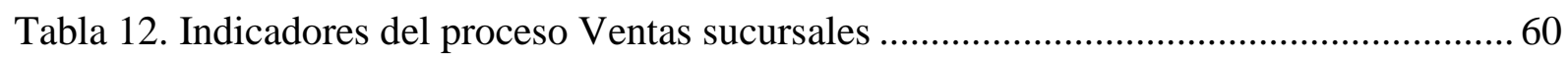

Tabla 13. Caracterización AS-IS del proceso Ventas contact center ........................................ 63

Tabla 14. Caracterización AS-IS del proceso Ventas contact center ........................................ 65

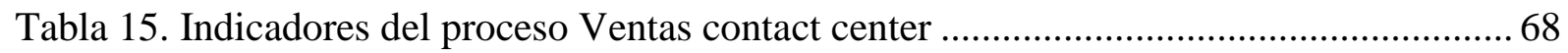

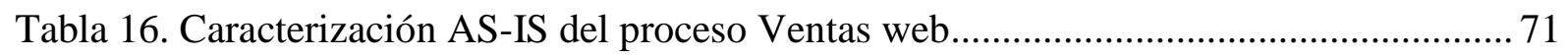

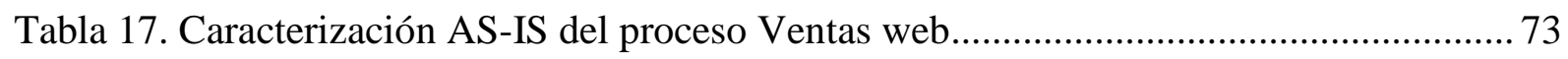

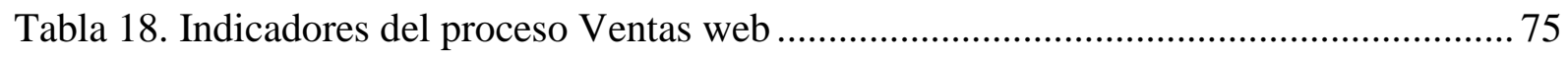

Tabla 19. Caracterización AS-IS del proceso Diseño y desarrollo de productos ..................... 78

Tabla 20. Caracterización AS-IS del proceso Diseño y desarrollo de productos ..................... 79

Tabla 21. Indicadores del proceso Diseño y desarrollo de productos ….................................... 80

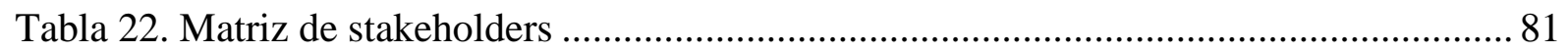

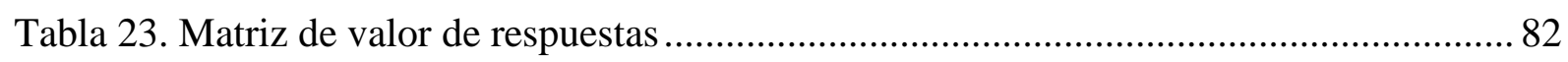

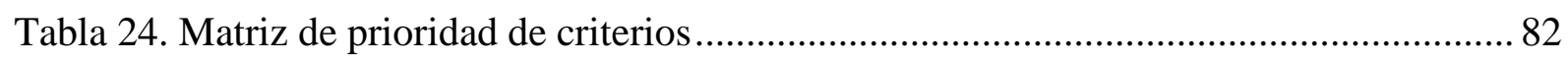

Tabla 25. Tabla de orden de priorización de criterios ............................................................. 83

Tabla 26. Matriz de prioridades del proceso Ventas sucursales .............................................. 83

Tabla 27. Matriz de prioridades del proceso Ventas sucursales .............................................. 84

Tabla 28. Matriz de prioridades del proceso Ventas sucursales ............................................. 84

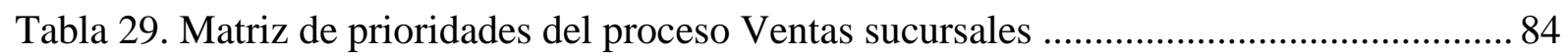

Tabla 30. Matriz de prioridades del proceso Ventas sucursales ............................................. 85

Tabla 31. Matriz de prioridades del proceso Ventas sucursales .............................................. 85

Tabla 32. Matriz de prioridades del proceso Ventas contact center......................................... 86

Tabla 33. Matriz de prioridades del proceso Ventas contact center....................................... 86 
Tabla 34. Matriz de prioridades del proceso Ventas contact center. . 87

Tabla 35. Matriz de prioridades del proceso Ventas contact center. 87

Tabla 36. Matriz de prioridades del proceso Ventas contact center. 87

Tabla 37. Matriz de prioridades del proceso Ventas contact center. . 88

Tabla 38. Matriz de prioridades del proceso Ventas web 89

Tabla 39. Matriz de prioridades del proceso Ventas web 89

Tabla 40. Matriz de prioridades del proceso Ventas web 89

Tabla 41. Matriz de prioridades del proceso Ventas web .90

Tabla 42. Matriz de prioridades del proceso Ventas web 90

Tabla 43. Matriz de prioridades del proceso Ventas web 90

Tabla 44. Matriz de prioridades del proceso Diseño y desarrollo de productos 91

Tabla 45. Matriz de prioridades del proceso Diseño y desarrollo de productos 91

Tabla 46. Matriz de prioridades del proceso Diseño y desarrollo de productos. .92

Tabla 47. Matriz de prioridades del proceso Diseño y desarrollo de productos . 92

Tabla 48. Matriz de prioridades del proceso Diseño y desarrollo de productos. .92

Tabla 49. Matriz de prioridades del proceso Diseño y desarrollo de productos. . 93

Tabla 50. Matriz de brecha del proceso AS-IS con el TO-BE 102

Tabla 51. Matriz de brecha del proceso AS-IS con el TO-BE 105

Tabla 52. Matriz de brecha del proceso AS-IS con el TO-BE 109

Tabla 53. Matriz de brecha del proceso AS-IS con el TO-BE 112

Tabla 54. Tiempo de implementación del P1 113

Tabla 55. Tiempo de implementación del P2. 114

Tabla 56. Tiempo de implementación del P3. 115

Tabla 57. Probabilidad de impacto. 116

Tabla 58. Escala de probabilidad 117

Tabla 59. Escala de impacto.

Tabla 60. Escala de importancia 118

Tabla 61. Riesgos identificados 118 
Figura 1. Finalidad del Turismo 12

Figura 2. Tipo de proveedores en agencia de viajes 21

Figura 3. Búsqueda de información antes del viaje $\quad 22$

Figura 4. Datos Turista Extranjero 23

Figura 5. Características del viaje - Turista Nacional 24

$\begin{array}{lr}\text { Figura 6. Arquitectura Empresarial } & 28\end{array}$

Figura 7. Ciclo de implementación de una arquitectura empresarial 31

Figura 8. Organigrama Viajes Falabella 35

Figura 9. Árbol de Valor $\quad 47$

Figura 10. Mapa de Procesos $\quad 51$

Figura 11. Diagrama AS IS del proceso Ventas sucursales 54

Figura 12. Diagrama AS IS del proceso Ventas contact center 61

Figura 13. Diagrama AS IS del proceso Ventas web 69

Figura 14. Diagrama AS IS del proceso Diseño y desarrollo de productos 76

Figura 15. Diagrama TO-BE del proceso Ventas sucursales 101

Figura 16. Diagrama TO-BE del proceso Ventas contact center 104

Figura 17. Diagrama TO-BE del proceso Ventas web 108

Figura 18. Diagrama TO-BE del proceso Diseño y desarrollo y de productos 111 


\section{RESUMEN}

La presente investigación se basó en la propuesta de implementación de una arquitectura de negocio para optimizar los procesos de las Áreas de Producto y Ventas para la agencia de viajes "Viajes Falabella”, donde las diversas fuentes de datos e información, cotizaciones de ventas no centralizadas y las actividades repetitivas no contribuyen a realizar un trabajo eficiente, no se puede tener indicadores de gestión que pueda alertar al negocio y poder aplicar las estrategias y/o planes de acción respectivos, así mismo poder ayudar al negocio a poder gestionar el margen actual de los productos, indicador clave en una agencia de viajes; es por ello que se busca implementar una arquitectura de negocio que permita manejar la gestión organizacional e incrementar su nivel de competencia con la finalidad de lograr el mejor desempeño y agilizar los procesos, garantizando un mejor manejo de los productos y toma de decisiones con información precisa.

Para la elaboración de la propuesta de solución se desarrolló diagramas TO-BE de los procesos de las Áreas de Producto y Ventas, los cuales indican mejoras sobre el estado actual de los procesos, identificando el índice de reducción de actividades y la propuesta de proyectos a implementar que permitirá a Viajes Falabella poder contar con una Arquitectura de Negocio.

De esta manera se pudo concluir que con la implementación de una arquitectura de negocio de los procesos de las Áreas de Producto y Ventas se puede optimizar los procesos y permitir a Viajes Falabella un mejor manejo de los productos y toma de decisiones con información precisa.

Palabras Claves: Viajes Falabella, Arquitectura de Negocio, Producto y Ventas, Agencia de Viajes. 


\section{ABSTRACT}

The present investigation was based on the proposal of implementation of a business architecture to optimize the processes of the Product and Sales Areas for the travel agency "Viajes Falabella", where the diverse sources of data and information, non-centralized sales quotations and repetitive activities do not contribute to efficient work, you cannot have management indicators that can alert the business and apply the respective strategies and / or action plans, as well as help the business to manage the current margin of the products, key indicator in a travel agency; that is why it seeks to implement a business architecture that allows managing organizational management and increase their level of competence in order to achieve the best performance and streamline processes, ensuring better management of products and decision making with accurate information.

For the elaboration of the solution proposal, TO-BE diagrams of the Product and Sales Areas processes were developed, which indicate improvements on the current state of the processes, identifying the rate of reduction of activities and the proposal of projects to implement that will allow Viajes Falabella to have a Business Architecture.

In this way it was possible to conclude that with the implementation of a business architecture of the Product and Sales Areas processes, processes can be optimized and allow Viajes Falabella to better manage the products and make decisions with accurate information.

Key Words: Viajes Falabella, Business Architecture, Product and Sales, Travel Agency, 


\section{INTRODUCCIÓN}

En la presente tesis se abordará el desarrollo de la arquitectura de negocios para la agencia Viajes Fallabella, teniendo como apoyo los estudios sobre la evolución del sector turismo, definiciones y agentes que lo componen, los factores condicionantes del turismo que han surgido producto de la globalización y las nuevas tecnologías.

La base señalada permitirá estructurar los procesos de la organización, como es el caso de los procesos de ventas y productos, para evaluar la situación actual y mostrar indicadores como sustento de la problemática.

Se han tomado en cuenta fuentes asociadas al diseño, estrategia de implementación, así como criterios de selección para la arquitectura de negocio que se aplicará.

Finalmente la propuesta está asociada al desarrollo de los diagramas TO-BE, los cuales indicarán las mejoras sobre el estado actual de los procesos. Además del análisis de impacto para identificar los riesgos y establecer las medidas de control para mitigar el daño 


\section{CAPÍTULO 1}

\section{MARCO TEÓRICO}

En el presente capítulo se presentará a las agencias de viajes que corresponden al sector materia de estudio de la tesis, se realizará una breve descripción del sector turismo y como ha ido evolucionando a lo largo de los años hasta convertirse en lo que es hoy.

Se presentará la evolución del sector turismo, definiciones y agentes que lo componen, para luego presentar la estructura del sector donde se detallarán los elementos que la componen, los factores condicionantes del turismo que han surgido producto de la globalización y las nuevas tecnologías, y como es el turismo internacional y en el Perú.

Se realizarán definiciones de agencias de viajes y sus tipos, así como los tipos de proveedores que intervienen a fin de entender nuestro sector de estudio y como tiene relación con el sector turismo. También se mostrarán las tendencias claves en las demandas de viajes y como las Tecnologías de la Información y Comunicaciones ha influido en el sector.

Para finalmente en el marco teórico, presentar la arquitectura empresarial y dentro de ella la arquitectura de negocio que en materia de la presente tesis se revisarán los conceptos, componentes, y sus beneficios de aplicación en las empresas e instituciones modernas. Se presentarán los más importantes y conocidos frameworks, así como las opciones de implementación y un caso de éxito. 


\section{Marco Teórico}

\section{1. Ámbito del Sector Turismo}

\subsubsection{El Sector Turismo - Definiciones}

El primer paso que debemos dar, es determinar en qué consiste el turismo. Podemos iniciar mencionando la palabra TURISMO deriva del latín tornus (torno) y tornare (redondear, tornear y girar) y el sufijo ismo que se refiere a la acción que realiza un grupo de personas, por lo que etimológicamente puede definirse al Turismo como las personas que viajan con la intención de regresar a su domicilio habitual. También podemos citar la definición dada por la organización más importante del sector, como es la Organización Mundial de Turismo de las Naciones Unidas. Según la OMT (1994), “el turismo comprende las actividades que realizan las personas durante sus viajes y estancias fuera de su entorno habitual, por un periodo de tiempo consecutivo inferior a un año, con fines de ocio, por negocio y otros motivos”. Tenemos que mencionar que el Turismo tiene varios fines, así como se muestran y se describe en el siguiente grafico la finalidad del turismo:

Figura 1. Finalidad del Turismo

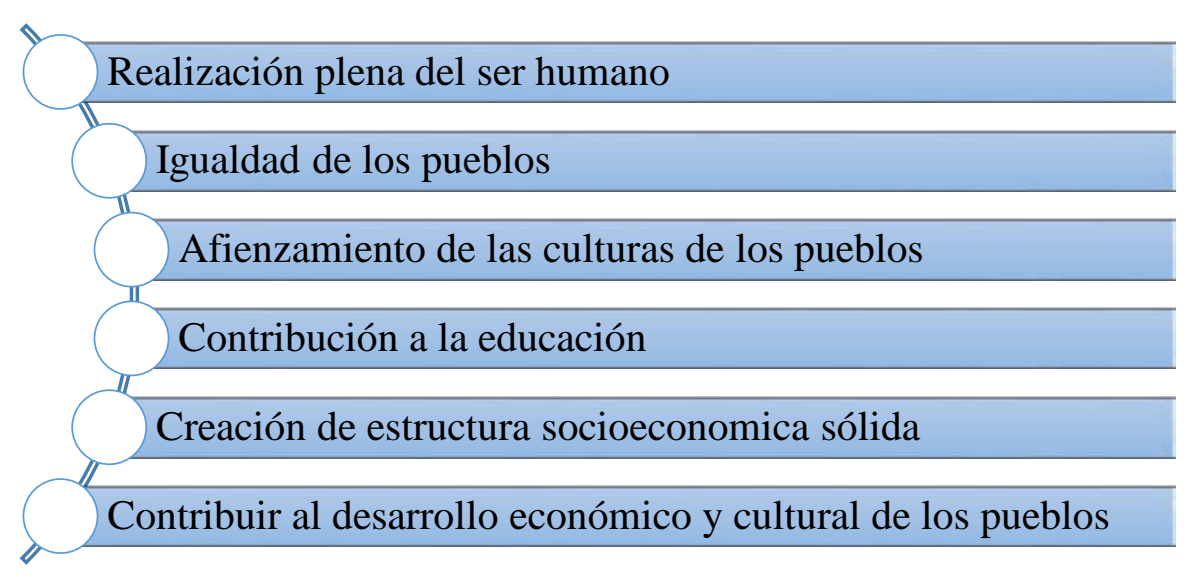

Fuente: Elaboración Propia 


\subsubsection{Evolución Histórica del Turismo}

Según el artículo sobre La Historia del Turismo en el mundo por Janet Arias Ramirez (2012) El turismo se ha manifestado en la humanidad desde el comienzo de los tiempos, aunque se le reconoce como industria macro económica a raíz de la revolución industrial.

Edad Antigua: En la Grecia clásica ya se practicaba el turismo de carácter deportivo y religioso, claro ejemplo de esto son los viajes a la ciudad de Olimpia para presenciar las olimpiadas o a los oráculos de Delfos y Dódona. Los romanos frecuentaban aguas termales (termas de Caracalla), espectáculos como teatro y hacían desplazamientos a las costas, esto se logró gracias a tres factores: la paz romana, desarrollo de vías de comunicación y prosperidad económica.

Edad Media: Es en esta época donde se da el mayor auge de turismo religioso. El cristianismo y el Islam se propagan y motivan desplazamientos por toda Europa generando así la elaboración de mapas, mesones y todo tipo de servicios para los caminantes.

Edad Moderna: Es en esta época cuando aparecen los primeros alojamientos con el nombre de hotel (palabra francesa para denominar los palacios urbanos) esto a causa de que las grandes personalidades viajaban con todo su séquito y en los palacios no había lugar suficiente para alojarlos. Dentro de los más destacados están las peregrinaciones de Venecia a Tierra Santa, conocido como el camino de Santiago y en el Islam la peregrinación a La Meca, los cual los creyentes están obligados a realizarla por lo menos una vez en la vida. También se dan las grandes expediciones marítimas de los españoles, portugueses e ingleses, lo cual ocasiona que más gente quiera viajar. A finales del siglo XVI se da la costumbre de hacer que los jóvenes aristócratas ingleses realicen el Grand Tour, para que aprendan in situ de la grandeza de los imperios griego y romano y se relacionen, ya que en un futuro ellos gobernaran el país.

Edad Contemporánea: En 1841 Thomas Cook realiza el primer viaje organizado y aunque sea considera un fracaso económico, da el antecedente para el paquete turístico que a la larga sería un rotundo éxito, diez años más tarde funda la primera agencia de viajes del mundo llamada “Thomas Cook \& Son”. Por su parte Cesar Ritz, quien desde joven ocupo todos los puestos existentes en un hotel, revolucionó esta industria incorporando el cuarto de baño en la habitación, incluyendo el desayuno y otros ítems como plus para los huéspedes. Además de perfeccionar la administración de dichos establecimientos, por lo que recibirá el apelativo de “Mago”. En 1950 debido al nuevo orden mundial se crea un boom en el turismo, que trae como 
consecuencia que se empiece a legislar este sector. En los años 70 la crisis energética y la consiguiente inflación crean una nueva crisis en la industria, la cual se extiende hasta finales del año 78. En los años 80 nuevamente el nivel de vida toma un repunte y ocasiona que muchos países adopten el turismo como fuente de ingresos. Esto facilitado por nuevos y mejores transportes como el concorde y el tubolev, trenes de alta velocidad y la consolidación del producto Charter (es una noción que procede de la lengua inglesa (charter) y que alude al desplazamiento por vía aérea que se contrata más allá de los viajes regulares que ofrecen las aerolíneas. Un vuelo chárter, por lo tanto, es aquel que se lleva a cabo de forma específica para una situación en particular; es decir, que no forma parte de los vuelos habituales y que no se ofrece por los canales de comercialización tradicionales) que obligó a que varias compañías regulares crearan su propia filial.

\subsubsection{Evolución Histórica del Turismo en el Perú}

\section{Primera etapa: Expansión de trasportes e infraestructura}

La historia del turismo en el Perú corre paralela al desarrollo de esta industria en el mundo. Durante las primeras décadas del siglo XX la expansión de los medios de comunicación terrestre (carreteras y ferrocarriles) y aérea y la consolidación de las clases medias asalariadas facilitaron un cierto desarrollo del turismo interno especializado en vacaciones y salud. Durante la primera mitad del siglo XX el turismo no formó parte de las políticas públicas porque no era considerado como un sector que generase divisas o trabajo. Sin embargo, se observa un lento crecimiento de esta actividad que va paralela a la expansión de vías de comunicación que facilitan la movilidad de la población y al crecimiento y consolidación de las clases medias asalariadas con suficientes ingresos estables para emprender viajes de descanso, recreación y salud. La construcción de vías férreas iniciada a mediados del siglo XIX y concluida a inicios del siglo XX (1851- 1910) sería la primera gran revolución de los transportes en la medida en que unió a las regiones norte, centro y sur. Esta amplia red ferroviaria permitió la circulación segura y cómoda de pasajeros. El periodo que va desde 1911 a 1930 se caracterizó por la gran expansión de los capitalismos norteamericano, europeo y japonés. Esta fase de prosperidad, llevó a que casi todas las ciudades capitales de la región doblaran, e incluso, triplicaran su población y se modernizaran. Dentro de este clima, el gobierno de Leguía (1919-1930) invirtió fuertemente en la modernización y expansión del aparato estatal. En este contexto los sectores medios crecieron notablemente y cambiaron de fisonomía debido al crecimiento de la burocracia estatal y al surgimiento de una capa de comerciantes y ejecutivos de las nuevas 
empresas nacionales y extranjeras. El Estado asumió el papel de impulsor de la economía a través de la inversión en obras públicas para atraer a la inversión privada. Se amplió significativamente la red vial con la construcción de carreras, líneas férreas y aeropuertos. Se inició la construcción de la Carretera Panamericana lo que abrió la posibilidad de realizar viajes en automóvil entre las ciudades de la costa. También se construyeron tramos de la Carretera Central que une a la capital, Lima, con la sierra central. La edificación del aeropuerto internacional de Lima permitió recibir vuelos del exterior y facilitó la comunicación con el interior. Este clima de bonanza propició el desarrollo de un cierto turismo interno hacia las ciudades de provincias, balnearios y centros medicinales. Ejemplo de ello son los complejos hoteleros de los balnearios de Huacachina en Ica y los Baños de Boza en Huaral, dos de los puntos más concurridos por las clases altas y medias iqueñas y limeñas hasta la década de los cincuenta. Asimismo, por el Aniversario de 100 años de Independencia, se emprendieron grandes obras para embellecer y modernizar a la ciudad de Lima. Ello incluyó la construcción de parques, plazas, hoteles, museos y monumentos. La crisis económica de fines de los años veinte supuso una violenta contracción de la economía nacional. Este periodo se caracteriza por el descontento popular y el control militar del aparato estatal hasta fines de la década de 1930 . El primer gobierno de Manuel Prado (1939-1945) significó el retorno a la democracia y una conducción de la economía según la cual el Estado debe asumir un rol protagonista en la tarea de modernizar el país en alianza con la inversión privada. El mercado interno creció debido a la expansión demográfica que se inició en la década de los cuarenta y a la política estatal de control de precios y aumento de salarios. Durante este periodo se creó la Escuela de Cicerones (1940) para la instrucción en la actividad turística, que luego se convertiría en CENFOTUR. También se establecieron las primeras corporaciones de desarrollo a través de las cuales el Estado buscaba apoyar y potenciar las iniciativas privadas de expansión económica. En 1942, se inauguró la cadena de Hoteles de Turistas propiedad de la compañía Hotelera del Perú S.A. y se culminó la construcción, de la carretera Panamericana que une a toda la costa. Ello facilitó la comunicación y ofreció servicios de hospedaje adecuados a los turistas. El corto gobierno de Bustamante y Rivero (1945-1948) se caracterizó por un mayor control e intervención estatal en la economía. Dentro de esta tónica, en 1946 se creó la Corporación Nacional de Turismo a la que se adjudicó la administración de la cadena de hoteles de turistas. Esta entidad continuó con la construcción hoteles. Los años 50 marcaron el inicio de un nuevo periodo de industrialización, modernización y urbanización.

\section{Segunda etapa: El Estado inversor}


La década de los sesenta significó un giro en el turismo mundial, este creció explosivamente gracias al abaratamiento de los medios de transporte y a la expansión de las clases medias y se convirtió en una industria de masas. Los países del tercer mundo ingresaron al mapa turístico como receptores de visitantes del primer mundo. En consecuencia, el turismo ingresa dentro de las políticas públicas como una posible vía de desarrollo. Dentro de este contexto, el primer mandato de Belaúnde (1963-1968) fue un punto de inflexión, por primera vez se diseñaron políticas públicas destinadas a incrementar el flujo de turistas internos e internacionales. Dentro de este marco se diseñó el Plan Copesco, un proyecto estatal para implementar infraestructura turística en el sur del Perú. Se elaboró junto a la empresa norteamericana Checchi and Company un estudio sobre "Las Posibilidades del Turismo en el Perú". En este periodo también se incentiva la educación en turismo. En 1965 se fundó la Escuela Nacional de Turismo que se convertiría en el Centro Nacional de Aprendizaje de Servidores en Hoteles (CENASH) destinado a capacitar a trabajadores de hoteles, restaurantes y agencias de turismo. En 1975 se incorporaron al SENATI como programas de Turismo y Hotelería. El golpe de Estado de Velasco (1968-1975) instauró por siete años un gobierno que favorecería un mayor control estatal de la economía. En adelante el turismo se convertiría en un sector de la economía y se buscó impulsarlo, a través de la promoción del Perú como destino, el apoyo al turismo interno y la construcción de infraestructura. En suma, el tipo de turismo que se incentivó fue el cultural en sus versiones histórico y arqueológico. Ello iba en consonancia con la ideología oficial que enfatizaba las raíces indígenas de la peruanidad y buscaba revalorizar el acervo cultural de la nación. El gobierno de Morales Bermúdez (1975-1980) se propuso revertir el modelo económico puesto en marcha por Velasco. Las políticas públicas con respecto a este sector dieron mayor énfasis al apoyo a la inversión privada. En 1977 se promulgó un régimen de incentivos para la actividad turística, entre los cuales se incluyó la exoneración de impuestos, facilidades de pago en la adquisición de terrenos de propiedad del Estado, créditos para el financiamiento con tasas de interés favorables a través de la Banca Estatal. También se otorgó incentivos tributarios a la inversión y/o reinversión privada a través de la liberación del impuesto a la renta en tales casos. (FOPTUR, 1981).

\section{Tercera etapa: El Estado Promotor}

En la década de los noventa la economía peruana y la seguridad interna comienzan a recuperarse. Durante el gobierno de Fujimori (1990-2000) se giró definitivamente a un modelo neo liberal en la conducción de la economía y en el diseño de políticas públicas. Se profundizó la privatización de las inversiones y se desmontó y reorganizó el aparato organizacional y la 
infraestructura estatal. Se disolvió ENTURPERU y los hoteles pertenecientes a la cadena Hoteles de Turistas fueron adquiridos por el sector privado. El cambio en la importancia económica del turismo fue de la mano con un incremento en la atención brindada desde el Estado a tal actividad. Desde 1993 se observa un crecimiento continuo del sector. Los ingresos de divisas crecieron a tasas del 20\% anual hasta 1998 año en que se generaron 913 millones de dólares en divisas. El año 1998 fue declarado oficialmente el "Año de los 600 mil turistas" y 1999 es el "Año del turismo interno". Con este fin se creó PROMPERU entidad que tiene como objetivo propiciar el crecimiento de los flujos turísticos, participar en eventos, establecer alianzas con diversos organismos internacionales y crear y promover productos turísticos peruanos en el mercado internacional. Por primera vez se planteó un Programa Integrado de Apoyo del Sector Turismo en el Perú (1996-1999) y se diseñó un Plan Maestro de Desarrollo Turístico Nacional de la República del Perú. El Programa apoyado por la UE, en principio, proponía mejorar la competitividad del Perú como destino turístico. En la práctica logró romper esquemas fomentando el desarrollo de productos innovadores que parten de iniciativas locales desde un enfoque de sostenibilidad dentro del marco de un "Turismo Vivencial". La gran mayoría de los proyectos del Programa estaban ubicados en áreas rurales y enfocados a actividades tales como agroturismo, trekking, rutas ancestrales, turismo participativo, etc. tanto en el norte (Cajamarca, Túcume y Huaraz) como el sur del país (Cusco y Valle Sagrado) y algunos de ellos todavía siguen vigentes hoy en día (septiembre 2016). Paralelamente, se buscó mejorar la oferta turística a través de la capacitación de los servidores de esta área y de programas destinados a generar cultura turística en la población. Se promulgó una nueva ley de turismo que creó diversas instancias que garantizan la seguridad del turista tales como la policía de turismo y la fiscalía de turismo. Dentro de este marco INDECOPI firmó un convenio con PROMPERU para, a través de la fiscalía del turismo, la policía de turismo y el servicio de protección al turismo, se informe al consumidor, se vigile que las empresas cumplan las normas y, dado el caso, se sancione a la empresa y se repare al consumidor. Es decir que se buscaba satisfacer necesidades e intereses del turista, pero no se buscaba construir herramientas para que la población local se sienta reconocida social y políticamente. El gobierno de Toledo (2001-2006) marcó el inicio de la recuperación económica del Perú en base al modelo ya en marcha durante el periodo de Fujimori. Las políticas públicas se centraron en la promoción del producto Perú y del turismo interno. Paralelamente se incentivó la inversión privada en infraestructura y se dio incentivos tributarios a la inversión en establecimientos de hospedaje. El turismo interno creció de manera sostenida durante década del 2000. Durante el 2003 se realizaron aproximadamente 13,7 millones de viajes por turismo interno. Incremento considerable respecto al flujo de turistas 
internos de 1,1 a 2,6 millones registrado durante el año 1997. Sin embargo, el crecimiento y flujo presentado fueron reducidos en comparación con el turismo internacional y en relación a la población. Esto se debió, en buena medida, a que la infraestructura turística es limitada. La estabilidad económica atrajo a las inversiones en hotelería y transportes aéreos, pero esta fue insuficiente. Tanto en hoteles como en transporte aéreo la inversión más fuerte provino de capitales multinacionales. En el caso de los hoteles, la inversión creció significativamente, pero se concentró en pocos destinos ya consagrados y destinados al turismo receptivo. El transporte se desarrolló en el área de los vuelos internacionales en tanto que el sector de vuelos nacionales retrocedió y la oferta es insuficiente. En consecuencia, a pesar de que este periodo se caracterizó por su tendencia hacia la institucionalización y formalización, el turismo no ha logrado desarrollar todo su potencial. El segundo gobierno de García (2006-2011) continúa con las políticas diseñadas en el Plan Estratégico Nacional 2005-2015. Se vive un clima de expansión económica que el Perú no veía desde la década de los setenta. El superávit fiscal permite al Estado emprender obras de infraestructura vial y construcción de aeropuertos. Las clases medias viven un periodo de bonanza que se refleja en el dinamismo del turismo interno, auspiciado por políticas que otorgan feriados a los trabajadores del sector público y con campañas publicitarias tales como “Escápate de la rutina” "Perú mucho gusto” y “El Perú lo tiene todo” puestas en marcha por PROMPERU.

\subsubsection{Tipos de Turismo}

Se ha indicado la evolución del turismo a nivel mundial y en el Perú, y se puede apreciar que el turismo en los últimos años es parte de la economía tanto mundial como dentro del Perú. Así mismo, en base a su gran crecimiento, se ha categorizado los diferentes tipos de turismo que existen, los cuales se detallan a continuación:

\section{Turismo de sol y playa (tradicional)}

Es la máxima expresión del turismo de masas, ya que las playas en los diferentes destinos turísticos, son las más visitadas por los turistas. Consiste primordialmente en pasar unos días de esparcimiento en un destino de costa, naturalmente con playa y mar, mismo que debe contar con espacios públicos destinados a esta actividad. Lo más común es que el turista se hospede en hoteles de lujo y adquiera paquetes "todo incluido" que les permita tener las menos preocupaciones posibles.

\section{Turismo de reuniones}


Consiste en el desplazamiento de viajeros fuera de su entorno habitual con fines lucrativos. Normalmente son empresas las que envían a sus trabajadores a juntas, conferencias, reuniones o exposiciones; estos van con los gastos pagados y en cierta manera están recibiendo un sueldo por este viaje. Las condiciones del destino visitado son más enfocadas a satisfacer las necesidades de un viajero que demanda los mejores servicios posibles, las que van desde conjuntos de exposiciones, salones de eventos, buenas vías de comunicación, entre otros.

\section{Turismo LGBT}

Tipo de turismo dirigido a la llamada “comunidad gay”, misma que incluye personas bisexuales y transexuales. Actualmente es un sector en constante crecimiento que aporta incluso más derrama económica que el turismo convencional. Lo que se busca cuando las personas se desplazan para hacer turismo LGBT, es todas las condiciones necesarias para tener tranquilidad, esto quiere decir que buscan destinos amigables para ellos, donde no haya discriminación, se respete la diversidad y haya espacios abiertos con seguridad para su integridad.

\section{Turismo de naturaleza}

Busca delimitar a un tipo de viajero más exigente, cuya principal motivación es estar en contacto con la naturaleza. Principalmente desarrollado por turistas jóvenes con inquietudes por el deterioro del medio ambiente y preocupados por temas como el calentamiento global, el desarrollo social y el enriquecimiento cultural. Este tipo de turismo tiene 3 grandes derivaciones: El ecoturismo que se desarrolla en áreas naturales y que tiene como fin la apreciación y conocimiento de la naturaleza; El turismo de aventura, tiene como principal motivo, realizar actividades recreativas que representen un esfuerzo emocional y físico; y por último el turismo rural donde se busca la convivencia e interacción con la gente propia del lugar.

\section{Turismo cultural}

Dentro del turismo cultural, los más conocidos son el turismo religioso y el gastronómico. Este es más exigente y tiene la posibilidad de desarrollarse en cualquier época del año; se viaja con la intensión “aprender algo”, ya que normalmente se realiza por gente con un nivel educativo más alto que el promedio. Es común que se busquen monumentos históricos del destino visitado, las manifestaciones gastronómicas más representativas del lugar y sucesos o leyendas que cuenten la historia del mismo. 


\section{2. Ámbito del Sector de Agencias de Viajes}

\subsubsection{Agencias de Viajes - Definiciones}

Una agencia de viajes es una empresa asociada al turismo, cuyo oficio es la intermediación, organización y realización de proyectos, planes e itinerarios, elaboración y venta de productos turísticos entre sus clientes y determinados proveedores de viajes, como por ejemplo: transportistas (aerolíneas, cruceros), servicio de alojamiento (hoteles), con el objetivo de poner los bienes y servicios turísticos a disposición de quienes deseen y puedan utilizarlos.

\subsubsection{Tipos de Agencias de Viajes}

\section{Mayoristas}

Son aquellas que proyectan, elaboran y ofrecen toda clase de servicios y viajes combinados para su afianzamiento. No pudiendo vender ni ofrecer su producto al usuario. Cada mayorista trabaja directamente con los hoteles y líneas aéreas específicas para elaborar paquetes que puedan venderse al público final o a otras agencias de viajes. Estos paquetes son de diferente naturaleza: algunos están diseñados para grupos y otros para individuos o parejas; otros exigen permanecer en dos o más hoteles; otros más cuentan con especialidades como paquetes para recién casados, paquetes para jugadores de golf o para esquiadores. A través de su relación con los hoteles el mayorista obtiene asignación de cierto número de habitaciones que puede vender sin verificar con el hotel (a esta acción se llama en el mundo de turismo Allomet). Además, al mayorista que ha establecido una línea de crédito con el hotel no se le pide hacer un depósito por anticipado. El mayorista expide un cupón a la agencia de viajes (minorista) y ésta a su vez, la entrega al cliente. El huésped presenta el cupón al momento del check in y éste lo usa posteriormente para facturar al mayorista y luego, el mayorista le factura al minorista.

\section{Minoristas}

Comercializan el producto de las agencias de viajes mayoristas vendiendo directamente al usuario turístico o proyectan, elaboran, organizan o venden toda clase de servicios y viajes combinados al turista, no pudiendo ofrecen ni comercializar sus productos a través de otros servicios. Esta agencia de viajes, es aquella que vende al público. Además de, detrás del negocio de viajes, están diversas agencias que trabajan al mayoreo, con las que las agencias minoristas hacen sus reservaciones en lugar de hacerlas directamente con el hotel. En la mayoría de los 
casos, sería muy costoso para las agencias minoristas comunicarse directamente con el hotel cada vez que tuvieran una reservación. Además, los negocios reservados directamente por el minorista exigen el envío de un depósito al hotel y en muchos casos, particularmente durante los períodos de gran actividad, la agencia minorista no puede saber de inmediato si el hotel podrá brindarle el alojamiento solicitado. Finalmente, en años recientes los clientes han pedido paquetes que combinan el alojamiento en el hotel, el viaje aéreo, los traslados en grupos y las excursiones.

\section{Receptivas}

Se localizan en los principales sitios en donde llegan los turistas y suelen ocupar espacios situados en lugares poco visibles desde el exterior. Actúan como representantes de las agencias emisoras, son las encargadas de recibir, acomodar y dar toda la información necesaria a los turistas clientes, de todo lo que les espera en el destino al cual van a visitar tratar de dar consejos y hacer lo más ameno posible la estancia del cliente en ese destino.

\subsubsection{Tipo de Proveedores de Agencias de Viajes}

En la siguiente figura se puede visualizar a todos los proveedores que intervienen en la gestión de una agencia de viajes.

Figura 2. Tipo de proveedores en agencia de viajes

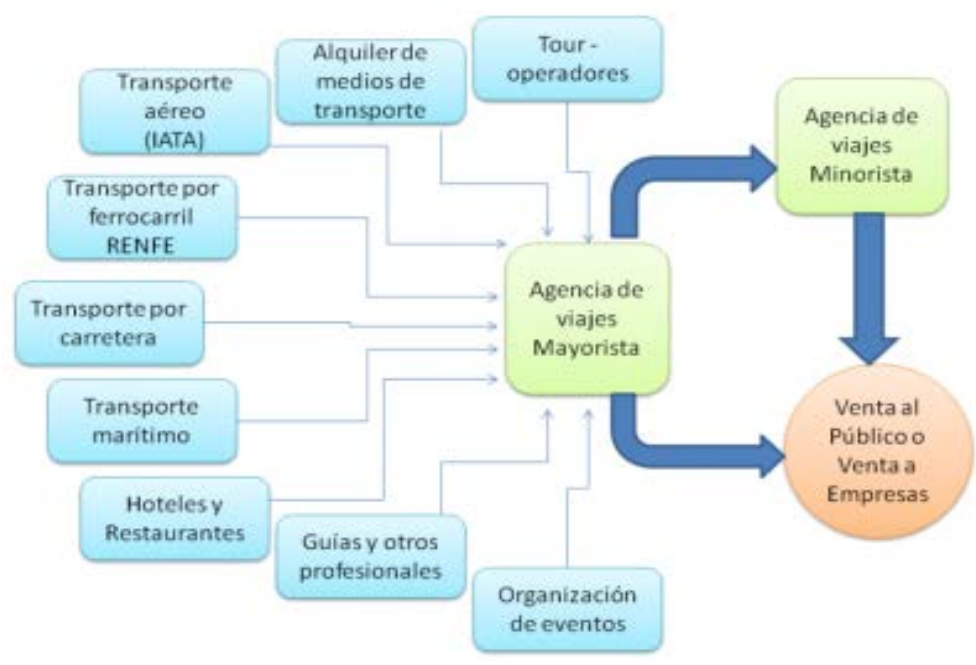

Fuente: Elaboración Propia

\subsubsection{Cifras Estadísticas del Sector Turismo - Agencias de Viajes en el Perú}

Gráfico 1. Balanza de Bienes y Servicios del sector turismo 
Perú: Balanza de Bienes y Servicios del sector turismo

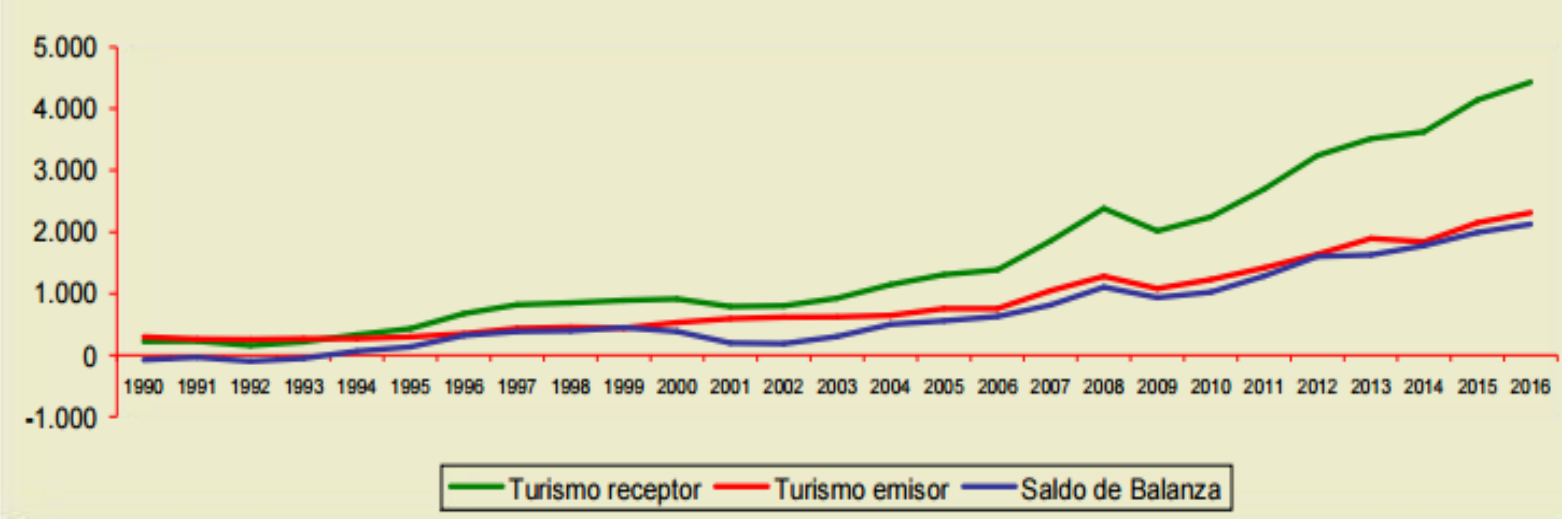

Fuente: B.C.R.P. BADATUR

Gráfico 2. Ingresos monetarios del turismo receptor (USD)

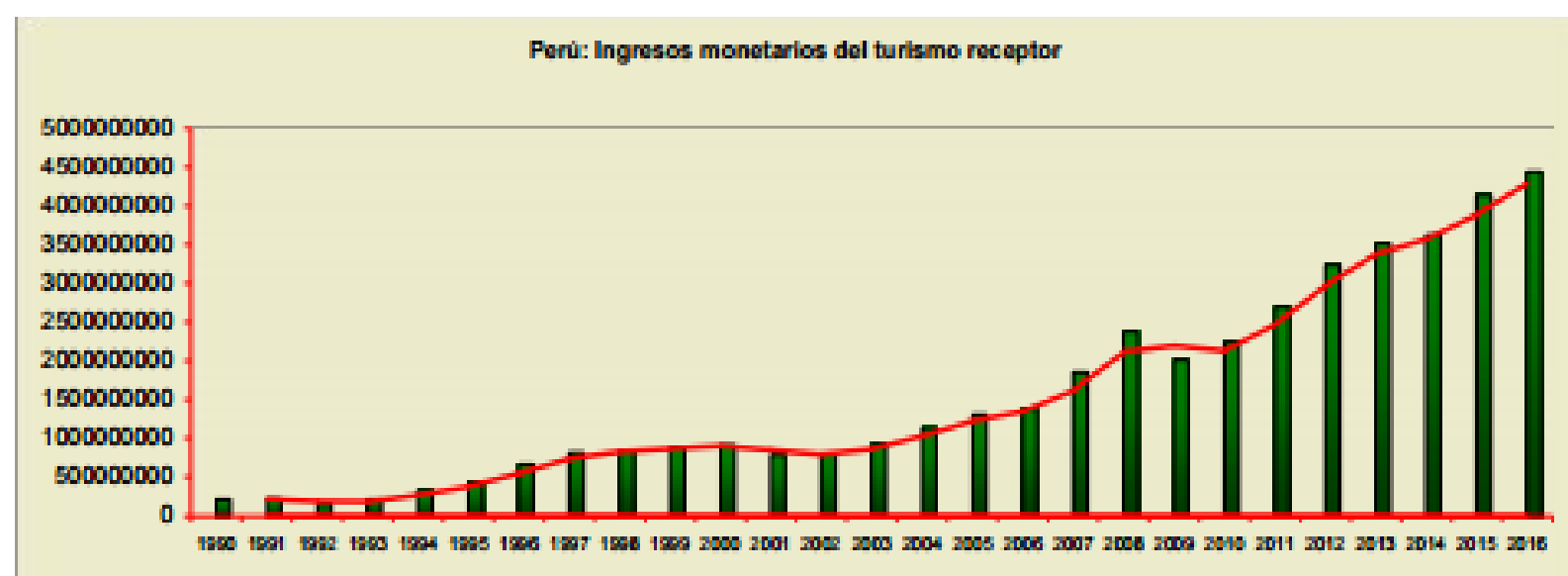

Fuente: B.C.R.P. BADATUR

Figura 3. Búsqueda de información antes del viaje 


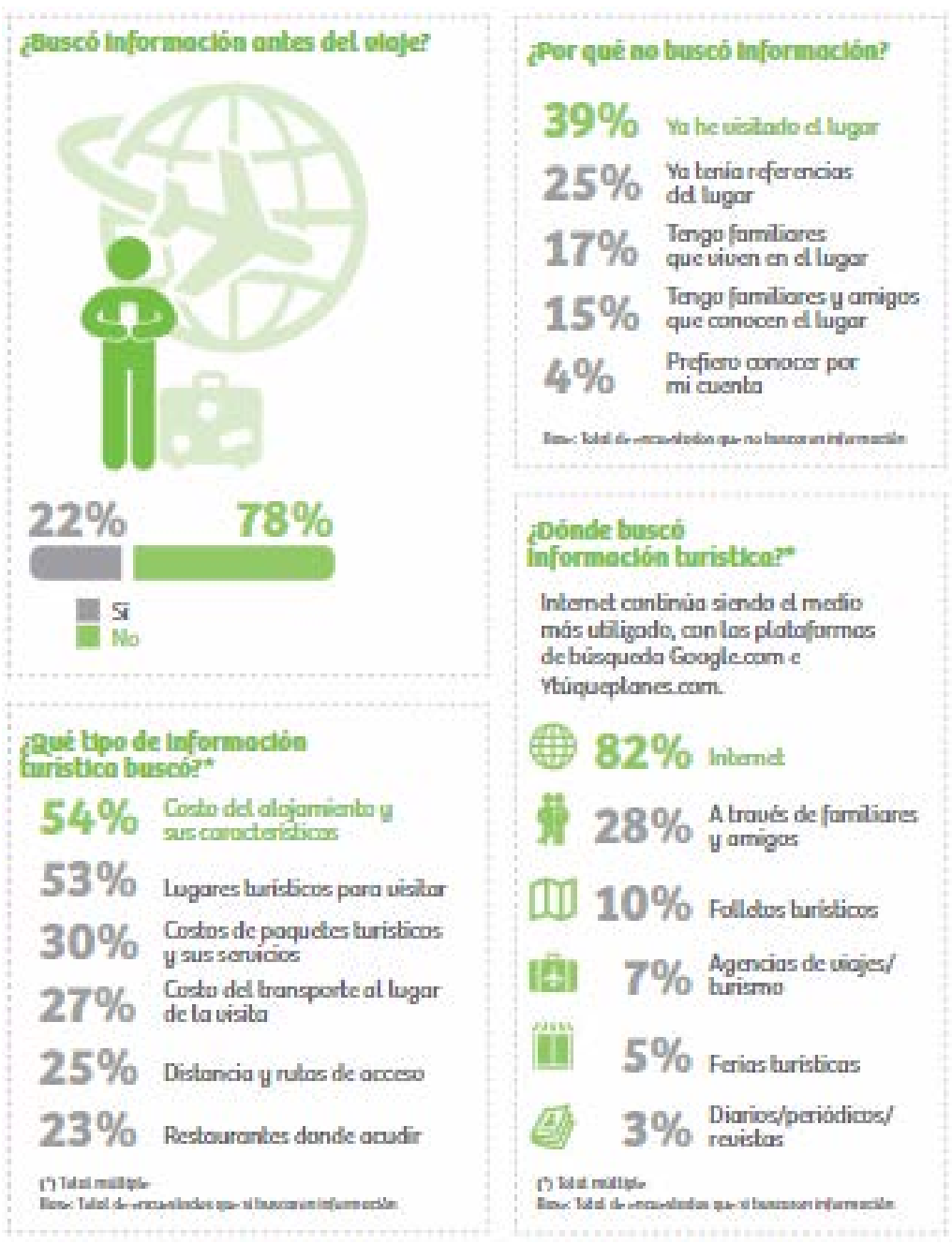

Fuente: www.promperu.gob.pe

Figura 4. Datos Turista Extranjero 


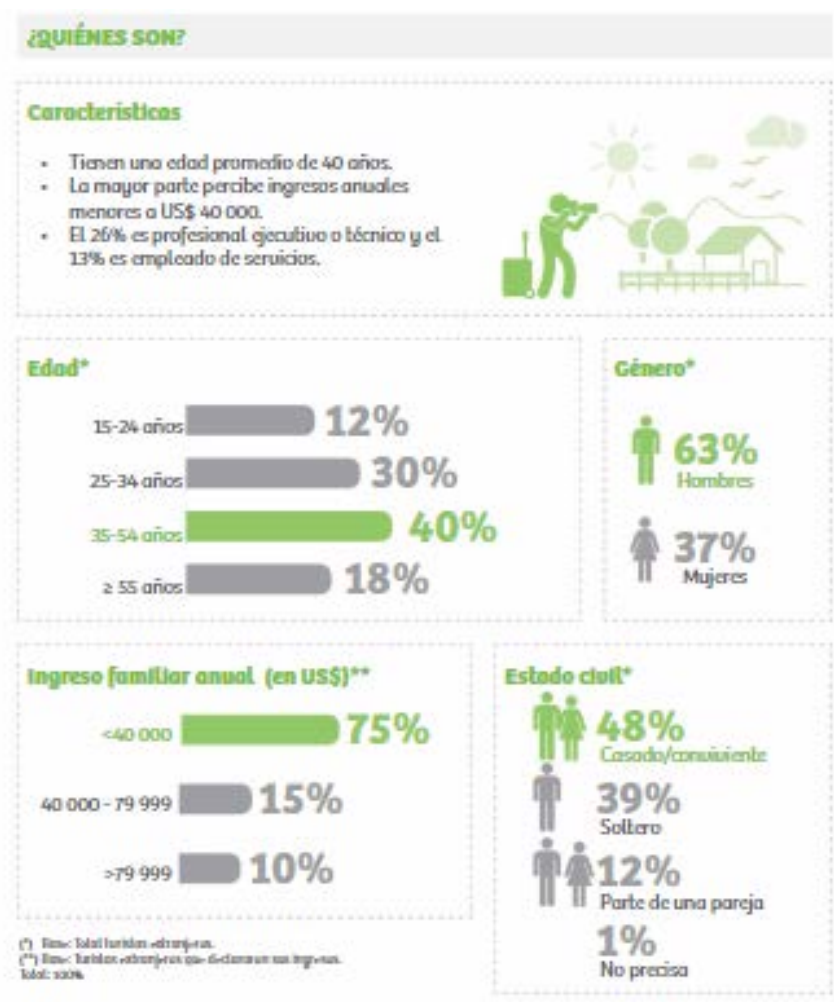

Fuente: www.promperu.gob.pe

Figura 5. Características del viaje - Turista Nacional

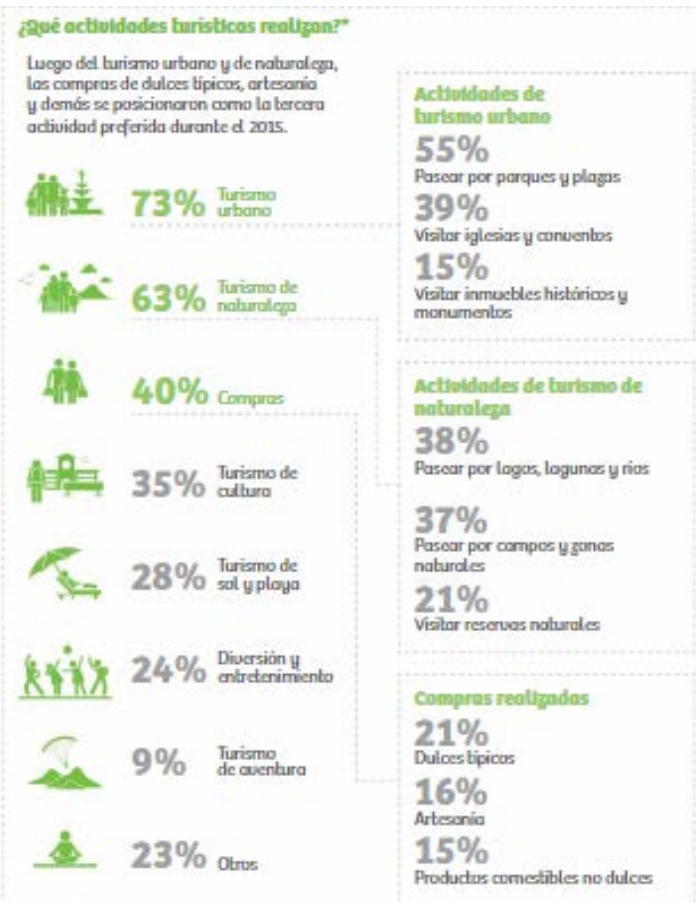

Fuente: www.promperu.gob.pe 


\subsubsection{Tendencias claves en las demandas de viajes y turismo}

La empresa Logismic, de México, presenta en su página web un artículo de investigación donde habla sobre las tendencias claves en la demanda de viajes y turismo en los últimos años. Veamos en este caso las 5 principales tendencias tecnológicas para agencias de viajes:

\section{Adopción de aplicaciones de viajes para celulares}

Con el lanzamiento de plataformas de comunicación con las últimas tecnologías, como el iPhone, el Nokia N95, y otros teléfonos multifunción, empezaremos a ver un desarrollo más frecuente de novedades para mejorar la experiencia del viajero frecuente a través de este tipo de plataformas. Los servicios que ofrecen localización satelital y otros sistemas se harán cada vez más populares a medida que los viajeros se vuelquen más hacia sus celulares para consultar direcciones, recomendaciones, destinos e información en general. Los celulares dejaron de ser un simple medio de contacto con nuestros conocidos, actualmente y a futuro se convertirán en verdaderos centros de organización de nuestra vida cotidiana, facilitándonos tareas como la obtención de información en lugares desconocidos, reservación de lugares en aviones, restaurantes, eventos deportivos, etc.

\section{Los nichos de las redes sociales seguirán creciendo y desarrollándose}

Han ayudado a mejorar la credibilidad de la eficiencia de estas redes en nuestra vida social, se espera que continúen emergiendo plataformas con estas mismas características en un futuro. Justamente se espera que aparezcan modificaciones de las principales redes con características que faciliten el contacto y la experiencia social de las personas que participan de uno u otro modo en el mundo de los viajes y las vacaciones. Por ejemplo, sitios donde proveedores de servicios de turismo encuentren a distribuidores locales de estos servicios, creando grupos confiables, estableciendo nuevos lazos comerciales y trabajando con el sistema de referendos, mediante el cual una compañía ya establecida en el negocio puede ayudar al surgimiento de otra que la complemente.

\section{Los tres gigantes no se irán a ninguna parte}

No debemos esperar que el monstruo de tres cabezas del mundo de las agencias online: Sabre (www.sabretravelnetwork.com), Amadeus (www.amadeus.net) y Travelport (www.travelport.com); desaparezca del mercado. A pesar de que muchos se mantienen en contra de las políticas de trabajo y comercialización de estas compañías, es innegable que 
siguen a la vanguardia de todos los adelantos en el área. Las últimas innovaciones en materia de software, modos de pago, destinos; casi siempre podemos encontrarlas en estas empresas de reconocida trayectoria. Esto se debe en parte al apoyo económico con el que cuentan, puesto que no solo obtienen un constante flujo de dinero de sus propias ganancias, sino que, en vista de su gran éxito, varios inversores las han apoyado y seguirán haciéndolo en la medida que nada indique que están por ser reemplazadas de las mentes de los compradores.

\section{El futuro de las Agencias Inteligentes}

¿De qué se trata esto? Pues estamos hablando de la incorporación cada vez más profunda y a mayores niveles de la inteligencia artificial, más específicamente, de los softwares diseñados especialmente para agencias de viajes. Los tiempos de ver a personas atrás de un mostrador, recomendando sitios basados en su experiencia humana parece que irán quedando atrás. Puede sonar muy raro sin duda. Si había algo que pensamos que nunca sería reemplazado es el consejo de alguien como nosotros, un humano. Pero los últimos avances parecen predecir lo contrario. Actualmente se está trabajando en el desarrollo de software inteligentes, y en cierto modo, “emocionales”. Es decir, capaces de conocer los gustos de las personas en base a sus características, elecciones en otras áreas, psicología, lugar donde vive, o historias de compras anteriores. Todo esto tiene que ver con el grado de exposición que tiene nuestra vida privada en las redes. Cada vez que ingresamos un dato personal a la web, ya sea en un formulario o en una red social, estamos compartiendo una parte de nosotros. Los nuevos programas serían capaces de recolectar toda esa información y crear un "perfil de comprador”; de modo de poder establecer una recomendación perfecta y ajustada a cada individuo. De ser así, lo más probable es que estas aplicaciones funcionen de modo sincronizado con Facebook, Twitter, LinkedIn y redes similares; ya que ellas son como formularios donde volcamos muchos de nuestros gustos personales. Como es de esperar, quedará abierto el debate sobre si esto es correcto o no, sobre cuánta información debería obtener Internet de nosotros. Pero esa discusión ya excede el propósito de esta investigación.

\section{Reservas online}

Debemos esperar en el futuro ver a más y más agencias proveedoras de servicios de viajes adoptar modalidades de reservas on-line. Hace unos años, un pequeño grupo de agencias se habían aventurado a este terreno desconocido hasta entonces, con programas algo rudimentarios, y aprendiendo a medida que funcionaban, fueron creando un mundo de negocios 
virtuales que terminó por sentar las bases del futuro de esta actividad. Actualmente esas empresas son los modelos a seguir, y las pequeñas empresas que van surgiendo deben ir adoptando esas nuevas tecnologías tan solo para estar a la altura de ellas y poder competirles. Las reservas online de servicios son una realidad consolidada, y nada indica que esté próxima a desaparecer sino todo lo contrario. Por eso hoy en día no podemos pensar en vivir sin conexión a Internet. Nuestro futuro dependerá cada día más de nuestra velocidad de banda ancha.

Esas son las 5 tendencias tecnológicas para agencias de viajes que se avecinan. El principio básico que subyace debajo es el mismo que parece atravesar todo nuestro futuro: Internet, el mundo online, la vida virtual. Estamos destinados a ser personas cibernéticas, y cada vez eso parece una realidad más tangible. En base a la información de este artículo, creemos que las tendencias están bien descritas, sin embargo creemos que esto se puede complementar con una gestión previa por parte de las agencias de viajes que permita buscar a los clientes que “necesitan del servicio de viaje” ya sea por vacaciones o viajes de negocios y no esperar que estos clientes busquen a las agencias de viajes, es decir dar a las agencias de viajes herramientas donde puedan ser Agencias de Viajes Proactivas y no Agencias de Viajes Reactivas.

\subsection{Arquitectura Empresarial}

\subsubsection{Definición de arquitectura empresarial}

Según Cesar E, Oswaldo M (2014) se tienen diferentes definiciones para arquitectura empresarial, en este caso citando a Lankhorst, “Arquitectura Empresarial es un conjunto coherente de principios, métodos y modelos empleados en el diseño y en la realización de la estructura organizacional empresarial, procesos de negocio, sistemas de información e infraestructura”; considerando la definición de Gartner, la arquitectura empresarial tiene un rol estratégico y la define de la siguiente manera “Arquitectura Empresarial es el proceso de traducir la visión del negocio y su estrategia en un cambio organizacional efectivo por medio de crear, comunicar y mejorar los requerimientos claves, principios y modelos que describen el estado futuro de la empresa y permiten su evolución”.

Otra definición a tener en cuenta es la proporcionada por la oficina federal de gestión de arquitectura empresarial del Estados Unidos: “Arquitectura Empresarial es una práctica de gestión para maximizar la contribución de los recursos de una agencia, inversiones de infraestructura tecnológica y actividades de desarrollo de sistemas, para alcanzar sus metas de rendimiento (performance) 
Tomando en cuenta las múltiples definiciones, arquitectura empresarial se concentra en dos temas claves: visión holística de la empresa y las relaciones entre los procesos. Es importante destacar los elementos resaltantes como son las personas, el negocio, las aplicaciones y las tecnologías. La siguiente figura muestra las capas de arquitectura de una organización, personas, negocio, aplicaciones, y tecnología. Además, de la secuencia de pasos a seguir para la implementación de una arquitectura empresarial:

Figura 6. Arquitectura Empresarial

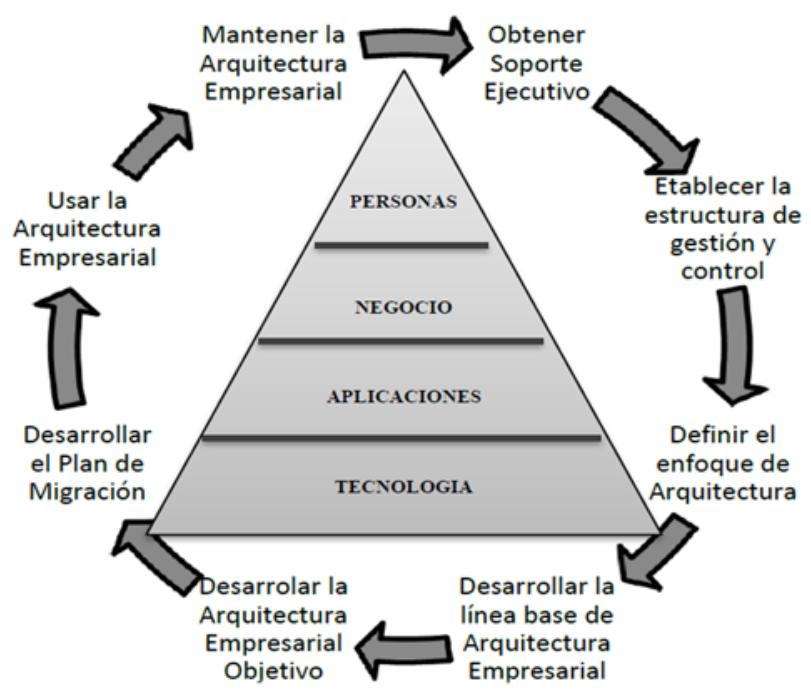

Fuente: Cesar Esquetini Cáceres, Oswaldo Moscoso Zea (2014)

\subsubsection{Metodologías de Arquitectura Empresarial}

Se tienen diversos enfoques para trabajar los temas de cambios en las organizaciones y la manera en la cual se debe enfrentarlos está definida en los frameworks. La pregunta a responder seria que es un framework, pues es un marco de trabajo con elementos y componentes que permiten ser una guía para construir una estructura. Entre los principales componentes se tienen:

- Procesos

- Principios

- Estrategias

- Herramientas

- Artefactos 
Existen diferentes frameworks entre ellos destacan: Zachman, TOGAF, TEAF, DODAF. Cada uno con su particularidad ha ido variando en el tiempo, incluyendo especificaciones o ampliando su campo de acción.

\subsubsection{Metodología de Selección del framework de Arquitectura Empresarial}

Se pueden contar con dos formas de evaluación, una de ellas consiste en considerar en pares cada modelo y evaluarlos en base a criterios específicos. A continuación, se consideran los criterios a consideran para cualquier evaluación, según Rafael C. y Hernando C. (2014) en el estudio de arquitectura empresarial y las organizaciones, se pueden establecer los siguientes criterios para la selección de una metodología de arquitectura empresarial:

- Complejidad taxonómica, hace referencia al uso simple de la metodología para clasificar los artefactos.

- Proceso completo, que tan bien guía la metodología en el paso a paso para crear una arquitectura.

- Guía de modelo de referencia, que tan útil ayuda a generar modelos de referencia.

- Guía práctica, que tanto ayuda en la asimilación de la metodología.

- Modelo de madurez, orientación de la metodología evaluando la efectividad y madurez.

- Enfoque de negocio, se refiere al empleo de la tecnología en bien del negocio, enfocado en reducir costos e incrementar ingresos

- Guía de gobernabilidad, que tanto ayuda en el entendimiento y creación de un modelo de gobierno

- Guía de modularidad, que tanto apoya la metodología en la definición de activos de arquitectura

- Disponibilidad de información, cantidad o calidad de información que se tendrá.

La otra forma de evaluación toma en cuenta criterios adicionales que permiten tener una visión más clara en la evaluación, según Fatemeh N, Rodina B, Babak D, Mohd N, Shahaboddin S (2015) se pueden considerar los siguientes criterios de selección:

- Iteraciones, fases. 
- Gestión del proceso, prácticas y fases empleadas para la implementación.

- Mantenimiento del proceso, prácticas para mantener el funcionamiento del modelo.

- Habilidad para interactuar con otros modelos, nivel de compatibilidad con otros modelos.

- Requerimiento de gestión de procesos.

- Paso a paso.

- Facilidad de entendimiento.

- Requerimientos no funcionales.

- Complejidad en la gestión.

- Herramientas de soporte.

- Gobernabilidad, prácticas y procesos asociados a la gobernabilidad de la arquitectura planteada.

- Uso, tipo de uso.

- Almacenamiento, hace referencia al repositorio de prácticas, procesos, artefactos.

- Facilidad de emplear, asociados a los requerimientos y pre requisitos.

\section{TOGAF}

Este modelo permite identificar los intereses de los participantes, empleando las mejores prácticas. Proporciona mecanismos y herramientas que ayudan en la definición, desarrollo, empleo y mantenimiento de la arquitectura empresarial. Cabe mencionar que este modelo es iterativo.

- Entre los principales beneficios de este modelo tenemos:

- Alto nivel de detalle y claridad en las especificaciones

- Enfoque en los cambios globales para transformar la organización

- Consistencia en resultados creados

El modelo TOGAF tiene relación con el método de desarrollo de arquitectura y se puede apreciar en la vista gráfica del modelo: 
Figura 7. Ciclo de implementación de una arquitectura empresarial

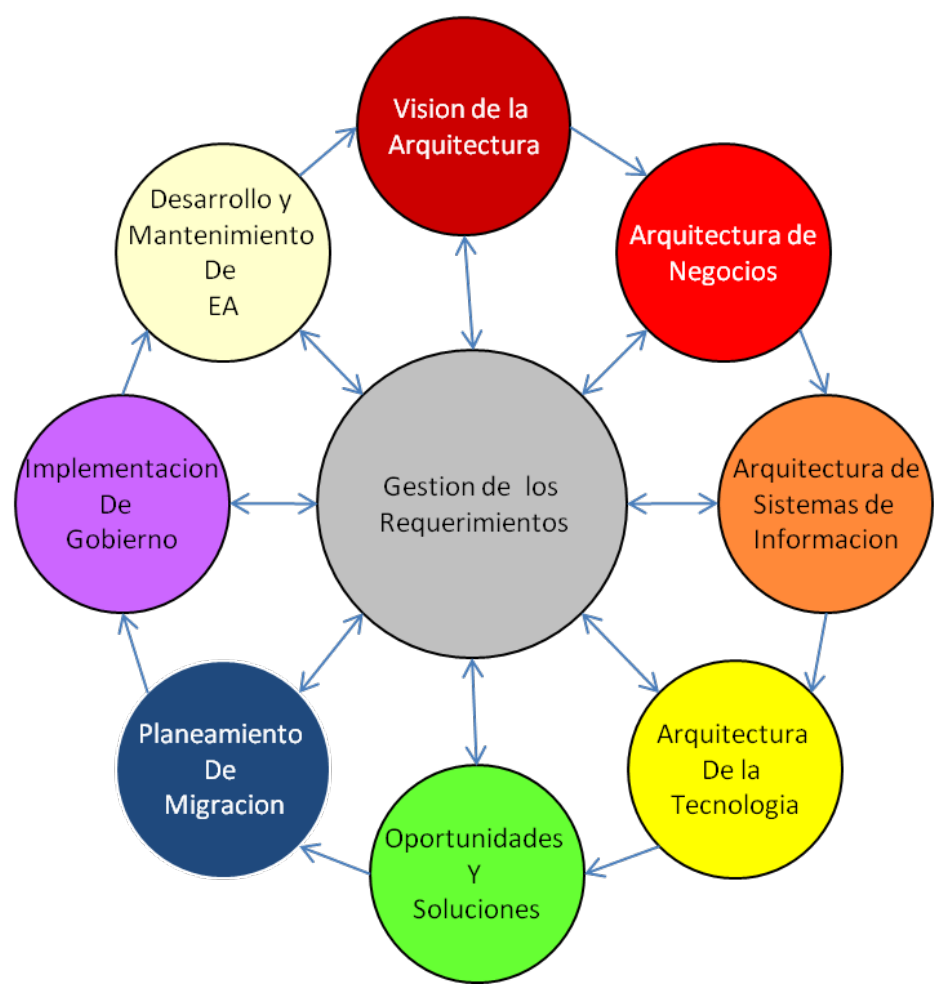

Fuente: Opengroup

En la Figura 7 se muestran las diferentes vistas del modelo y la secuencia de ejecución.

\subsubsection{Arquitectura de Negocios}

La gestión de arquitectura de negocios es ampliamente conocida para el manejo efectivo de las organizaciones, resulta importante en la gestión de cambios en los entornos e incrementa los niveles de competencia.

Implementar la gestión de arquitectura de negocios representa un gran cambio para toda la organización. Para crear valor en los stakeholders, todas las funciones realizadas deben encajar de manera exacta con los procesos.

De acuerdo a lo indicado por Christian Schmidt and Daniel Simon en su libro el método propuesto se centra en las buenas prácticas descritas de gestión descritas en TOGAF. El modelo a emplear cuenta con dos etapas: la definición y la implementación.

En la primera parte se necesita establecer la motivación, en este contexto se quiere establecer el por qué se realizará el análisis y desarrollará las mejoras posteriores. Basado en estos puntos se define el modelo de negocios identificando las actividades y servicios brindados. Esto 
permite responder cuales capacidades se requieren para implementar en termino de roles, procesos y tecnologías de información.

El establecimiento de objetivos y la estrategia a emplear depende de que tan madura se encuentre la organización. Antes de aplicar la totalidad de conceptos y herramientas, se debe especificar el contexto y las necesidades. Como es el caso de Viajes Falabella, el modelado ASIS de los procesos, el organigrama de la compañía, el mapa de los principales procesos y como están asociados a los objetivos estratégicos.

El propósito de esta etapa es dejar claro el alcance e identificar aspectos internos y externos que afecten el desarrollo de las actividades. 


\section{CAPITULO 2}

\section{SITUACIÓN ACTUAL}

En el presente capítulo se presentará información de la empresa seleccionada como caso de estudio, la agencia Viajes Falabella, así como la visión, misión, organigrama, market share, indicadores financieros, indicadores de rentabilidad, indicadores de crecimiento, árbol de valor y los objetivos estratégicos.

Se presentará como está estructurado todos los procesos de la organización a través del mapa de procesos, y las estrategias a partir del análisis FODA.

Para finalmente plantear el problema donde se describirán los procesos que tienen problemas, a fin de que se evalúe su situación actual y se muestren indicadores como sustento de la problemática. 


\section{Situación Actual}

\subsection{Información de la empresa}

Cuando hablamos de una agencia de viajes, por lo general creemos que nos encontramos frente a una empresa pequeña y sencilla que se dedica a trasladar a personas a lugares divertidos. Nuestra experiencia en el rubro nos ha convencido de que esa descripción es totalmente errada: las agencias de viajes desempeñan una compleja actividad empresarial de ámbito internacional que no sólo se circunscribe a distribuir servicios turísticos, si no que crea, produce y promueve complicados productos turísticos que desarrollan destinos y satisfacen exigentes y profundas necesidades del mercado del viajero.

Viajes Falabella desarrolla la función de intermediaria en los servicios de alojamiento, venta de transporte aéreo, venta de transporte ferroviario, transporte por carretera, venta de transporte acuático y en otros servicios relacionados como reservas a museos, sitios de interés cultural, espectáculos, entre otros.

Los viajes de negocios son los desplazamientos realizados por motivos de trabajo y en ellos se incluyen tanto los viajes individuales como los viajes en grupos realizados por hombres de negocios, ejecutivos, políticos, deportistas, entre otros.

En resumen, todos estos productos son: Viajes profesionales individuales o en grupo, Viajes de vacaciones para grupos de empresa, Viajes de incentivos, Viajes a ferias y exposiciones, y Viajes para asistir a Congresos, Conferencias, Convenciones y otras reuniones.

Las tiendas por departamento han logrado un gran éxito ampliando su oferta de productos a través de la diversificación horizontal, creando empresas anexas o subsidiarias para negocios complementarios, como el caso de supermercados, seguros, financiera, viajes, entre otros. El Grupo Falabella ha revolucionado el mercado peruano, gracias a una capacidad de ofrecer lo que el público busca, en un ambiente cálido, acogedor, lleno de vida, y con todas las comodidades que uno pueda desear. Basados en una muy agresiva actividad comercial, se han ganado al público ofreciendo un mix de productos cada vez más completo, a precios adecuados y sustentados en una tarjeta de crédito que ofrece la flexibilidad necesaria para decidir una compra rápidamente. 
Identificada la oportunidad en el sector turismo, el Grupo Falabella crea Viajes Falabella Chile en el año 1,997, en los últimos años ha logrado constituirse como la tercera agencia más importante del país y se evidencia que el crecimiento los seguirá favoreciendo; en la actualidad cuenta con líneas de negocios sólidamente constituidas y bien posicionadas como Vacaciones, Ferias y Congresos, Viajes de Promoción (estudiantes), Viajes de Negocios y Viajes de Novios.

En el Perú, Viajes Falabella inició sus operaciones el mes de Setiembre del 2000. En una primera etapa todas las tácticas comerciales estuvieron dirigidas al público en general. Una vez que la empresa estuvo firme en este segmento, se ingresó a una segunda etapa, enfocando acciones a nichos como Viajes de Promoción y Viajes de Novios. Los resultados al término del primer año de gestión fueron positivos y alentadores, se superó el presupuesto de ventas en 11\% y la empresa se ubicó entre las 15 Agencias de Viajes más importantes del Perú.

Viajes Falabella Perú atendió desde un inicio a Saga Falabella y a la Financiera CMR (ahora Banco Falabella) en sus viajes de negocios, por lo que identificamos que estábamos frente a un mercado muy rentable, las ventas de estas dos empresas constituyeron el $20 \%$ del total facturado, el margen de los productos y servicios vendidos eran superiores a los de otras líneas; adicionalmente la estacionalidad de la compra permitía equilibrar las temporadas de baja del turismo vacacional.

\section{Visión}

Estar posicionados como la 1ra. Agencia de Viajes por brindar un servicio competitivo y confiable, líder en el Perú.

\section{Misión}

Ser una empresa líder en el mercado de viajes, entregando la mejor asesoría a cada persona, empresa o grupo, mediante colaboradores altamente capacitados, cuya orientación al servicio del pasajero, nos permita ofrecer la mejor solución a sus requerimientos de viaje, apoyados en nuestros conocimientos, experiencia, tecnología, innovación y ética profesional.

\section{Organigrama}

En la actualidad, el organigrama de Viajes Falabella es el que se muestra, siendo las áreas básicas de gestión las siguientes: Área de Producto, Área de Ventas y Área de Administración y Finanzas.

Figura 8. Organigrama Viajes Falabella 


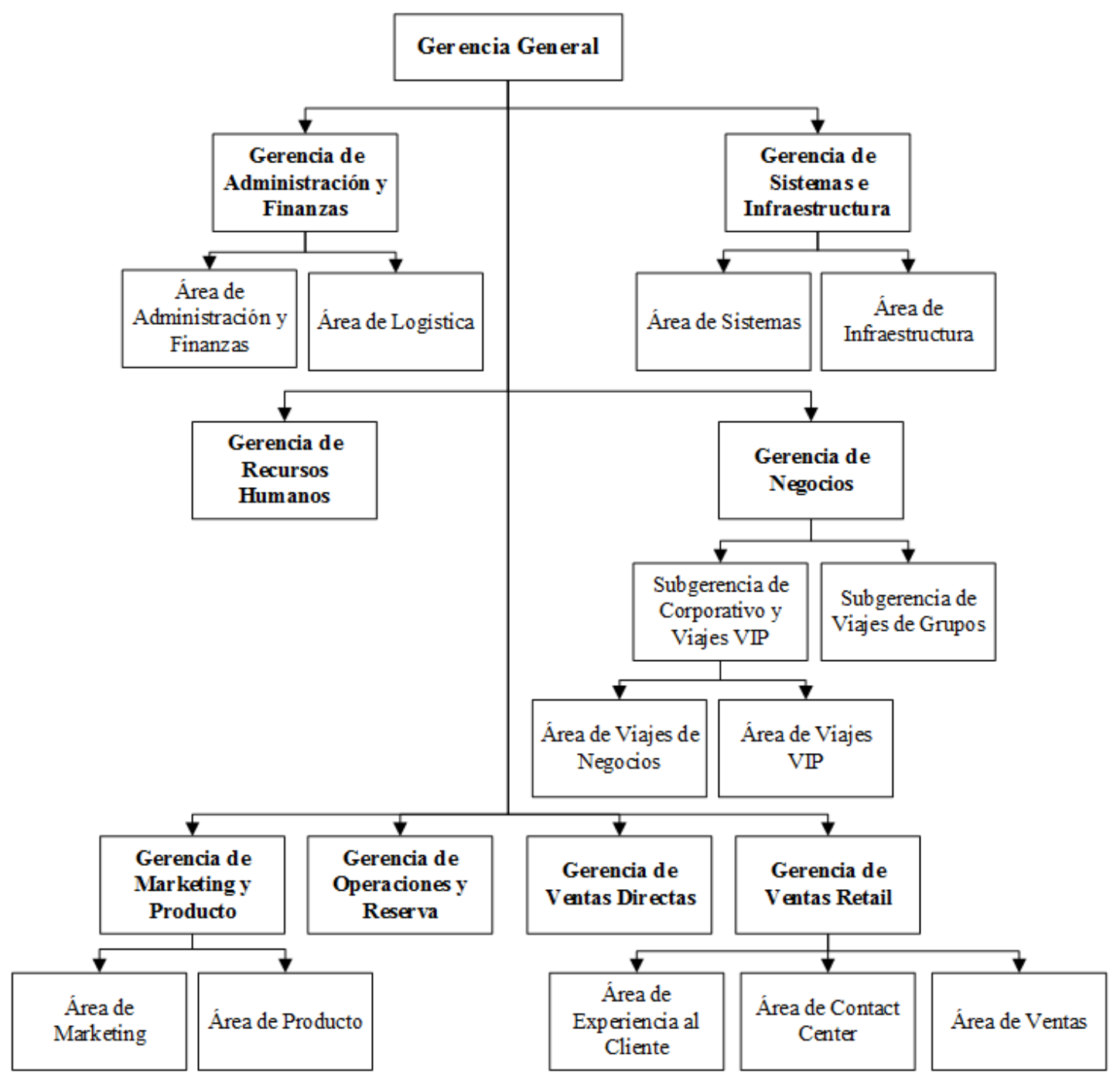

Fuente: Plan Estratégico 2015 - 2016 Viajes Falabella

- Área de Producto: Es la encargada de organizar y operar los servicios y productos turísticos. Realizan la función productora y sus actividades básicas son:

- Diseño y organización de servicios y productos.- cotización y preparación de la información que luego se plasma en circulares y programas de viaje y folletos.

- Contratación.- contactan, seleccionan y contratan proveedores en todo el mundo, transportistas, hoteles, agencias de viajes receptivas, restaurantes, guías, entre otros, para la posterior inclusión en los productos.

- Central de Reservas.- recibe y controla las peticiones y reservas de plazas de los puntos de venta a través del teléfono, fax y por correo electrónico. El control de plazas es 
informatizado para su operación rápida y eficaz. Emiten la documentación viajera: planes de viaje, bonos, boletos de transporte, otros.

- Base de datos.- se centra la documentación informatizada imprescindible para responder a las consultas de clientes internos y externos.

- Operaciones.- responsables de controlar el orden en las operaciones de los servicios prestados al cliente, asumen la solución a las posibles contingencias o problemas que pueden surgir durante los viajes.

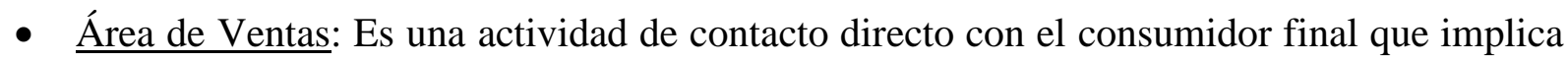
atención, información, asesoría y venta de servicios sueltos, viajes y productos, ya sea de forma personal o por tele venta. Y sus actividades básicas son:

- Información y asesoría. Analizar los destinos y la oferta turística del mercado antes de que el cliente requiera sus servicios.

- Investigación de las necesidades y expectativas del cliente que atienden.

- Reflexión y selección “mental”, entre los servicios o productos del mercado, de aquellos más adecuados para el cliente en cuestión. Información y asesoría.

- Solución, de las necesidades viajeras del cliente.

- Actividades técnicas y comerciales: Reserva y venta de servicios-productos sueltos y combinados.

- Televenta: cuando ejercen el puesto de telemarketing o correo electrónico.

- Otras actividades técnicas:

- Colaboración en la organización y cotización de viajes a la medida.

- Información, contactos y contratos con proveedores.

- Redacción de planes de viaje.

- Colaboración en ocasiones como guía, o tramitación de documentos.

- Actividades administrativas:

- Acogida y atención inicial al cliente. Correspondencia. Archivo.

- Preparación y emisión de documentación de viaje.

- Atención al teléfono, y recepción y emisión de fax, E-mail. 
- Facturación y cobro de clientes. Mantenimiento del fichero de clientes.

- Área de Administración y Finanzas. Área encargada del control económico y del control administrativo. A continuación, desglosamos las actividades principales:

- División Financiera:

- Confección de balances y demás libros contables.

- Gestión fiscal tributaria.

- Gestión y control de costos, gastos, ingresos, de fondos de tesorería.

- Facturación, cobro a clientes. Validación de facturas y pago a proveedores.

- Elaboración de presupuestos de explotación y análisis comparativo.

- División Administrativa:

- Organización administrativa. Normas internas de funcionamiento.

- Diseño de documentos. Control de expedientes.

- Compras y control de material.

- Control de boletos aéreos y terrestres.

- Contratos de mantenimiento.

- $\quad$ División de Personal o de Gestión de Recursos Humanos:

- Planillas. Selección y contratación. Motivación. Formación y rotación.

- Horarios, turnos y vacaciones. Relaciones Humanas.

- Productividad y rentabilidad de los empleados.

- Gerencia General: Falabella Holding que es propietaria de Viajes Falabella S.A. y su directorio nombró al Gerente General, que tiene como funciones principales:

- Representar a la empresa ante todas las instancias.

- Planear, organizar, coordinar, dirigir y controlar la gestión integral de la empresa para su eficiente desarrollo y operación

- Fijar los lineamientos del plan estratégico y comercial.

- Elaborar las políticas generales y comerciales (precios, descuentos, otros) de la empresa siguiendo los lineamientos de la Corporación Falabella. 
- Cumplir con la función de apoderado de la empresa (de acuerdo a los niveles de autorización aprobados por el Directorio).

- Mantener informado al Directorio sobre la gestión de las diferentes áreas.

- Sustentar ante los directivos de Chile y Perú el presupuesto anual.

- Presentar ante los directivos de Perú y Chile los resultados de gestión integral y comercial de la empresa en forma mensual y anual.

- Aprobar y firmar toda documentación correspondiente a la importación o adquisición de materiales y/o equipos necesarios para la operación.

- Investigar y analizar mercados actuales y potenciales.

- Supervisar la ejecución de las estrategias comerciales diseñadas y aprobadas.

- Definir y aprobar las políticas de créditos y cobranzas de la empresa.

- Analizar la información de la competencia y tomar las medidas correctivas o preventivas necesarias para las estrategias comerciales de la empresa.

- Participar en la atención y negociación con clientes preferenciales.

- Dar conformidad a las cuentas por pagar y documentación relacionada al pago de proveedores, recursos humanos, caja e información requerida por Chile.

- Autorizar y firmar los gastos dentro y fuera del presupuesto de las diferentes Áreas de la empresa.

- Elaborar el presupuesto de ventas en coordinación con el Área de Ventas.

- Comparar, evaluar y analizar la venta real con la venta presupuestada a fin de tomar medidas correctivas.

\section{Market Share}

En el Perú, el mercado de agencias de viajes según la Asociación Internacional de Transporte Aéreo (IATA) asciende a 1,500 millones de dólares al cierre del año 2015 y está conformado por 3,150 agencias, de las cuales sólo 250 son IATA: las 30 primeras representan el 70\% del mercado total. El mercado de Viajes de Negocios es de 70 millones (representa el 35\% del mercado total) y está concentrado principalmente en las siguientes empresas: 
Gráfico 3. Market Share 2015 - 2016

\section{Participación Mercado (Venta MM S/.)}

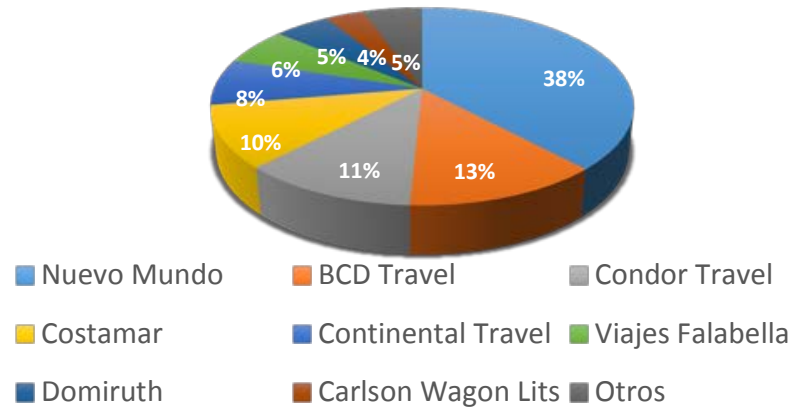

Fuente: Plan Estratégico 2015 - 2016 Viajes Falabella

Tabla 1. Market Share 2015 - 2016

\begin{tabular}{|l|c|c|}
\hline \multicolumn{1}{|c|}{ Agencias } & MM (S/) & \% Mcdo \\
\hline Nuevo Mundo & 600.0 & $38.1 \%$ \\
BCD Travel & 200.0 & $12.7 \%$ \\
Condor Travel & 180.0 & $11.4 \%$ \\
Costamar & 160.0 & $10.2 \%$ \\
Continental Travel & 120.0 & $7.6 \%$ \\
Viajes Falabella & 96.0 & $\mathbf{6 . 1 \%}$ \\
Domiruth & 79.0 & $5.0 \%$ \\
Carlson Wagon Lits & 55.0 & $3.5 \%$ \\
Otros & 85.9 & $5.4 \%$ \\
\hline TOTAL & $\mathbf{1 , 5 7 5 . 9}$ & $\mathbf{1 0 0 . 0 \%}$ \\
\hline
\end{tabular}

Fuente: Plan Estratégico 2015 - 2016 Viajes Falabella

Las características principales de estas empresas es que son IATA (Capacidad para manejar stocks de boletos automatizados). Su principal beneficio es la información, capacidad de ofrecer múltiples alternativas de precio y calidad para un mismo destino. Trabajan con agencias mayoristas y consolidadores. Su negocio es el turismo en general, tanto interno como internacional

\section{Indicadores Financieros}

Como se puede ver el en el Gráfico 4 y 5, las ventas e ingresos totales por año aumentaron el 2015 respecto al 2014 en un 34\%, siendo muy significativo para Viajes Falabella si se compara con el 2013. En general, se puede ver que la tendencia de ventas e ingresos ha subido con el 
paso de los años dando a Viajes Falabella una posición entre los agentes de viajes más grandes del mundo, así como también se puede ver en el Gráfico 3.

Gráfico 4. Ventas Totales por Año

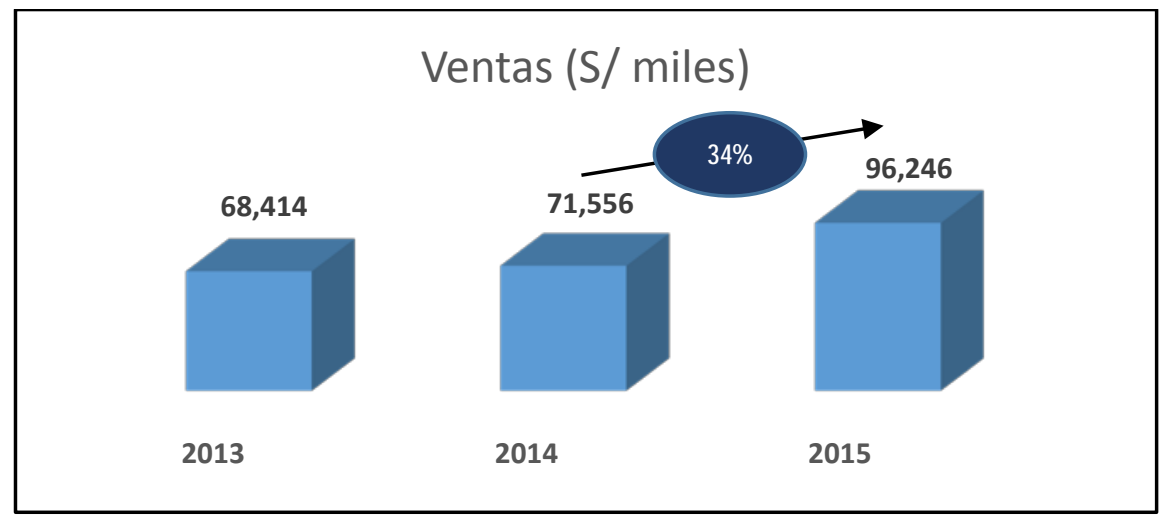

Fuente: Plan Estratégico 2015 - 2016 Viajes Falabella

Gráfico 5. Ingresos Totales por Año

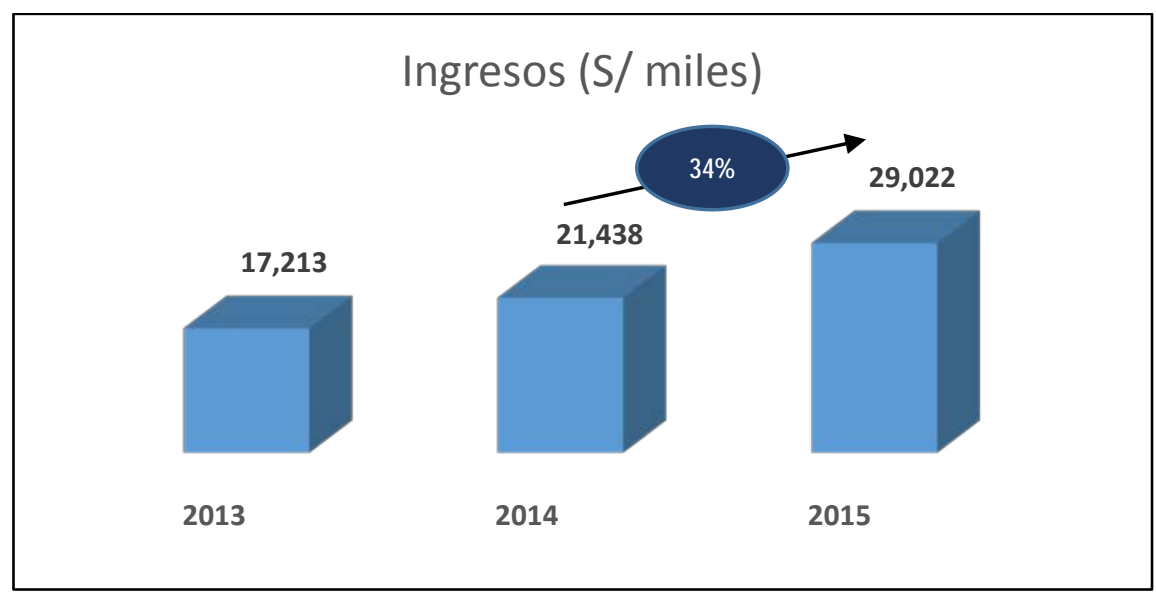

Fuente: Plan Estrategico 2015 - 2016 Viajes Falabella

Respecto a los costos totales por año, Gráfico 6, ha aumentado progresivamente a lo largo de los años, teniendo un mayor aumento en el 2015 con un 33\% respecto al 2014, justo en uno de los mejores años de Viajes Falabella. 
Gráfico 6. Costos Totales por año

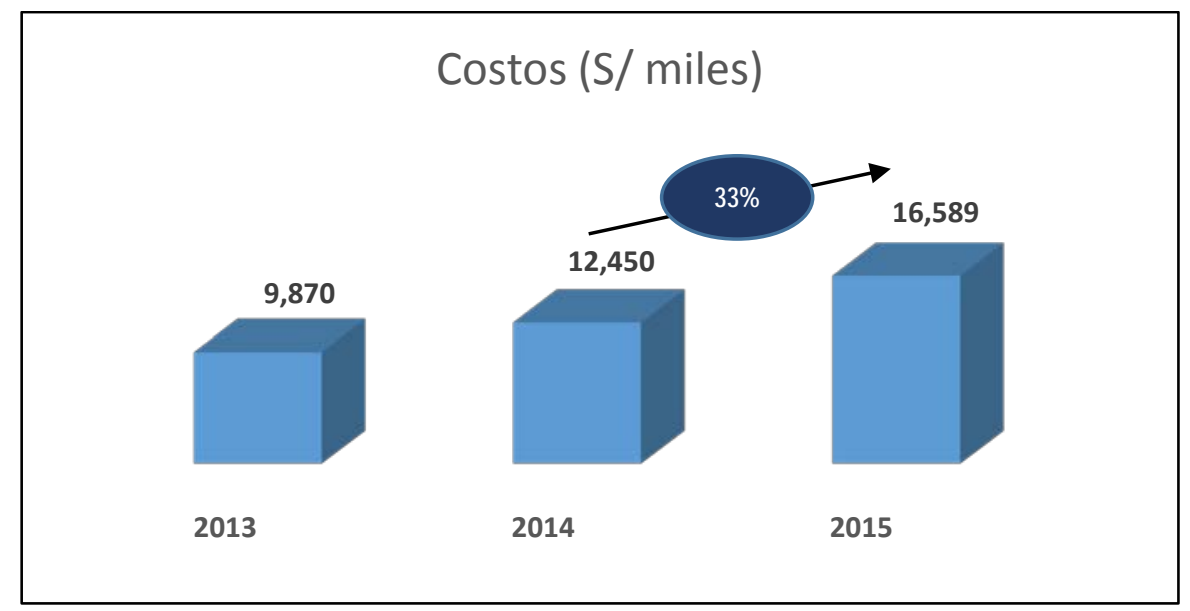

Fuente: Plan Estrategico 2015 - 2016 Viajes Falabella

Y, respecto a los gastos administrativos, Gráfico 7, en el 2015 aumento un 18\% respecto al 2014, siendo un costo esperado con el crecimiento por las ventas ya que contienen los salarios del personal, alquileres de oficinas, papelería de oficina, suministros y equipo de oficinas, mobiliario, entre otros gastos.

Gráfico 7. Gastos Administrativos por año

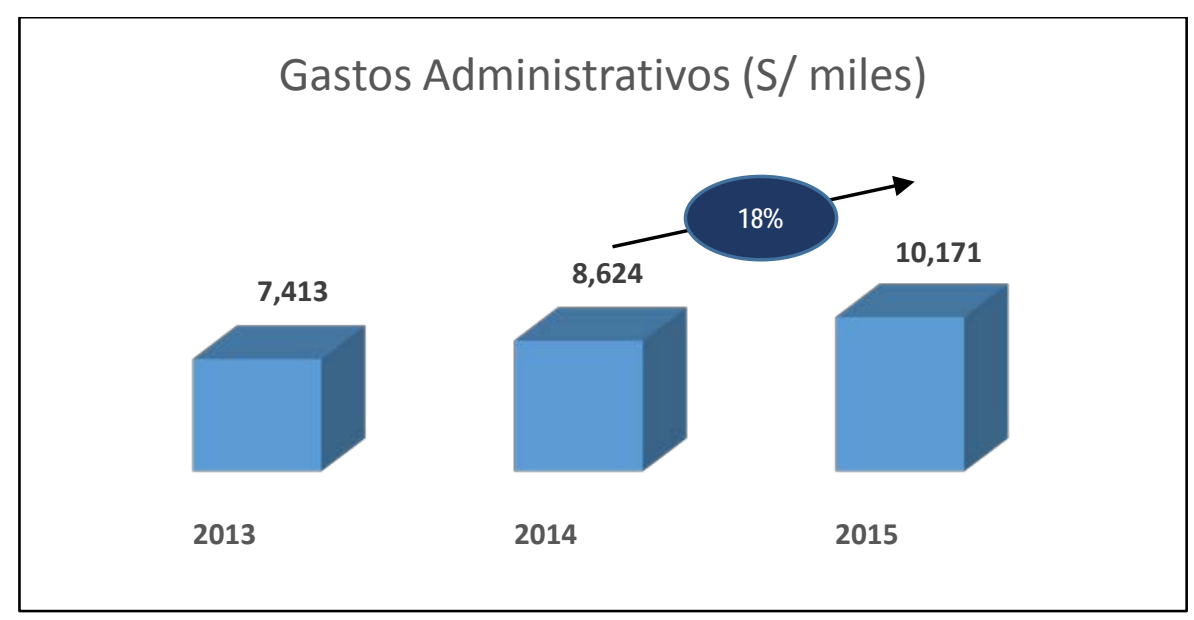

Fuente: Plan Estratégico 2015 - 2016 Viajes Falabella

Por último, se puede visualizar en los Gráficos 8 y 9, que la utilidad operativa fue en perdida en el 2013, estabilizándose en el 2014 y recuperándose en su totalidad en el 2015. Asimismo, la utilidad neta en el 2015 aumento en un 233\% respecto al 2014, pudiendo recuperarse de las pérdidas del 2013. 
Gráfico 8. Utilidad Operativa por año

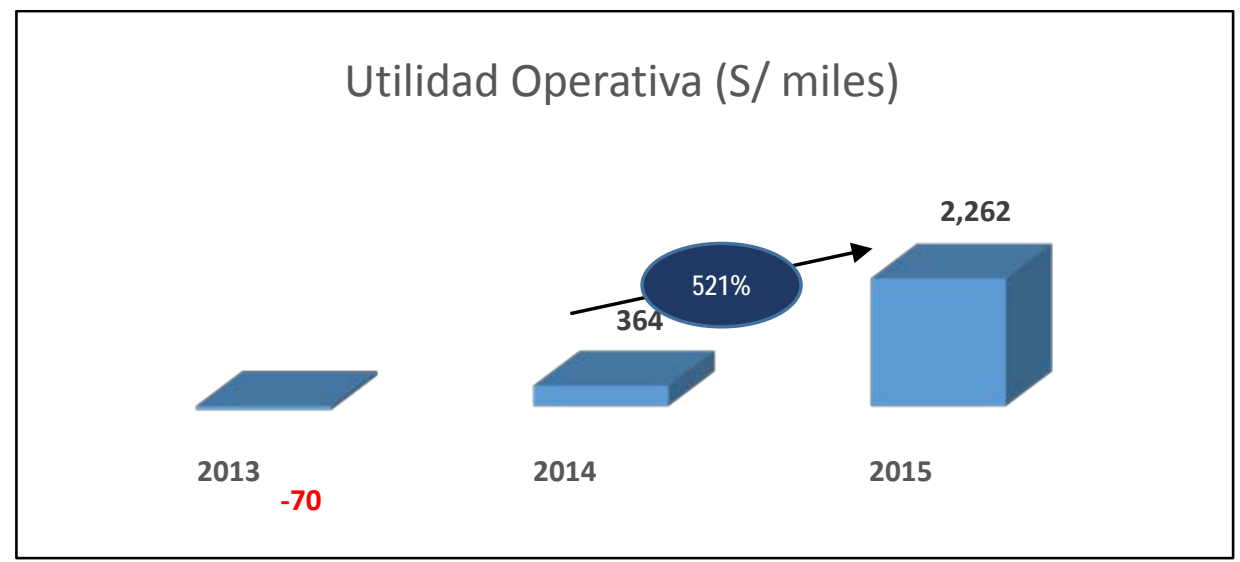

Fuente: Plan Estratégico 2015 - 2016 Viajes Falabella

Gráfico 9. Utilidad Neta por año

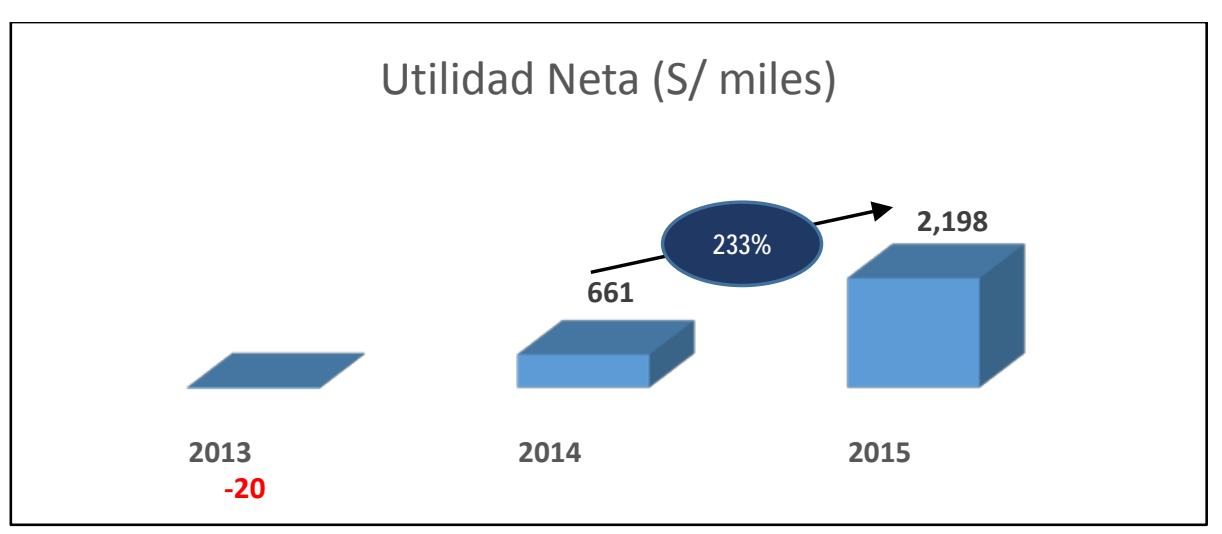

Fuente: Plan Estratégico 2015 - 2016 Viajes Falabella

En resumen, el 2015 fue un excelente año para Viajes Falabella, pues se recuperó de una caída y pérdida de capital en el 2013, logrando posicionarse entre los 10 mejores del rubro de agencias de viajes a nivel mundial y creciendo organizacionalmente a nivel nacional para satisfacer la demanda de las personas por contratar sus servicios.

\section{Indicadores de Rentabilidad}

De acuerdo al Gráfico 10, el ratio operativo de eficiencia muestra que los años 2013-2015 hubo una leve mejoría, pasando de 43 a 35 céntimos de gastos, entendiéndose que por cada sol que ha ingresado a Viajes Falabella se gastó 40 céntimos aproximadamente. 
Gráfico 10. Eficiencia: Ratio Operativo

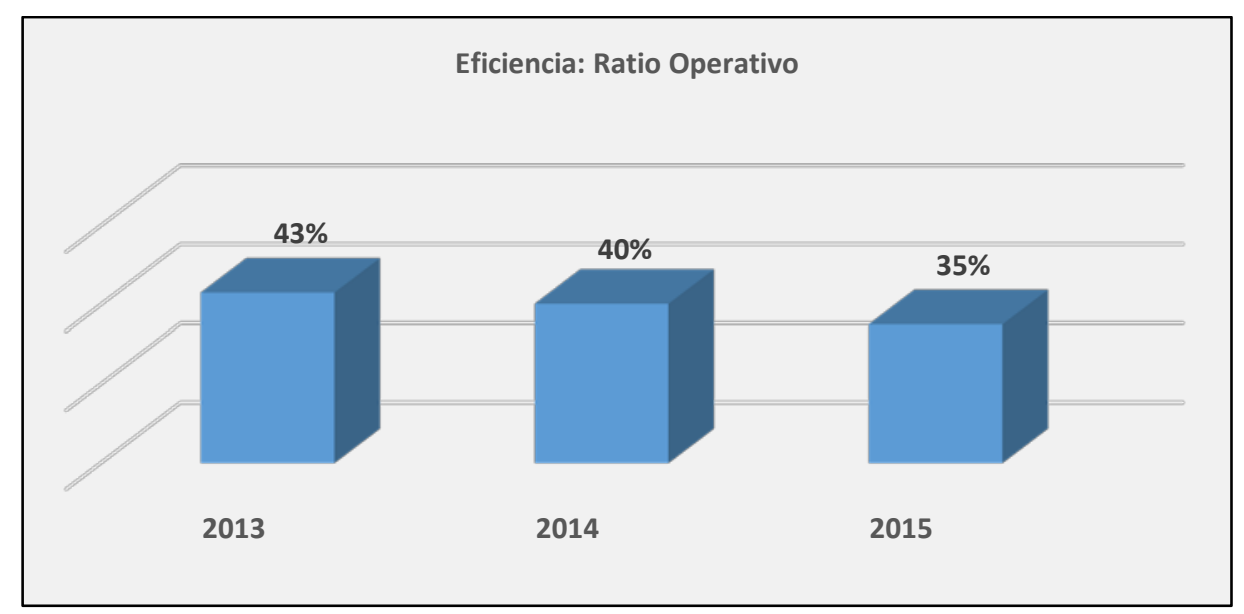

Fuente: Plan Estratégico 2015 - 2016 Viajes Falabella

Tabla 2. Eficiencia: Ratio Operativo

\begin{tabular}{|l|r|r|r|}
\hline & \multicolumn{1}{|c|}{$\mathbf{2 0 1 3}$} & \multicolumn{1}{c|}{$\mathbf{2 0 1 4}$} & \multicolumn{1}{c|}{$\mathbf{2 0 1 5}$} \\
\hline Eficiencia: Ratio Operativo & $43 \%$ & $40 \%$ & $35 \%$ \\
\hline GAV & $\mathbf{7 , 4 1 3}$ & 8,624 & 10,171 \\
\hline Total Ingresos & $\mathbf{1 7 , 2 1 3}$ & $\mathbf{2 1 , 4 3 8}$ & $\mathbf{2 9 , 0 2 2}$ \\
\hline
\end{tabular}

Fuente: Plan Estratégico 2015 - 2016 Viajes Falabella

En el Gráfico 11, se puede ver como el GAV sobre las ventas tuvo una leve mejoría en el 2014 ya que aumentó en un $1 \%$ respecto al año 2014, no siendo muy significativo para la empresa que busca mayor crecimiento en sus ventas.

\section{Gráfico 11. Eficiencia: GAV / Ventas}

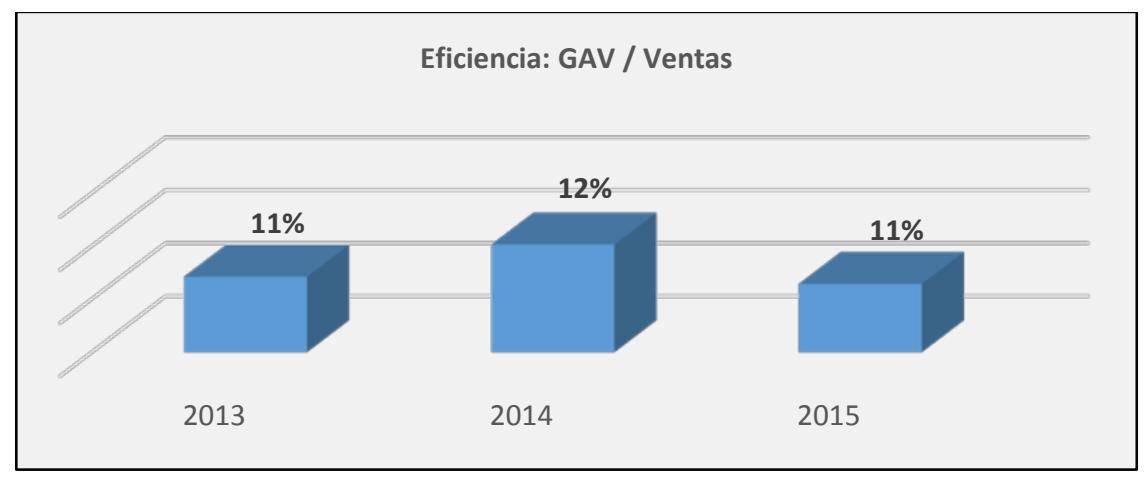

Fuente: Plan Estratégico 2015 - 2016 Viajes Falabella 
Tabla 3.Eficiencia: GAV / Ventas

\begin{tabular}{|l|r|r|r|}
\hline & \multicolumn{1}{|c|}{2013} & \multicolumn{1}{c|}{2014} & \multicolumn{1}{c|}{2015} \\
\hline Eficiencia: GAV / Ventas & $11 \%$ & $12 \%$ & $11 \%$ \\
\hline GAV & 7,413 & 8,624 & 10,171 \\
\hline Total Ventas & $\mathbf{6 8 , 4 1 4}$ & $\mathbf{7 1 , 5 5 6}$ & $\mathbf{9 6 , 2 4 6}$ \\
\hline
\end{tabular}

Fuente: Plan Estratégico 2015 - 2016 Viajes Falabella

En el Gráfico 12, se puede visualizar como la utilidad neta sobre las ventas subió en un 1\% en cada año, si bien es significativo, y a pesar de haber obtenido grandes ingresos y haber crecido en los últimos años, los gastos operativos han dejado ver que la utilidad se mantiene o tiene poco aumento a lo largo de los años.

\section{Gráfico 12. Rentabilidad: Utilidad Neta / Ventas}

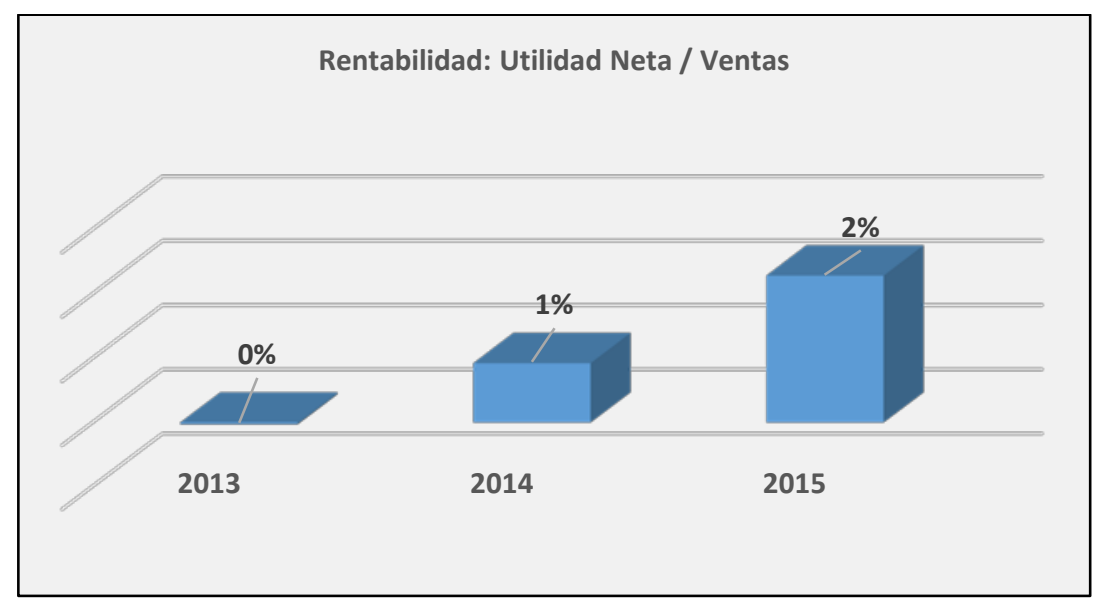

Fuente: Plan Estratégico 2015 - 2016 Viajes Falabella

Tabla 4. Rentabilidad: Utilidad Neta / Ventas

\begin{tabular}{|l|r|r|r|}
\hline & \multicolumn{1}{|c|}{2013} & \multicolumn{1}{|c|}{2014} & \multicolumn{1}{c|}{2015} \\
\hline Rentabilidad: Utilidad Neta / Ventas & $0 \%$ & $1 \%$ & $2 \%$ \\
\hline GAV & -20 & 661 & 2,198 \\
\hline Total Ventas & $\mathbf{6 8 , 4 1 4}$ & $\mathbf{7 1 , 5 5 6}$ & $\mathbf{9 6 , 2 4 6}$ \\
\hline
\end{tabular}

Fuente: Plan Estratégico 2015 - 2016 Viajes Falabella

\section{Indicadores de Crecimiento}

En el Gráfico 13, se puede ver que las ventas de Viajes Falabella con CMR, que pertenece a la corporación Falabella, han crecido en el 2015. Sin embargo, si se toma en cuenta los indicadores 
anteriores, a pesar del crecimiento y de los costos que incurren en los gastos administraos y operacionales, no permite que Viajes Falabella sea tan rentable como se podría pensar.

Gráfico 13. Gestión: \% Ventas CMR Locales

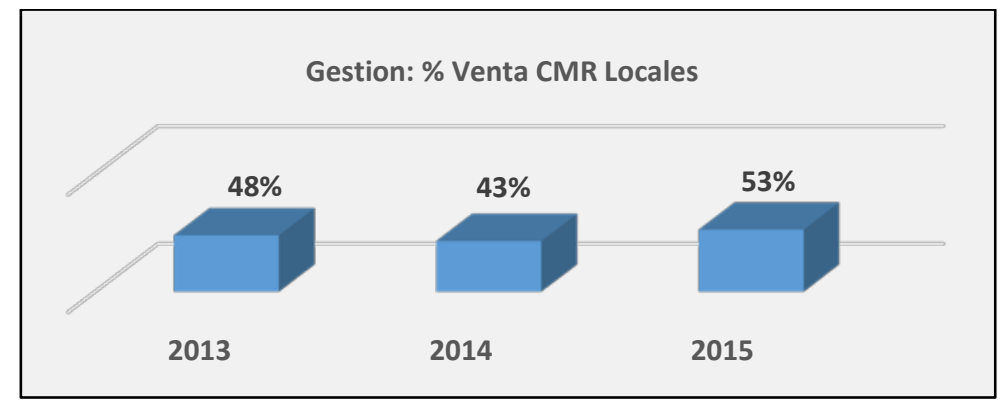

Fuente: Plan Estratégico 2015 - 2016 Viajes Falabella

Tabla 5.Gestion: \% Ventas CMR Locales

\begin{tabular}{|l|r|r|r|}
\hline & \multicolumn{1}{|c|}{2013} & \multicolumn{1}{c|}{2014} & \multicolumn{1}{c|}{2015} \\
\hline Gestion: \% Venta CMR Locales & $48 \%$ & $43 \%$ & $53 \%$ \\
\hline Venta con Tarjeta CMR & 32,733 & 30,769 & 50,655 \\
\hline Total Ingresos & $\mathbf{6 8 , 4 1 4}$ & $\mathbf{7 1 , 5 5 6}$ & $\mathbf{9 6 , 2 4 6}$ \\
\hline
\end{tabular}

Fuente: Plan Estratégico 2015 - 2016 Viajes Falabella

En el Gráfico 14, se puede ver como las ventas por unidades de negocio es muy variado, siendo la web el que mayor impacto y alcance tuvo en el 2015.

Gráfico 14. Crecimiento Unidad de Negocio

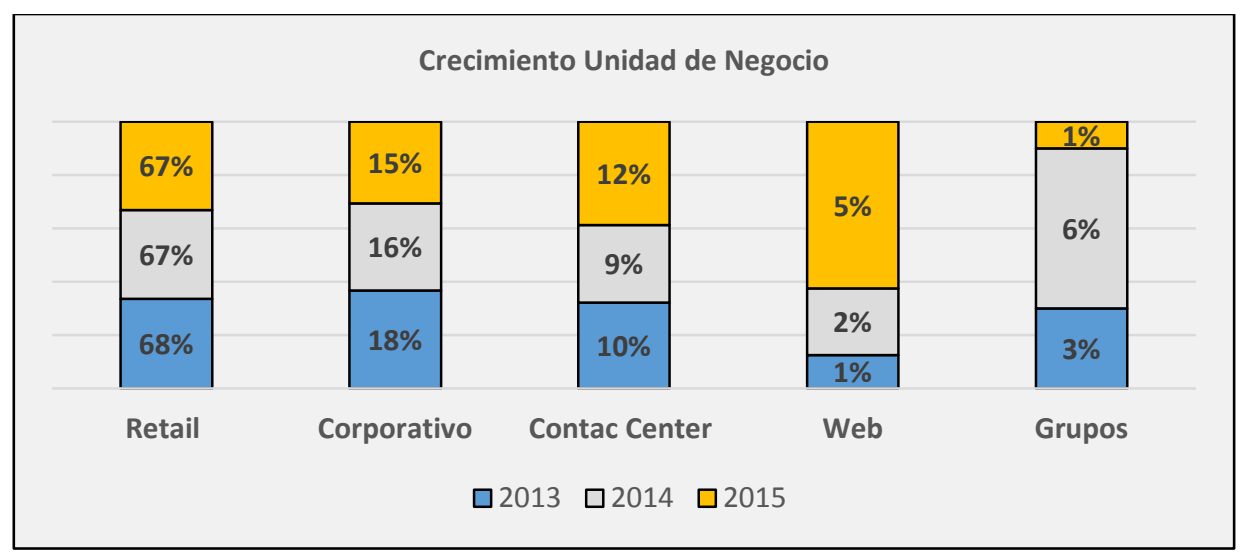

Fuente: Plan Estratégico 2015 - 2016 Viajes Falabella

\section{Árbol de Valor}


Figura 9. Árbol de Valor

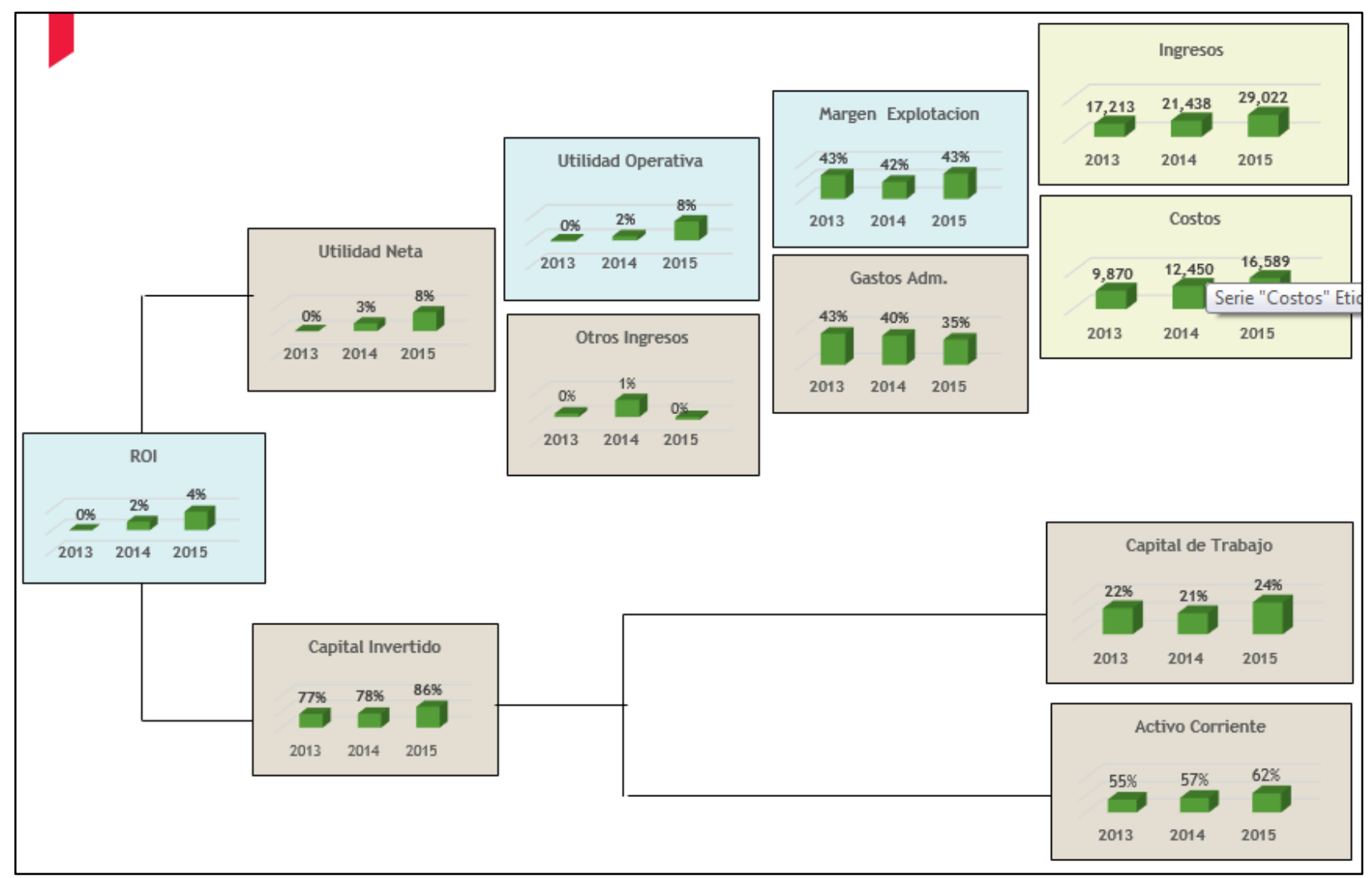

Fuente: Plan Estratégico 2015 - 2016 Viajes Falabella

\section{Objetivos estratégicos}

Grupo Falabella.- emplea la estrategia genérica de diversificación horizontal, y se muestra cuando ingresa al mercado peruano con una Agencia de Viajes.

Viajes Falabella.- emplea como estrategia genérica el “crecimiento intensivo” sustentada en una estrategia de penetración de mercado, de desarrollo de producto y de desarrollo de mercado.

Estos objetivos estratégicos se observan en el aprovechamiento de una serie de oportunidades de crecimiento en las diversas actividades comerciales de una agencia de viajes: desarrollando el mercado de viajes de vacaciones, viajes de promoción, y luna de miel, junto con la expansión de su acción comercial a provincias; y hoy con la decisión de incursionar en el mercado corporativo al tratar de conseguir una mayor participación en el mercado para los productos o servicios presentes, en los mercados presentes. Se detallan los Objetivos Estratégicos:

- Lograr una mayor eficiencia operacional. 
- Incrementar nuestra participación de mercado.

- Posicionar Corporativo, Grupos, Luna de Miel y vacaciones en el mercado.

- Invertir en el desarrollo tecnológico para automatización de procesos.

Tabla 6. Objetivos Estratégicos

\begin{tabular}{|c|c|c|c|c|}
\hline $\begin{array}{c}\text { Temas } \\
\text { Estratégicos }\end{array}$ & Objetivos Estratégicos & Metas & Plazo & Responsable \\
\hline \multirow{2}{*}{$\begin{array}{l}\text { 1. Posicionados } \\
\text { como la } 1 \text { ra. } \\
\text { Agencia de Viajes }\end{array}$} & $\begin{array}{l}\text { 1.1. Lograr una mayor } \\
\text { eficiencia operacional. }\end{array}$ & $\begin{array}{c}\text { Alcanzar una rentabilidad } \\
\text { mayor a } 5 \% .\end{array}$ & 2 años & $\begin{array}{l}\text { Gerencia General, } \\
\text { Área Comercial }\end{array}$ \\
\hline & $\begin{array}{l}\text { 1.2. Incrementar nuestra } \\
\text { participación en el mercado. }\end{array}$ & Incrementar en un $8 \%$. & 1 año & $\begin{array}{l}\text { Gerencia General, } \\
\text { Área Comercial }\end{array}$ \\
\hline $\begin{array}{l}\text { 2. Brindar un } \\
\text { servicio }\end{array}$ & $\begin{array}{l}\text { 2.1. Posicionar corporativo, } \\
\text { grupos, luna de miel y } \\
\text { vacaciones en el mercado. }\end{array}$ & $\begin{array}{c}\text { Incrementar en un } 40 \% \text { las } \\
\text { ventas totales. }\end{array}$ & 2 años & Área Comercial \\
\hline Perú. & $\begin{array}{l}\text { 2.2. Invertir en el desarrollo } \\
\text { tecnológico para } \\
\text { automatización de procesos. }\end{array}$ & $\begin{array}{l}\text { Reducir un 9o\% del tiempo } \\
\text { de atención al cliente. }\end{array}$ & 3 años & Área de Sistemas \\
\hline
\end{tabular}

Fuente: Plan Estratégico 2015 - 2016 Viajes Falabella

\subsection{Análisis FODA}

\section{Fortalezas:}

- Alto reconocimiento de marca, respaldo Falabella.

- Alto conocimiento del cliente.

- Valor mediante atención y soporte multicanal.

- Calidad de servicio: standard corporativo.

- Conveniencia para los clientes del mundo Falabella: Novios, Puntos, Oportunidades Únicas.

- Horario flexible en tiendas.

\section{Oportunidades:}

- Automatización y estandarización de procesos. 
- Integración con proveedores.

- BI clientes holding.

- Desarrollo vertical: alquiler de autos, actividades, cruceros, Home \& apartments, pases, traslados, paquetes dinámicos.

- Nuevos formatos de atención: kioskos, stands, pantallas.

- Desarrollo canal Mobile.

- Promociones de financiación a través de CMR.

- Eliminación de la visa Schengen para Perú.

\section{Debilidades:}

- Alta manualidad, baja sistematización.

- Posicionamiento como agencia 'tradicional'.

- Bajo market share.

- Baja inversión de marketing vs competidores.

- Baja capacidad de desarrollo TI vs industria.

\section{Amenazas:}

- Crecimiento canales directos proveedores.

- Surgimiento global de nuevos competidores virtuales, mobile y low cost.

- Ataques de grupos radicales.

- Inseguridad Ciudadana.

- Alza en el precio del petróleo.

Tabla 7. Matriz FODA Cruzada

\begin{tabular}{|l|l|l|}
\hline & Fortalezas - F & Debilidades - D \\
\hline
\end{tabular}




\begin{tabular}{|c|c|c|}
\hline $\begin{array}{ll}- & \text { FORTALEZAS } \\
- & \text { OPORTUNIDADES } \\
- & \text { DEBILIDADES } \\
- & \text { AMENAZAS }\end{array}$ & $\begin{array}{l}\text { 1. Alto reconocimiento de marca, } \\
\text { respaldo Falabella } \\
\text { 2. Alto conocimiento del cliente. } \\
\text { 3. Valor mediante atención y } \\
\text { soporte multicanal. } \\
\text { 4. Calidad de servicio: standard } \\
\text { corporativo. } \\
\text { 5. Conveniencia para los clientes } \\
\text { del mundo Falabella: Novios, } \\
\text { Puntos, } \\
\text { 6. Oportunidades Únicas. } \\
\text { 7. Horario flexible en tiendas. } \\
\end{array}$ & \begin{tabular}{|ll} 
1. & Alta manualidad, baja \\
sistematización. \\
2.
\end{tabular} \\
\hline Oportunidades - $\mathrm{O}$ & Estrategias - FO & gias - DO \\
\hline 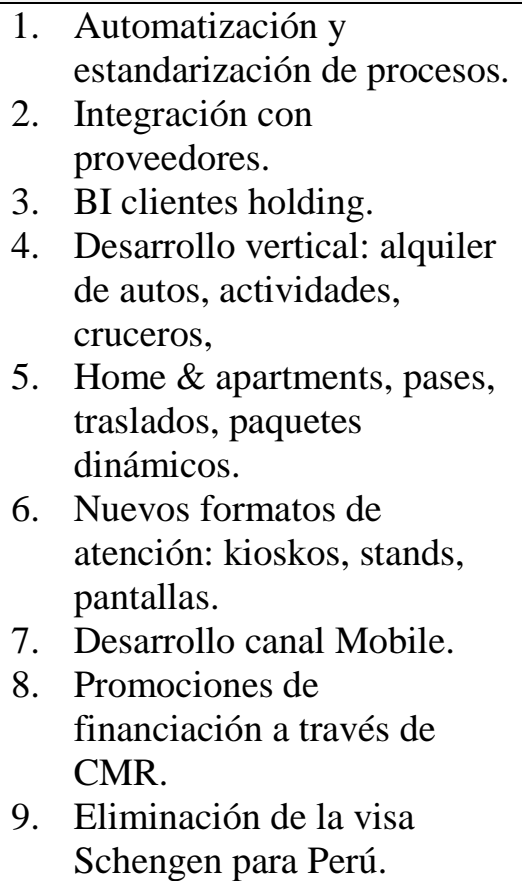 & $\begin{array}{l}\text { 1. Planear e introducir un modelo } \\
\text { con visión a lograr una } \\
\text { empresa integrada con sus } \\
\text { clientes y proveedores con la } \\
\text { certeza de facilitar las } \\
\text { relaciones y conllevar a la } \\
\text { disminución de costes de } \\
\text { transacción. }\end{array}$ & $\begin{array}{l}\text { 1. Desarrollar e implementar } \\
\text { un modelo de gestión } \\
\text { enfocado a las operaciones } \\
\text { y a la excelencia operativa } \\
\text { teniendo como visión una } \\
\text { empresa integrada } \\
\text { operando con procesos } \\
\text { eficientes. } \\
\text { 2. Contar con la } \\
\text { infraestructura de } \\
\text { tecnología y de sistemas } \\
\text { que permita alcanzar las } \\
\text { estrategias empresariales. } \\
\text { Asimismo, el modelo de } \\
\text { gestión de las tecnologías } \\
\text { de información que asegure } \\
\text { el crecimiento continuo de } \\
\text { la mano con el negocio. }\end{array}$ \\
\hline Amenazas - A & Estr & Estrategias - DA \\
\hline 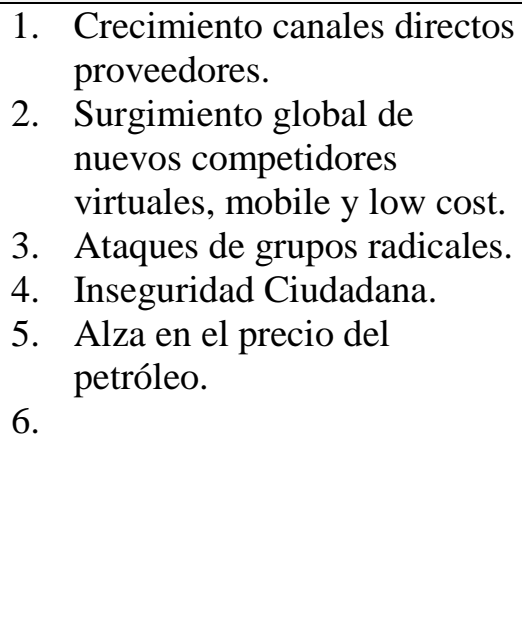 & $\begin{array}{l}\text { Incorporar un modelo de } \\
\text { administración de las } \\
\text { relaciones con el cliente que } \\
\text { esté volcada al entendimiento } \\
\text { y anticipación de las } \\
\text { necesidades de los clientes } \\
\text { actuales y potenciales y al } \\
\text { mismo tiempo permita } \\
\text { identificarlos a los clientes } \\
\text { con valor para la empresa, } \\
\text { diferenciarlos y diseñar } \\
\text { acciones para conseguir su } \\
\text { fidelidad y relaciones } \\
\text { duraderas. }\end{array}$ & $\begin{array}{l}\text { 1. Diseñar y poner en marcha } \\
\text { estrategias de marketing } \\
\text { orientadas a aumentar la } \\
\text { cuota en los actuales } \\
\text { mercados donde tiene } \\
\text { presencia la empresa, y a la } \\
\text { expansión en mercados o } \\
\text { segmentos aún no } \\
\text { incursionados. }\end{array}$ \\
\hline
\end{tabular}

Fuente: Plan Estratégico 2015 - 2016 Viajes Falabella 


\subsection{Mapa de Procesos}

Figura 10. Mapa de Procesos

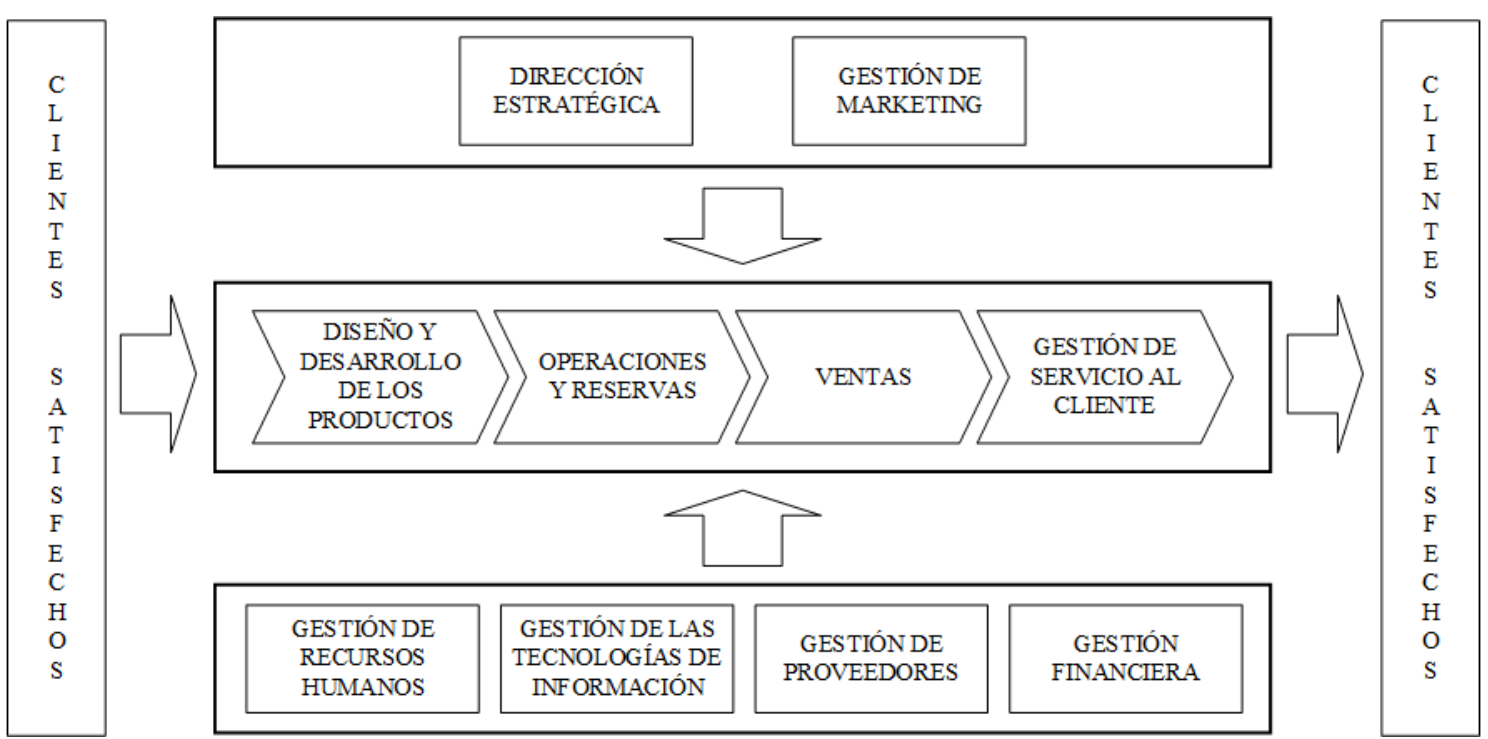

Fuente: Plan Estratégico 2015 - 2016 Viajes Falabella

\subsection{Priorización de procesos}

Tabla 8. Matriz de priorización

\begin{tabular}{|c|c|c|c|c|c|c|c|c|c|c|}
\hline \multirow[b]{2}{*}{ Objetivos/Procesos } & \multicolumn{2}{|c|}{ Estratégicos } & \multicolumn{4}{|c|}{ Operativos } & \multicolumn{4}{|c|}{ Soporte } \\
\hline & 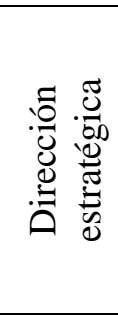 & 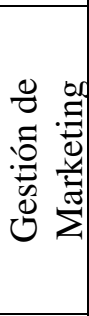 & 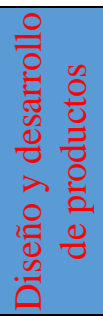 & 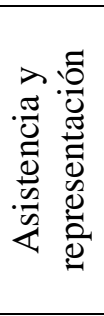 & $\begin{array}{l}\frac{\tilde{J}}{\tilde{U}} \\
\stackrel{0}{\vec{U}}\end{array}$ & 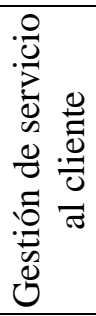 & 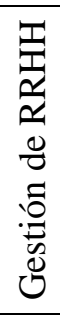 & 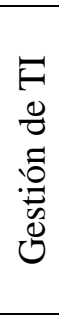 & 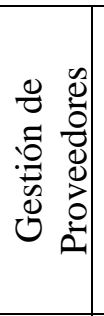 & 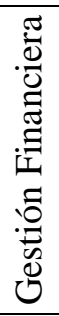 \\
\hline Lograr una mayor eficiencia operacional & $\mathrm{x}$ & & $\mathrm{x}$ & & & $\mathrm{x}$ & $\mathrm{x}$ & $\mathrm{x}$ & $\mathrm{x}$ & $\mathrm{x}$ \\
\hline $\begin{array}{l}\text { Incrementar nuestra participación en el } \\
\text { mercado }\end{array}$ & $\mathrm{x}$ & $\mathrm{x}$ & & & $\mathrm{x}$ & & & & & \\
\hline $\begin{array}{l}\text { Posicionamiento corporativo por } \\
\text { categorías }\end{array}$ & $\mathrm{x}$ & $\mathrm{x}$ & $\mathrm{x}$ & $\mathrm{x}$ & $\mathrm{x}$ & & & & $\mathrm{x}$ & \\
\hline $\begin{array}{l}\text { Invertir en el desarrollo tecnológico para } \\
\text { automatización de procesos }\end{array}$ & $\mathrm{x}$ & & $x$ & & $\mathrm{x}$ & & & $\mathrm{x}$ & & \\
\hline
\end{tabular}

Fuente: Elaboración propia

Los procesos seleccionados son ventas y desarrollo de productos, ambos se encuentran en concordancia con los objetivos estratégicos de Viajes Falabella y son los que tienen mayor cohesión. El análisis de estudio se basará en estos dos procesos. 
Tabla 9. Matriz de asignación de responsabilidades

\begin{tabular}{|c|c|c|c|c|c|c|c|c|c|c|}
\hline \multirow[b]{2}{*}{ Áreas/Procesos } & \multicolumn{2}{|c|}{ Estratégicos } & \multicolumn{4}{|c|}{ Operativos } & \multicolumn{4}{|c|}{ Soporte } \\
\hline & 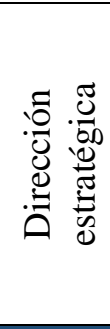 & 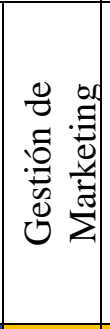 & 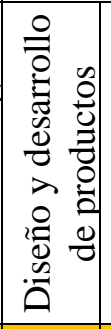 & 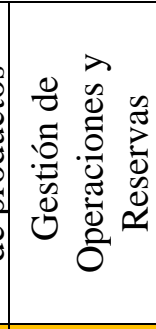 & $\begin{array}{l}\stackrel{y}{0} \\
\stackrel{\tilde{0}}{>}\end{array}$ & 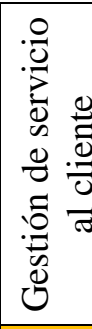 & 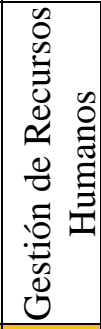 & 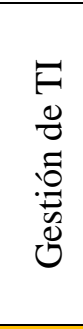 & 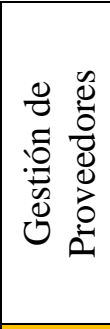 & 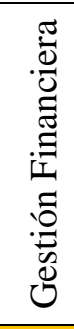 \\
\hline Gerencial General & A & I & I & I & I & I & I & I & I & I \\
\hline $\begin{array}{l}\text { Gerencia de Sistemas e } \\
\text { Infraestructura }\end{array}$ & $\mathrm{R}$ & & & & & & & A & & \\
\hline Área de Sistemas & & & & & & & & $\mathrm{R}$ & & \\
\hline Área de Infraestructura & & & & & & & & $\mathrm{R}$ & & \\
\hline $\begin{array}{l}\text { Gerencia de Recursos } \\
\text { Humanos }\end{array}$ & $\mathrm{R}$ & & & & & & $\mathrm{A} / \mathrm{R}$ & & & \\
\hline $\begin{array}{l}\text { Gerencia de Administración } \\
\text { y Finanzas }\end{array}$ & $\mathrm{R}$ & C & & & & & C & C & A & A \\
\hline $\begin{array}{l}\text { Área de Administración y } \\
\text { Finanzas }\end{array}$ & & & & & & & & & & $\mathrm{R}$ \\
\hline Área de Logística & & & & & & & & & $\mathrm{R}$ & \\
\hline Gerencia de Ventas & $\mathrm{R}$ & I & C & I & A & A & & & & \\
\hline $\begin{array}{l}\text { Sub Gerencia de Ventas } \\
\text { Directas }\end{array}$ & & I & C & I & $\mathrm{R}$ & & & & & \\
\hline $\begin{array}{l}\text { Sub Gerencia de Ventas } \\
\text { Retail }\end{array}$ & & I & C & I & $\mathrm{R}$ & $\mathrm{R}$ & & & & \\
\hline $\begin{array}{l}\text { Área de Experiencia al } \\
\text { Cliente }\end{array}$ & & & & & $\mathrm{R}$ & $\mathrm{R}$ & & & & \\
\hline $\begin{array}{l}\text { Área de Contact } \\
\text { Center }\end{array}$ & & & & I & $\mathrm{R}$ & $\mathrm{R}$ & & & & \\
\hline Área de Ventas & & & & I & $\mathrm{R}$ & & & & & \\
\hline Gerencia de Negocios & $\mathrm{R}$ & & A & C & C & & & & & \\
\hline $\begin{array}{l}\text { Sub Gerencia de Viajes } \\
\text { Corporativos y Viajes } \\
\text { VIP }\end{array}$ & & & $\mathrm{R}$ & $\mathrm{C}$ & C & & & & & \\
\hline Área de Viajes VIP & & & $\mathrm{R}$ & & C & & & & & \\
\hline $\begin{array}{l}\text { Área de Viajes de } \\
\text { Negocios }\end{array}$ & & & $\mathrm{R}$ & & C & & & & & \\
\hline $\begin{array}{l}\text { Sub Gerencia de Viajes } \\
\text { de Grupos }\end{array}$ & & & $\mathrm{R}$ & C & C & & & & & \\
\hline $\begin{array}{l}\text { Gerencia de Operaciones y } \\
\text { Reservas }\end{array}$ & $\mathrm{R}$ & & & $\mathrm{A} / \mathrm{R}$ & & & & & & \\
\hline Gerencia de Marketing & $\mathrm{R}$ & A & & & & & & & & \\
\hline
\end{tabular}

\begin{tabular}{|c|c|}
\hline $\mathrm{R}$ & Responsable \\
\hline $\mathrm{A}$ & Aprobador \\
\hline $\mathrm{C}$ & Consultado \\
\hline $\mathrm{I}$ & Informado \\
\hline
\end{tabular}

Fuente: Elaboración propia 


\subsection{Descripción de Macroprocesos}

- Ventas

- Proceso de Ventas Sucursales (Consulta de servicios intranet, Consulta de servicios carpeta compartida, Cotizaciones, pago)

- Proceso de Venta Contact Center (Consulta de servicios intranet, Consulta de servicios carpeta compartida, Cotizaciones, pago)

- $\quad$ Proceso de Ventas Web (Cotizaciones, pago)

- Diseño y desarrollo de productos

- Proceso Diseño y desarrollo de los Productos 
2.5.1. Ventas sucursales

Figura 11. Diagrama AS IS del proceso Ventas sucursales

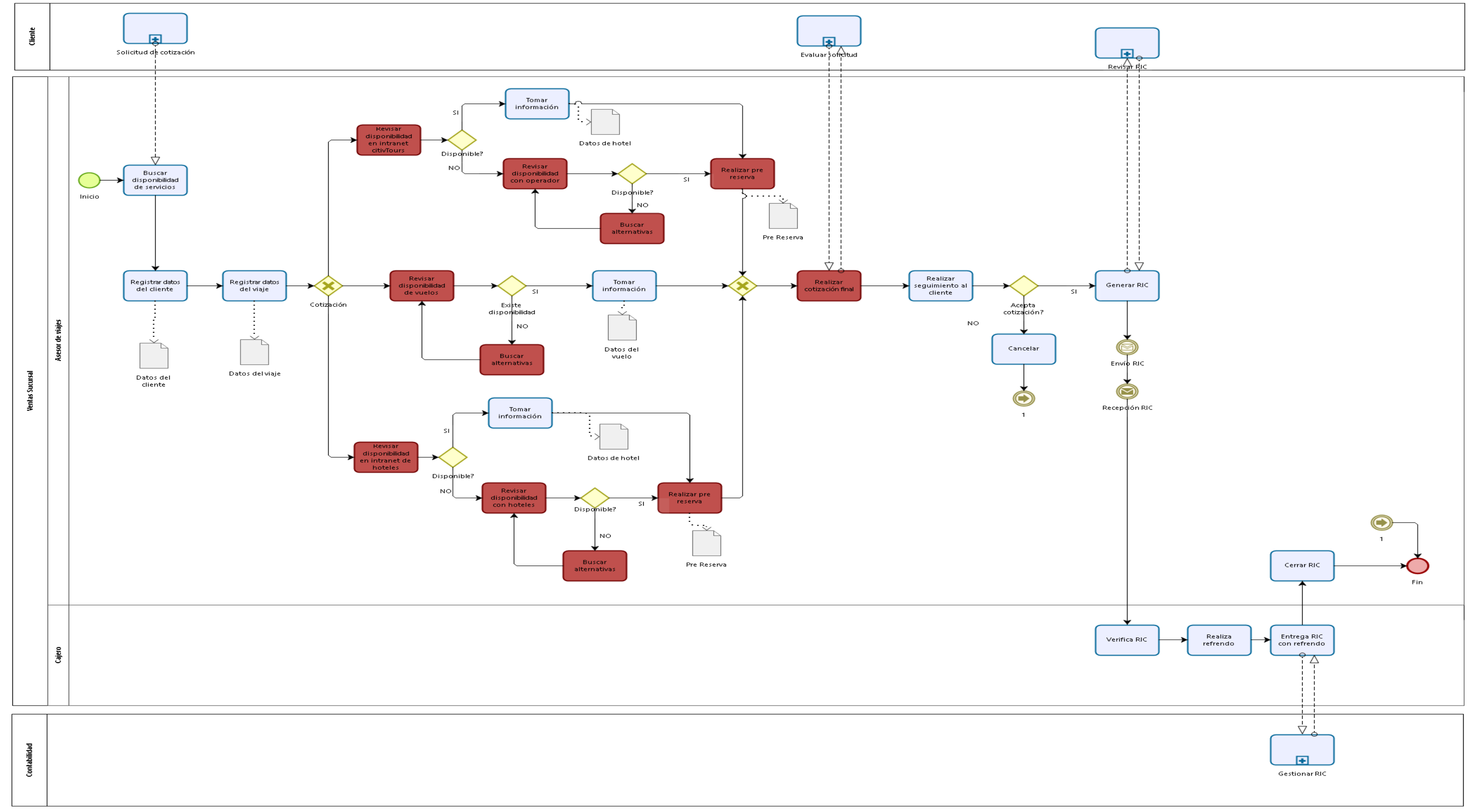

Fuente: Elaboración propia 
En este diagrama se pone foco en las siguientes actividades:

- Revisar disponibilidad en Intranet de city tours

- Revisar disponibilidad de vuelos

- Revisar disponibilidad en intranet de hoteles

- Revisar disponibilidad con operador

- Buscar alternativas de vuelos

- Revisar disponibilidad con hoteles

- Buscar alternativas de hoteles

- Realizar pre reserva de city tours

- Realizar pre reserva de hoteles

- Realizar cotización final

Según el levantamiento de información realizado con los expertos del negocio y responsables del área de Ventas, estas actividades son críticas y definen el comportamiento y resultado de todo el proceso de ventas en sucursales. 


\section{Caracterización}

Tabla 10. Caracterización AS-IS del proceso Ventas sucursales

\section{NOMBRE DEL}

MACROPROCESO:

NOMBRE DEL PROCESO:

\section{VENTAS}

PROCESO DE VENTAS SUCURSALES

RESPONSABLES DEL PROCESO

- Asesor de Viaje

- Caja Registradora - Saga Falabella

- Contabilidad

\section{OBJETIVO}

- Realizar la cotización de boletos aéreos, paquetes turísticos o cualquier necesidad del cliente

- Gestionar el seguimiento de las cotizaciones realizadas

- Gestionar el cierre de ventas

\section{PROVEEDORES:}

- Gerencia de Operaciones

- Gerencia de Producto

- Gerencia de Marketing

\section{Buscar disponibilidad de servicios}

Registrar datos del cliente

Registrar datos del viaje

Revisar disponibilidad en intranet de cityTours

Revisar disponibilidad con operador

Buscar alternativas

Tomar información

Realizar pre reserva

Revisar disponibilidad de vuelos

Buscar alternativas

Tomar información

Revisar disponibilidad en intranet de hoteles

Revisar disponibilidad con hoteles

Buscar alternativas

Realizar pre reserva

Tomar información

Realizar cotización final

Realizar seguimiento al cliente

Cancelar

Generar RIC

Verifica RIC

\section{ENTRADAS:}

- Diseño del Producto de viaje

- Solicitud de Cotización del cliente.

\section{ACTIVIDADES}




\begin{tabular}{|c|c|}
\hline Realiza refrendo & \\
\hline Entrega RIC con refrendo & \\
\hline Cerrar RIC & \\
\hline SALIDAS & CLIENTES \\
\hline - Cotización & - Cliente \\
\hline - Recibo de Ingreso a Caja & $\begin{array}{l}\text { - Gerencia de Administración y Finanzas } \\
\text { (Administración, Contabilidad, Tesorería, Sistemas) }\end{array}$ \\
\hline
\end{tabular}

Fuente: Elaboración propia

\section{Análisis causa raíz}

Gráfico 15. Análisis causa raíz del proceso Ventas sucursales

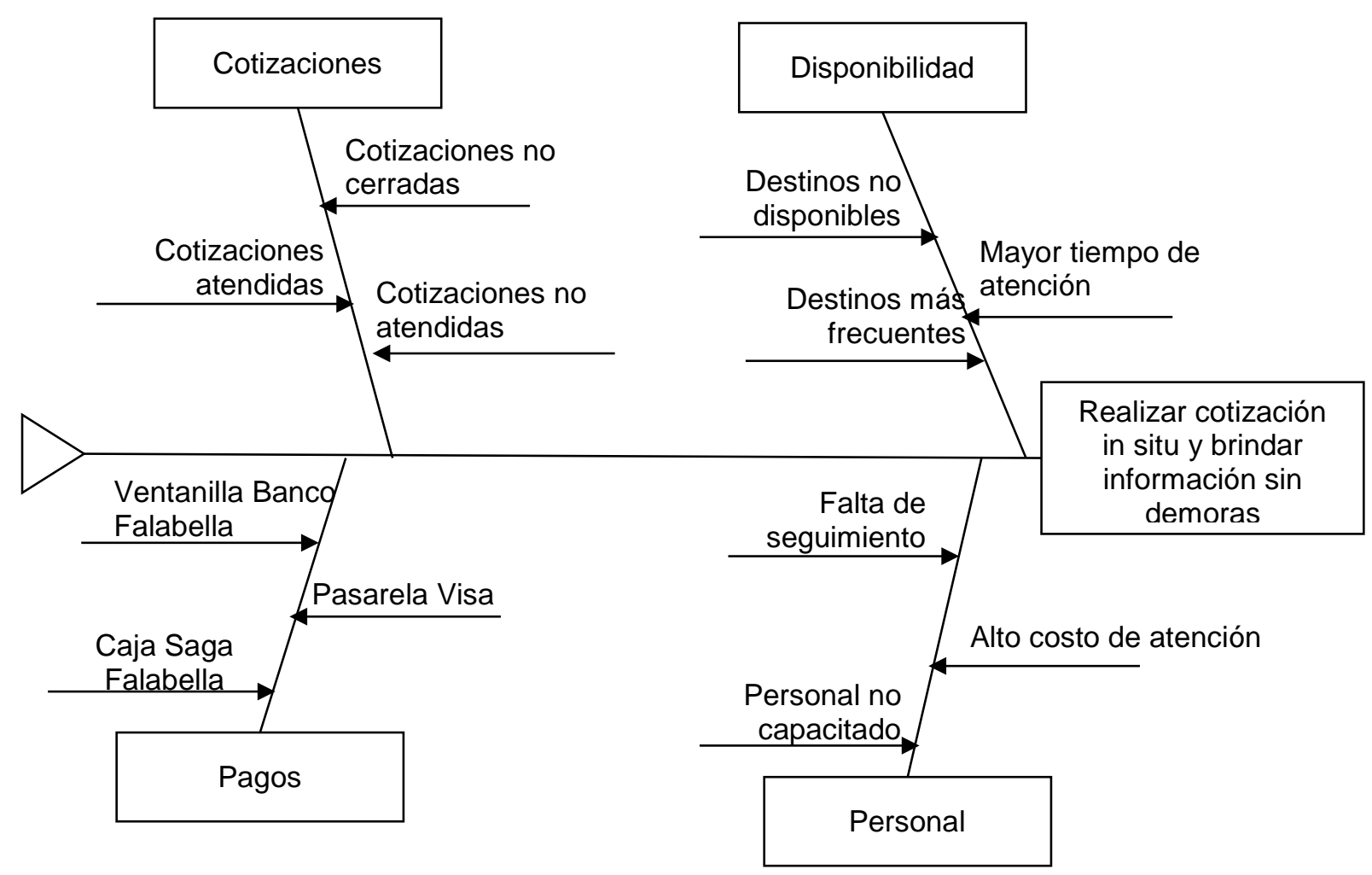

Fuente: Elaboración propia 


\section{Caracterización}

Tabla 11. Caracterización AS-IS del proceso Ventas sucursales

\begin{tabular}{|c|c|c|c|}
\hline Entradas & Actividad & Salida & Responsable \\
\hline Solicitud del cliente & Buscar disponibilidad de servicios & Vista de disponibilidad de servicios & Asesor de ventas \\
\hline Vista de disponibilidad de servicios & Registrar datos del cliente & Datos del cliente ingresados & Asesor de ventas \\
\hline Datos del cliente ingresados & Registrar datos del viaje & Datos del viaje ingresados & Asesor de ventas \\
\hline Datos del viaje ingresados & $\begin{array}{l}\text { Revisar disponibilidad en intranet } \\
\text { de cityTours }\end{array}$ & $\begin{array}{c}\text { Vista en intranet de disponibilidad de city } \\
\text { tours }\end{array}$ & Asesor de ventas \\
\hline $\begin{array}{l}\text { Vista en intranet de disponibilidad } \\
\text { de city tours }\end{array}$ & $\begin{array}{c}\text { Revisar disponibilidad con } \\
\text { operador }\end{array}$ & Vista de disponibilidad de operador & Asesor de ventas \\
\hline Vista de disponibilidad de operador & Buscar alternativas & Vista de alternativas de operadores & Asesor de ventas \\
\hline $\begin{array}{l}\text { Vista en intranet de disponibilidad } \\
\text { de city tours }\end{array}$ & Tomar información & Información de city tours seleccionada & Asesor de ventas \\
\hline $\begin{array}{l}\text { Vista de disponibilidad de operador } \\
\text { Información de city tours } \\
\text { seleccionada }\end{array}$ & Realizar pre reserva & Pre reserva de city tours realizada & Asesor de ventas \\
\hline Datos del viaje ingresados & Revisar disponibilidad de vuelos & Vista de disponibilidad de vuelos & Asesor de ventas \\
\hline Vista de disponibilidad de vuelos & Buscar alternativas & Vista de alternativas de vuelos & Asesor de ventas \\
\hline Vista de disponibilidad de vuelos & Tomar información & Información de vuelos seleccionada & Asesor de ventas \\
\hline
\end{tabular}




\begin{tabular}{|c|c|c|c|}
\hline Entradas & Actividad & Salida & Responsable \\
\hline Datos del viaje ingresados & $\begin{array}{l}\text { Revisar disponibilidad en intranet } \\
\text { de hoteles }\end{array}$ & $\begin{array}{l}\text { Vista en intranet de disponibilidad de } \\
\text { hoteles }\end{array}$ & Asesor de ventas \\
\hline $\begin{array}{l}\text { Vista en intranet de disponibilidad } \\
\text { de hoteles }\end{array}$ & Revisar disponibilidad con hoteles & Vista de disponibilidad de hoteles & Asesor de ventas \\
\hline Vista de disponibilidad de hoteles & Buscar alternativas & Vista de alternativas de hoteles & Asesor de ventas \\
\hline $\begin{array}{l}\text { Vista de disponibilidad de hoteles } \\
\text { Información de hoteles seleccionada }\end{array}$ & Realizar pre reserva & Pre reserva de hotel realizada & Asesor de ventas \\
\hline $\begin{array}{l}\text { Vista en intranet de disponibilidad } \\
\text { de hoteles }\end{array}$ & Tomar información & Información de hoteles seleccionada & Asesor de ventas \\
\hline $\begin{array}{l}\text { Pre reserva de city tours realizada } \\
\text { Pre reserva de hotel realizada } \\
\text { Información de vuelos seleccionada }\end{array}$ & Realizar cotización final & Cotización realizada & Asesor de ventas \\
\hline Cotización realizada & Realizar seguimiento al cliente & Conformidad del cliente & Asesor de ventas \\
\hline Conformidad del cliente & Cancelar & Cotización cancelada & Asesor de ventas \\
\hline Cotización realizada & Generar RIC & RIC generado & Asesor de ventas \\
\hline RIC generado & Verifica RIC & RIC verificado & Cajero \\
\hline RIC verificado & Realiza refrendo & RIC refrendado & Cajero \\
\hline RIC refrendado & Entrega RIC con refrendo & RIC con refrendo entregado & Cajero \\
\hline RIC con refrendo entregado & Cerrar RIC & RIC cerrado & Asesor de ventas \\
\hline
\end{tabular}


Fuente: Elaboración propia

\section{Indicadores}

Tabla 12. Indicadores del proceso Ventas sucursales

\begin{tabular}{|c|c|c|}
\hline INDICADOR: & FORMA DE CÁLCULO: & ACTIVIDAD \\
\hline $\begin{array}{l}\text { Porcentaje de Cotizaciones } \\
\text { Cerradas en Ventas }\end{array}$ & $\begin{array}{l}\text { (Número de Cotizaciones en Ventas / Total de } \\
\text { Cotizaciones )* } 100\end{array}$ & $\begin{array}{l}\text { Realizar cotización final } \\
\text { Revisar disponibilidad de vuelos } \\
\text { Revisar disponibilidad en intranet citiyTours }\end{array}$ \\
\hline $\begin{array}{l}\text { Porcentaje de Cotizaciones } \\
\text { Atendidas }\end{array}$ & $\begin{array}{l}\text { (Número de Cotizaciones Atendidas / Total de } \\
\text { Cotizaciones )* } 100\end{array}$ & $\begin{array}{l}\text { Realizar cotización final } \\
\text { Revisar disponibilidad de vuelos } \\
\text { Revisar disponibilidad en intranet citiyTours }\end{array}$ \\
\hline $\begin{array}{l}\text { Porcentaje de Cotizaciones NO } \\
\text { Atendidas }\end{array}$ & $\begin{array}{l}\text { (Número de Cotizaciones NO Atendidas / Total } \\
\text { de Cotizaciones )* } 100\end{array}$ & $\begin{array}{l}\text { Realizar cotización final } \\
\text { Revisar disponibilidad de vuelos } \\
\text { Revisar disponibilidad en intranet citiyTours }\end{array}$ \\
\hline $\begin{array}{l}\text { Porcentaje de Cotizaciones por } \\
\text { Destino }\end{array}$ & $\begin{array}{l}\text { (Número de Cotizaciones en Ventas x Destino / } \\
\text { Total de Cotizaciones )* } 100\end{array}$ & $\begin{array}{l}\text { Realizar cotización final } \\
\text { Revisar disponibilidad de vuelos } \\
\text { Revisar disponibilidad en intranet citiyTours }\end{array}$ \\
\hline
\end{tabular}

Fuente: Elaboración propia 
2.5.2. Ventas contact center

Figura 12. Diagrama AS IS del proceso Ventas contact center

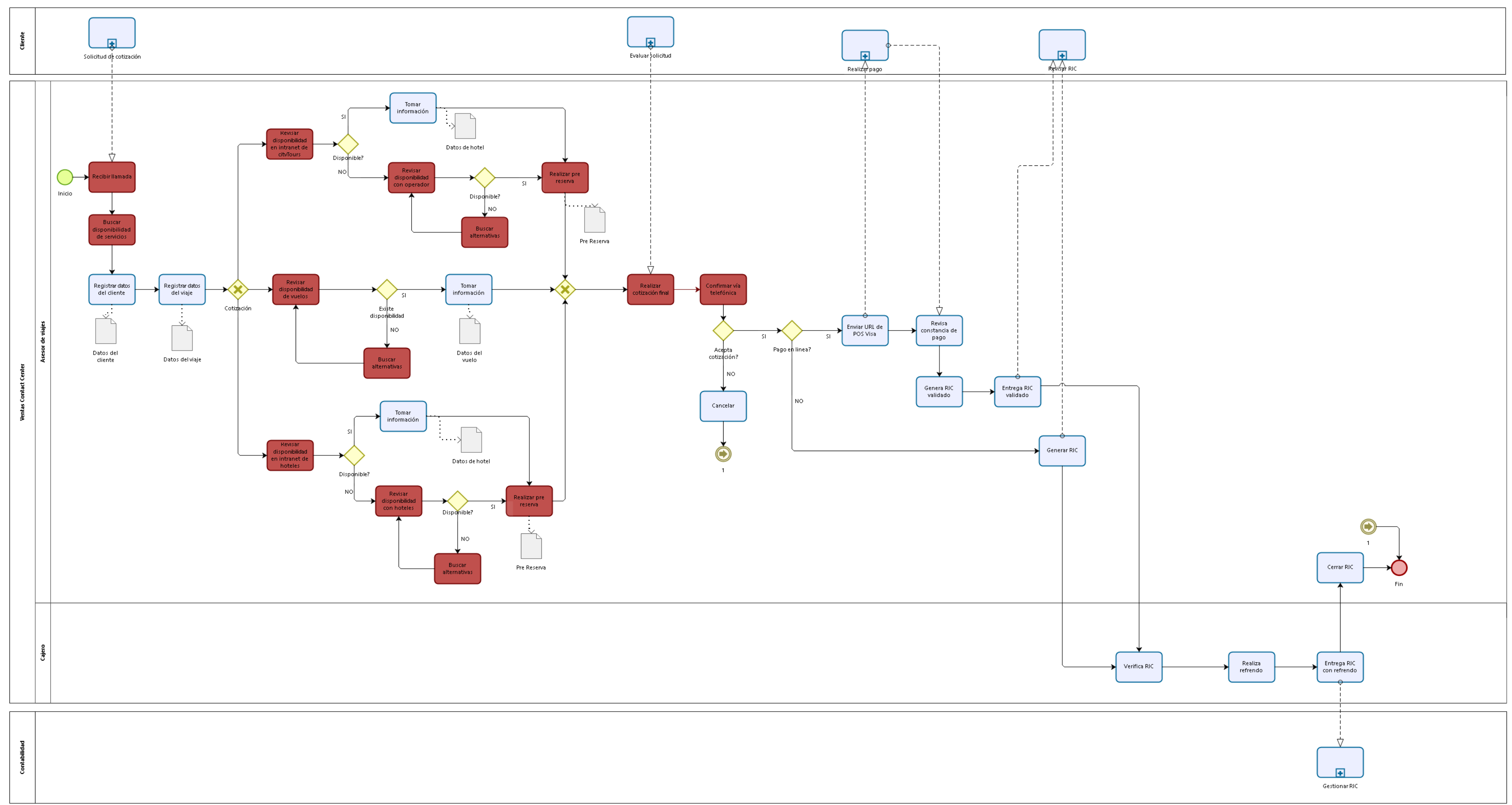

Fuente: Elaboración propia 
En este diagrama se pone foco en las siguientes actividades:

- Recibir llamada

- Buscar disponibilidad de servicios

- Revisar disponibilidad en intranet de city tours

- Revisar disponibilidad de vuelos

- Revisar disponibilidad en intranet de hoteles

- Revisar disponibilidad con operador

- Buscar alternativas de vuelos

- Revisar disponibilidad con hoteles

- Buscar alternativas de hoteles

- Realizar pre reserva de city tours

- Realizar pre reserva de hoteles

- Realizar cotización final

- Confirmar vía telefónica

- Enviar URL POS Visa

Según el levantamiento de información realizado con los expertos del negocio y responsables del área de Contact Center, estas actividades son críticas y definen el comportamiento y resultado de todo el proceso de ventas en Contact Center. 


\section{Caracterización}

Tabla 13. Caracterización AS-IS del proceso Ventas contact center

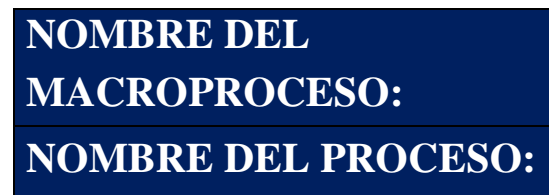

\section{VENTAS}

PROCESO DE VENTAS CONTACT CENTER

RESPONSABLES DEL PROCESO

- Asesor de Viaje

- Caja Registradora - Saga Falabella

- Contabilidad

\section{OBJETIVO}

- Realizar la cotización de boletos aéreos, paquetes turísticos o cualquier necesidad del cliente vía telefónica

- Gestionar el seguimiento de las cotizaciones realizadas

- Gestionar el cierre de ventas

PROVEEDORES:

- Gerencia de Operaciones

- Gerencia de Producto

- Gerencia de Marketing

\section{ENTRADAS:}

- Diseño del Producto de viaje

- Solicitud de Cotización del cliente.

\section{ACTIVIDADES}

Recibir llamada

Buscar disponibilidad de servicios

Registrar datos del cliente

Registrar datos del viaje

Revisar disponibilidad en intranet de cityTours

Revisar disponibilidad con operador

Buscar alternativas

Tomar información

Realizar pre reserva

Revisar disponibilidad de vuelos

Buscar alternativas

Tomar información

Revisar disponibilidad en intranet de hoteles

Revisar disponibilidad con hoteles

Buscar alternativas

Realizar pre reserva 


\begin{tabular}{|l|l|}
\hline Tomar información \\
\hline Realizar cotización final \\
\hline Confirmar vía telefónica \\
\hline Cancelar \\
\hline Enviar URL de POS Visa \\
\hline Revisa constancia de pago \\
\hline Genera RIC validado \\
\hline Entrega RIC validado \\
\hline Generar RIC \\
\hline Verifica RIC \\
\hline Realiza refrendo \\
\hline Entrega RIC con refrendo \\
\hline Cerrar RIC \\
\hline \multicolumn{1}{|c|}{ SALIDAS } \\
\hline Cotización \\
\hline Recibo de Ingreso a Caja & $\bullet$ \\
\hline
\end{tabular}

Fuente: Elaboración propia

\section{Análisis causa raíz}

Gráfico 16. Análisis causa raíz del proceso Ventas contact center
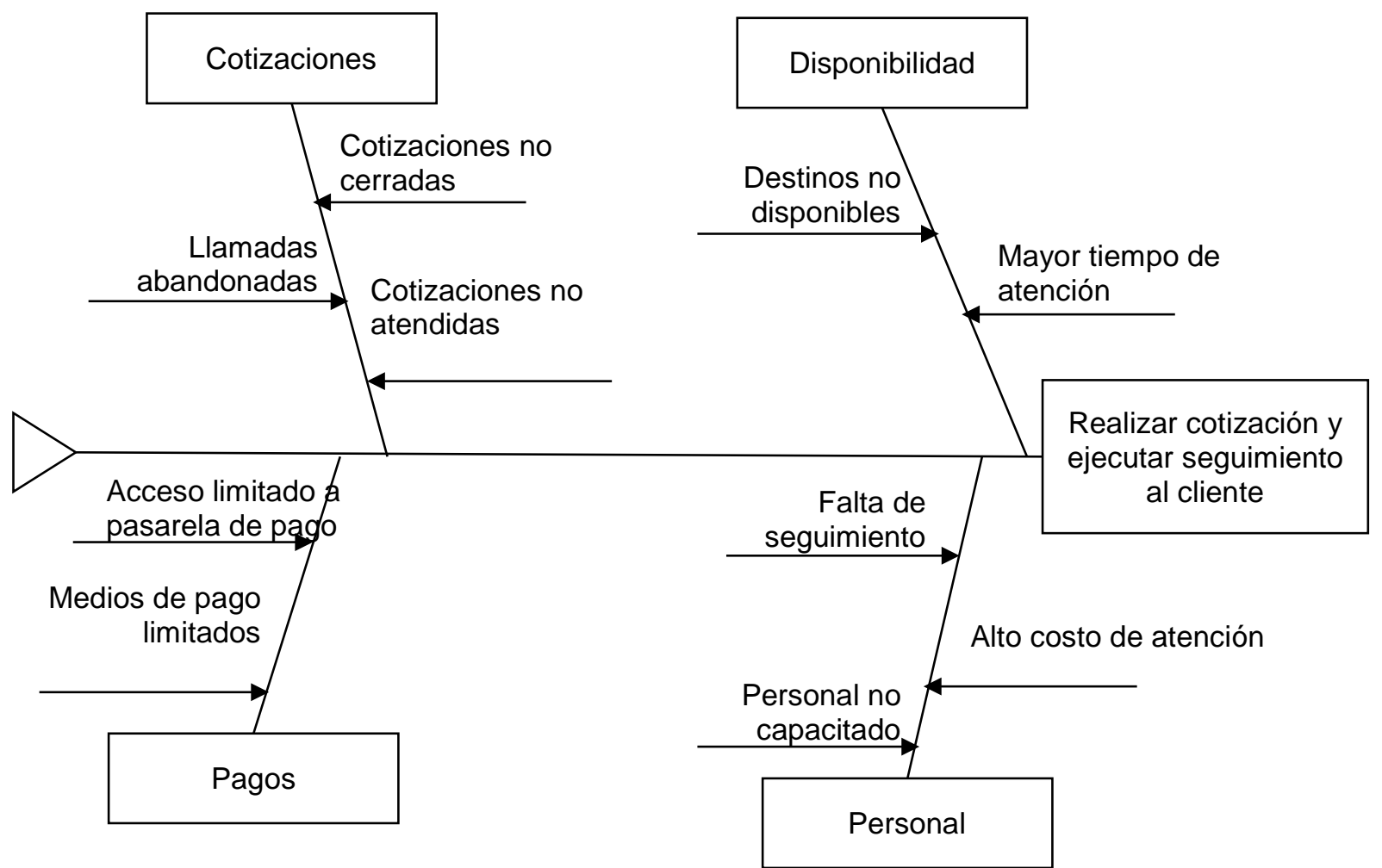

Fuente: Elaboración propia 


\section{Caracterización}

Tabla 14. Caracterización AS-IS del proceso Ventas contact center

\begin{tabular}{|c|c|c|c|}
\hline Entradas & Actividad & Salida & Responsable \\
\hline Solicitud del cliente & Recibir llamada & Llamada realizada & Asesor de ventas \\
\hline Requerimiento del cliente & Buscar disponibilidad de servicios & Vista de disponibilidad de servicios & Asesor de ventas \\
\hline Vista de disponibilidad de servicios & Registrar datos del cliente & Datos del cliente ingresados & Asesor de ventas \\
\hline Datos del cliente ingresados & Registrar datos del viaje & Datos del viaje ingresados & Asesor de ventas \\
\hline Datos del viaje ingresados & $\begin{array}{l}\text { Revisar disponibilidad en intranet de } \\
\text { cityTours }\end{array}$ & Vista en intranet de disponibilidad de city tours & Asesor de ventas \\
\hline $\begin{array}{l}\text { Vista en intranet de disponibilidad de } \\
\text { city tours }\end{array}$ & Revisar disponibilidad con operador & Vista de disponibilidad de operador & Asesor de ventas \\
\hline Vista de disponibilidad de operador & Buscar alternativas & Vista de alternativas de operadores & Asesor de ventas \\
\hline $\begin{array}{l}\text { Vista en intranet de disponibilidad de } \\
\text { city tours }\end{array}$ & Tomar información & Información de city tours seleccionada & Asesor de ventas \\
\hline $\begin{array}{l}\text { Vista de disponibilidad de operador } \\
\text { Información de city tours seleccionada }\end{array}$ & Realizar pre reserva & Pre reserva de city tours realizada & Asesor de ventas \\
\hline Datos del viaje ingresados & Revisar disponibilidad de vuelos & Vista de disponibilidad de vuelos & Asesor de ventas \\
\hline
\end{tabular}




\begin{tabular}{|c|c|c|c|}
\hline Entradas & Actividad & Salida & Responsable \\
\hline Vista de disponibilidad de vuelos & Buscar alternativas & Vista de alternativas de vuelos & Asesor de ventas \\
\hline Vista de disponibilidad de vuelos & Tomar información & Información de vuelos seleccionada & Asesor de ventas \\
\hline Datos del viaje ingresados & $\begin{array}{l}\text { Revisar disponibilidad en intranet de } \\
\text { hoteles }\end{array}$ & Vista en intranet de disponibilidad de hoteles & Asesor de ventas \\
\hline $\begin{array}{l}\text { Vista en intranet de disponibilidad de } \\
\text { hoteles }\end{array}$ & Revisar disponibilidad con hoteles & Vista de disponibilidad de hoteles & Asesor de ventas \\
\hline Vista de disponibilidad de hoteles & Buscar alternativas & Vista de alternativas de hoteles & Asesor de ventas \\
\hline $\begin{array}{l}\text { Vista de disponibilidad de hoteles } \\
\text { Información de hoteles seleccionada }\end{array}$ & Realizar pre reserva & Pre reserva de hotel realizada & Asesor de ventas \\
\hline $\begin{array}{l}\text { Vista en intranet de disponibilidad de } \\
\text { hoteles }\end{array}$ & Tomar información & Información de hoteles seleccionada & Asesor de ventas \\
\hline $\begin{array}{l}\text { Pre reserva de city tours realizada } \\
\text { Pre reserva de hotel realizada } \\
\text { Información de vuelos seleccionada }\end{array}$ & Realizar cotización final & Cotización realizada & Asesor de ventas \\
\hline Cotización realizada & Confirmar vía telefónica & Conformidad del cliente & Asesor de ventas \\
\hline Conformidad del cliente & Cancelar & Cotización cancelada & Asesor de ventas \\
\hline Cotización realizada & Enviar URL de POS Visa & URL POS enviada & Asesor de ventas \\
\hline
\end{tabular}




\begin{tabular}{|c|c|c|c|}
\hline Entradas & Actividad & Salida & Responsable \\
\hline URL POS enviada & Revisa constancia de pago & Constancia de pago revisada & Asesor de ventas \\
\hline Constancia de pago revisada & Genera RIC validado & RIC generado validado & Asesor de ventas \\
\hline RIC generado validado & Entrega RIC validado & RIC validado entregado & Asesor de ventas \\
\hline RIC validado entregado & Generar RIC & RIC generado & Cajero \\
\hline RIC generado & Verifica RIC & RIC verificado & Cajero \\
\hline RIC verificado & Realiza refrendo & RIC refrendado & Cajero \\
\hline RIC refrendado & Entrega RIC con refrendo & RIC con refrendo entregado & Cajero \\
\hline RIC con refrendo entregado & Cerrar RIC & RIC cerrado & Cajero \\
\hline
\end{tabular}

Fuente: Elaboración propia 


\section{Indicadores}

Tabla 15. Indicadores del proceso Ventas contact center

\begin{tabular}{|c|c|c|}
\hline INDICADOR & FORMA DE CÁLCULO & ACTIVIDADES \\
\hline $\begin{array}{l}\text { Porcentaje de Cotizaciones } \\
\text { Cerradas en Ventas }\end{array}$ & $\begin{array}{l}\text { (Número de Cotizaciones en Ventas / Total de } \\
\text { Cotizaciones) } * 100\end{array}$ & $\begin{array}{l}\text { Realizar cotización final } \\
\text { Revisar disponibilidad de vuelos } \\
\text { Revisar disponibilidad en intranet citiyTours }\end{array}$ \\
\hline $\begin{array}{l}\text { Porcentaje de Cotizaciones } \\
\text { Atendidas }\end{array}$ & $\begin{array}{l}\text { (Número de Cotizaciones Atendidas / Total de } \\
\text { Cotizaciones) } * 100\end{array}$ & $\begin{array}{l}\text { Realizar cotización final } \\
\text { Revisar disponibilidad de vuelos } \\
\text { Revisar disponibilidad en intranet citiyTours }\end{array}$ \\
\hline $\begin{array}{l}\text { Porcentaje Tasa de Abandono de } \\
\text { llamadas }\end{array}$ & $\begin{array}{l}\text { (Número de llamadas Abandonadas / Número de llamadas } \\
\text { recibidas) *100 }\end{array}$ & $\begin{array}{l}\text { Recibir llamada } \\
\text { Realizar cotización final }\end{array}$ \\
\hline $\begin{array}{l}\text { Porcentaje de Cotizaciones NO } \\
\text { Atendidas }\end{array}$ & $\begin{array}{l}\text { (Número de Cotizaciones NO Atendidas / Total de } \\
\text { Cotizaciones) } * 100\end{array}$ & $\begin{array}{l}\text { Realizar cotización final } \\
\text { Revisar disponibilidad de vuelos } \\
\text { Revisar disponibilidad en intranet citiyTours }\end{array}$ \\
\hline $\begin{array}{l}\text { Porcentaje de Cotizaciones por } \\
\text { Destino }\end{array}$ & $\begin{array}{l}\text { (Número de Cotizaciones en Ventas x Destino / Total de } \\
\text { Cotizaciones) } * 100\end{array}$ & $\begin{array}{l}\text { Realizar cotización final } \\
\text { Revisar disponibilidad de vuelos } \\
\text { Revisar disponibilidad en intranet citiyTours }\end{array}$ \\
\hline
\end{tabular}

Fuente: Elaboración propia 
Figura 13. Diagrama AS IS del proceso Ventas web

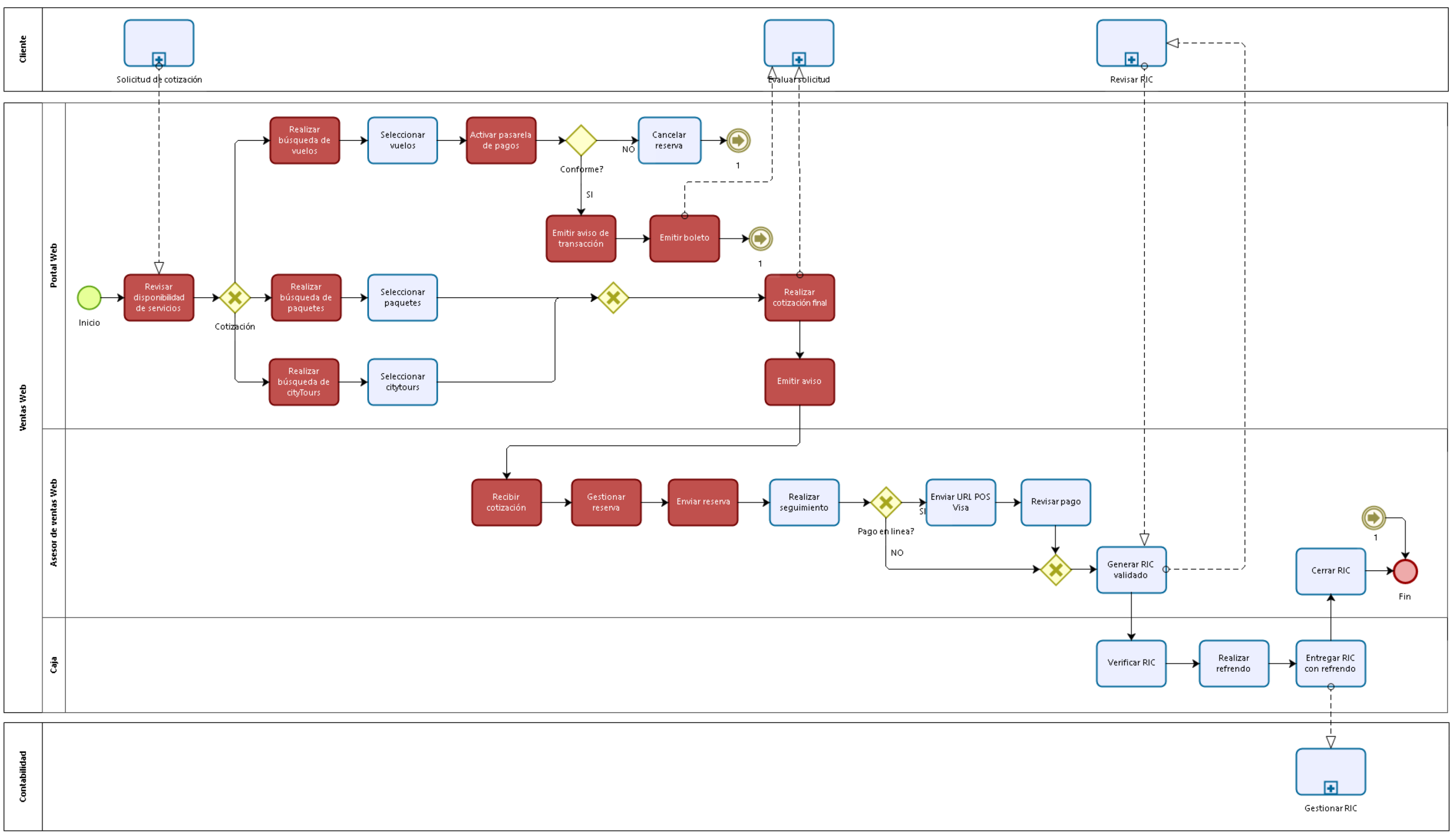

Fuente: Elaboración propia 
En este diagrama se pone foco en las siguientes actividades:

- Revisar disponibilidad de servicios

- Realizar búsqueda de vuelos

- Realizar búsqueda de paquetes

- Realizar búsqueda de city tours

- Activar pasarela de pagos

- Emitir aviso de transacción

- Emitir boleto

- Realizar cotización final

- Emitir aviso

- Recibir cotización

- Gestionar reserva

- Enviar reserva

- Realizar seguimiento

- Enviar URL POS Visa

Según el levantamiento de información realizado con los expertos del negocio y responsables del área Web, estas actividades son críticas y definen el comportamiento y resultado de todo el proceso de ventas en el portal Web. 


\section{Caracterización}

Tabla 16. Caracterización AS-IS del proceso Ventas web

\begin{tabular}{|c|c|}
\hline NOMBRE DEL MACROPROCESO: & VENTAS \\
\hline NOMBRE DEL PROCESO: & PROCESO DE VENTAS WEB \\
\hline \multicolumn{2}{|c|}{ RESPONSABLES DEL PROCESO } \\
\hline - Página Web & - Caja Registradora - Saga Falabella \\
\hline - $\quad$ Pasarela de Pago & - Contabilidad \\
\hline
\end{tabular}

- Permitir al cliente final realizar cotizaciones y venta de los distintos servicios turisticos

- Gestionar el seguimiento de las cotizaciones realizadas

- Gestionar el cierre de ventas

\section{PROVEEDORES:}

- Gerencia de Operaciones

- Gerencia de Producto

- Gerencia de Marketing

\section{ENTRADAS:}

- Diseño del Producto de viaje

- Solicitud de Cotización del cliente.

\section{ACTIVIDADES}

Revisar disponibilidad de productos

Realizar búsqueda de vuelos

Seleccionar vuelos

Activar pasarela de pagos

Emitir aviso de transacción

Cancelar reserva

Emitir boleto

Realizar búsqueda de paquetes

Seleccionar paquetes

Realizar búsqueda de citytours

Seleccionar citytours

Realizar cotización final

Emitir aviso

Recibir cotización

Gestionar reserva

Enviar reserva

Realizar seguimiento

Enviar URL POS Visa

Revisar pago

Generar RIC validado

Verificar RIC

Realizar refrendo

Entregar RIC con refrendo 


\begin{tabular}{|c|c|}
\hline \multicolumn{2}{|l|}{ Cerrar RIC } \\
\hline SALIDAS: & CLIENTES: \\
\hline - Cotización & - Cliente \\
\hline $\begin{array}{l}\text { - Confirmación de Pago por parte de } \\
\text { Pasarela de Pago }\end{array}$ & $\begin{array}{l}\text { - Gerencia de Administración y Finanzas } \\
\text { (Administración, Contabilidad, Tesorería, } \\
\text { Sistemas) }\end{array}$ \\
\hline - Recibo de Ingreso a Caja & \\
\hline
\end{tabular}

Fuente: Elaboración propia

\section{Análisis causa raíz}

Gráfico 17. Análisis causa raíz del proceso Ventas web

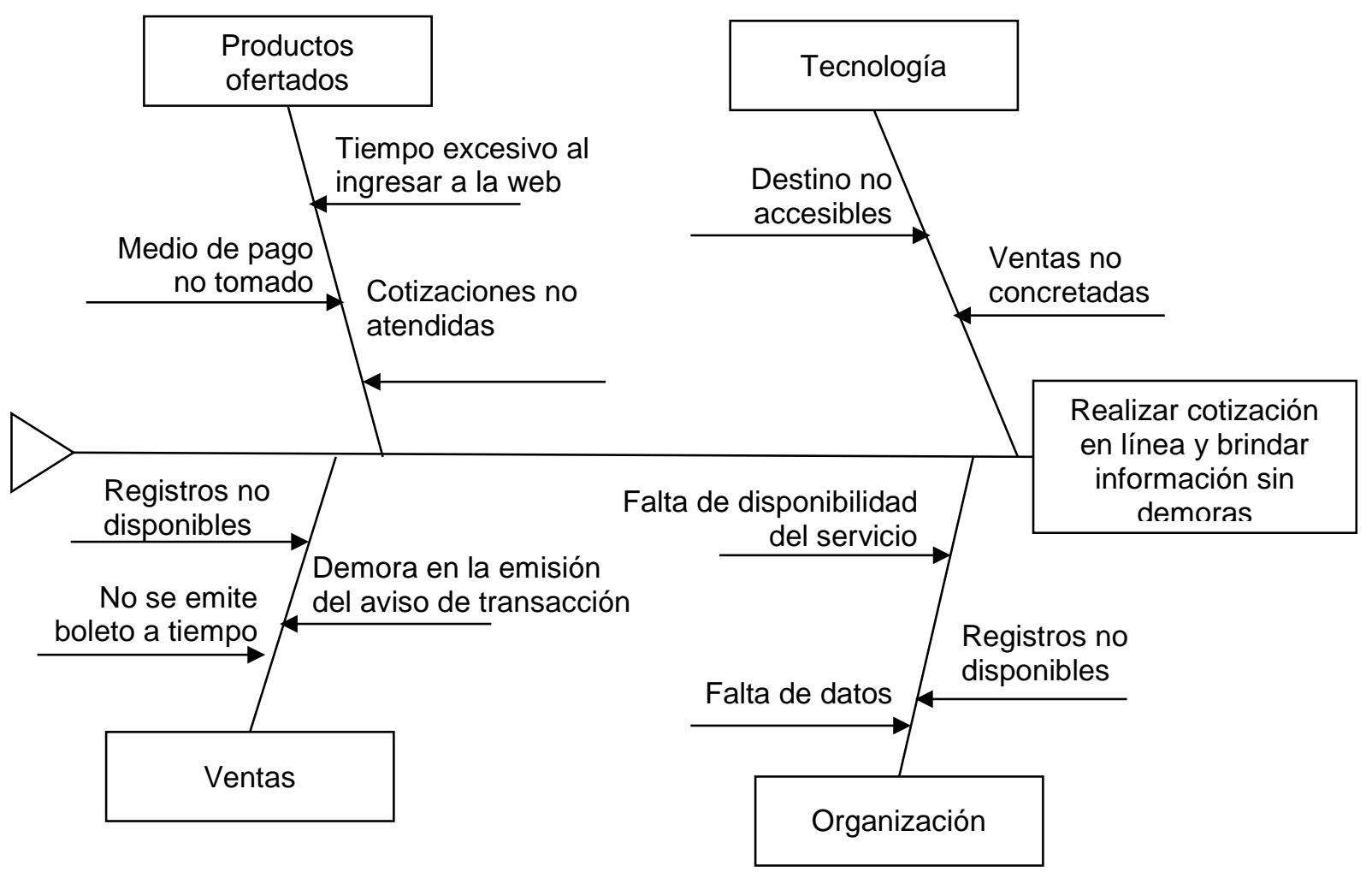

Fuente: Elaboración propia 


\section{Caracterización}

Tabla 17. Caracterización AS-IS del proceso Ventas web

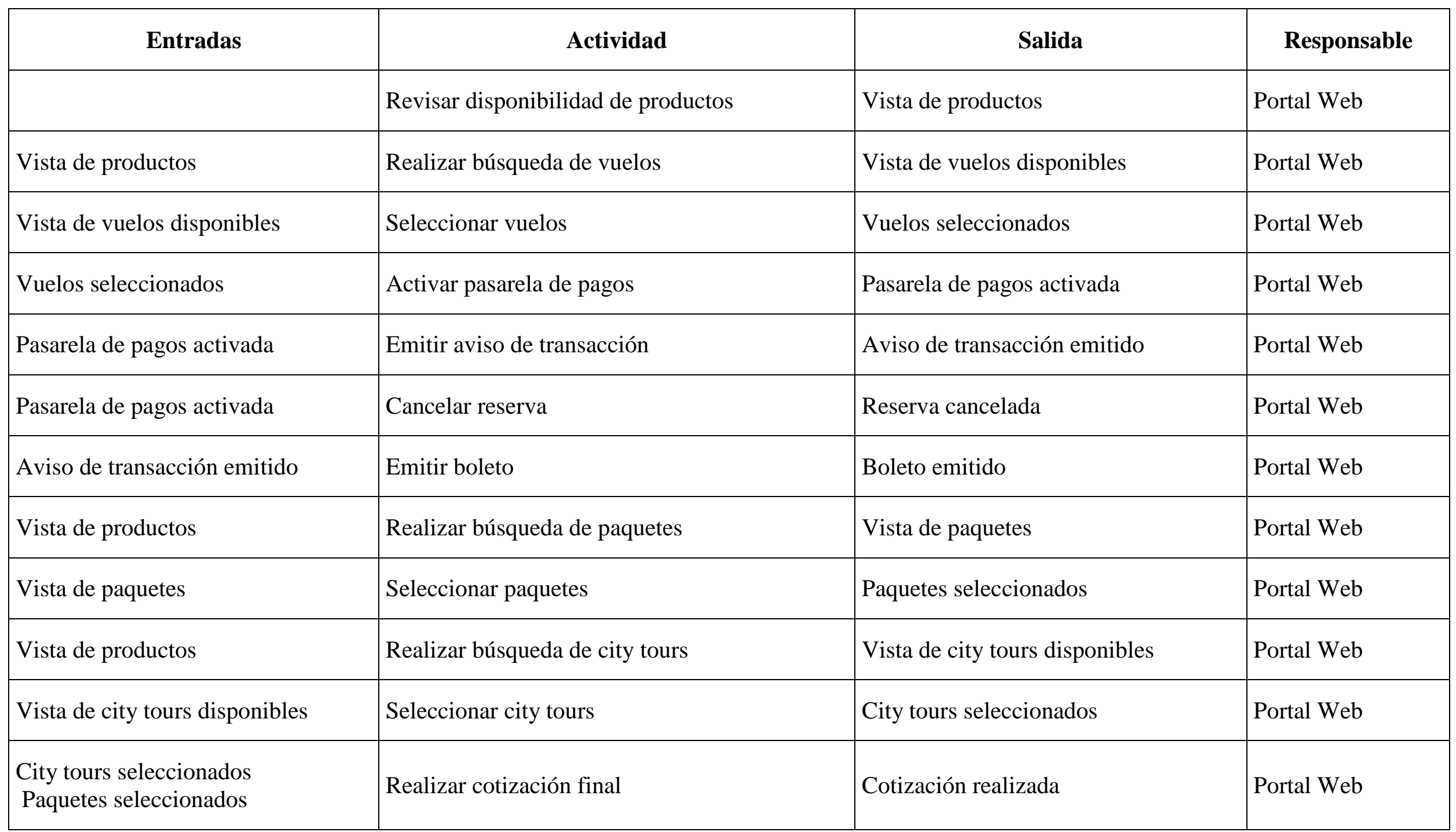




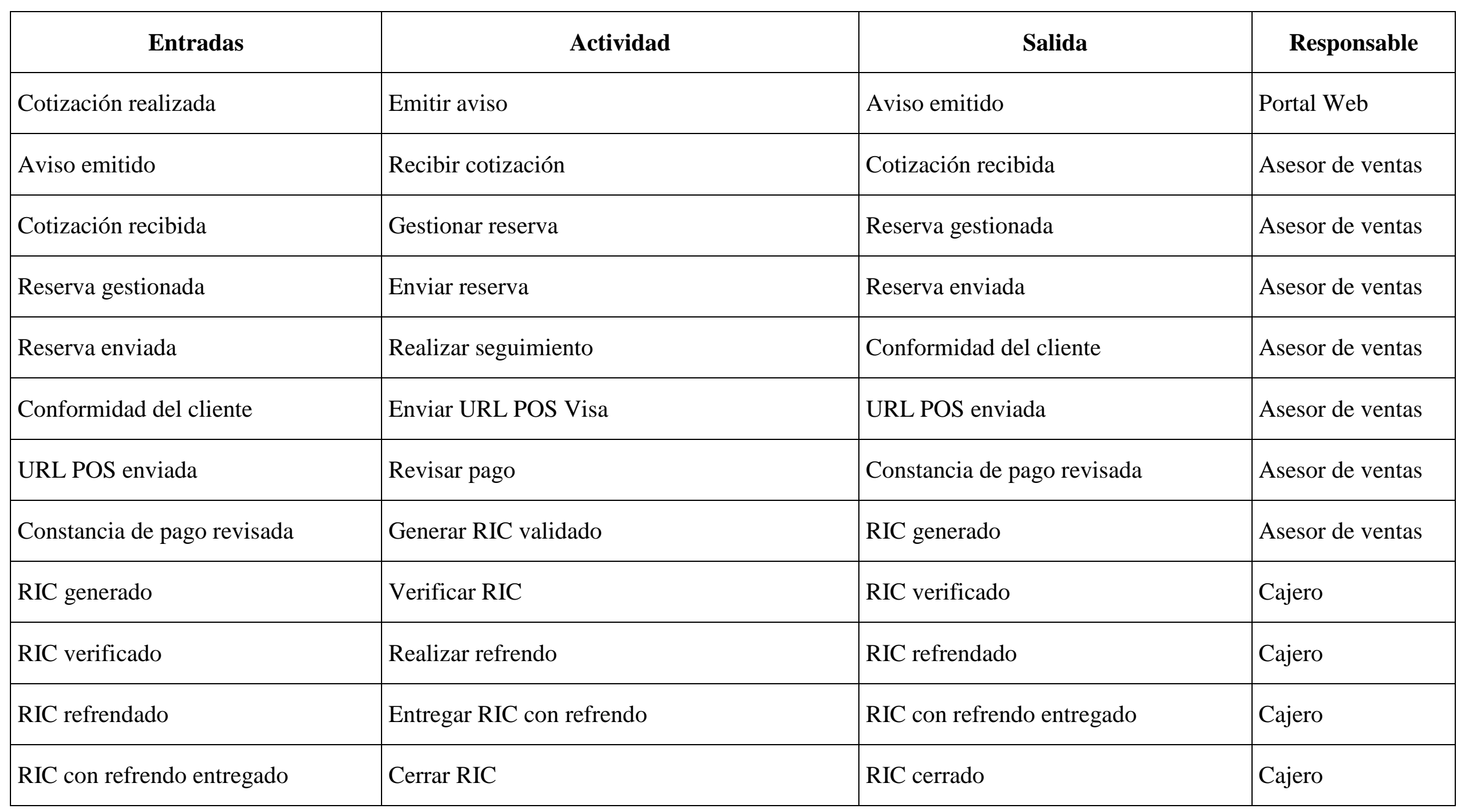

Fuente: Elaboración propia 


\section{Indicadores}

Tabla 18. Indicadores del proceso Ventas web

\begin{tabular}{|c|c|c|}
\hline INDICADOR: & FORMA DE CÁLCULO: & ACTIVIDAD \\
\hline Tiempo de Uptime Pagina Web & $\begin{array}{l}\text { (Número horas totales - Número de horas NO } \\
\text { disponible / Total de horas totales) } * 100\end{array}$ & $\begin{array}{l}\text { Enviar URL POS Visa } \\
\text { Emitir aviso }\end{array}$ \\
\hline Porcentaje de Cotizaciones Atendidas & $\begin{array}{l}\text { (Número de Cotizaciones Atendidas / Total de } \\
\text { Cotizaciones) } * 100\end{array}$ & $\begin{array}{l}\text { Realizar cotización final } \\
\text { Enviar URL POS Visa } \\
\text { Emitir aviso }\end{array}$ \\
\hline Porcentaje de Ventas en línea & $\begin{array}{l}\text { (Número de Transacciones por Pasarela de Pago } \\
\text { / Total de Transacciones) } * 100\end{array}$ & $\begin{array}{l}\text { Recibir llamada } \\
\text { Realizar cotización final }\end{array}$ \\
\hline $\begin{array}{l}\text { Porcentaje de Cotizaciones NO } \\
\text { Atendidas }\end{array}$ & $\begin{array}{l}\text { (Número de Cotizaciones NO Atendidas / Total } \\
\text { de Cotizaciones) } * 100\end{array}$ & $\begin{array}{l}\text { Realizar cotización final } \\
\text { Revisar disponibilidad en intranet city tours }\end{array}$ \\
\hline Porcentaje de Cotizaciones por Destino & $\begin{array}{l}\text { (Número de Cotizaciones en Ventas x Destino / } \\
\text { Total de Cotizaciones) } * 100\end{array}$ & $\begin{array}{l}\text { Realizar cotización final } \\
\text { Revisar disponibilidad en intranet city tours }\end{array}$ \\
\hline
\end{tabular}

Fuente: Elaboración propia 


\subsubsection{Diseño y desarrollo de productos}

Figura 14. Diagrama AS IS del proceso Diseño y desarrollo de productos

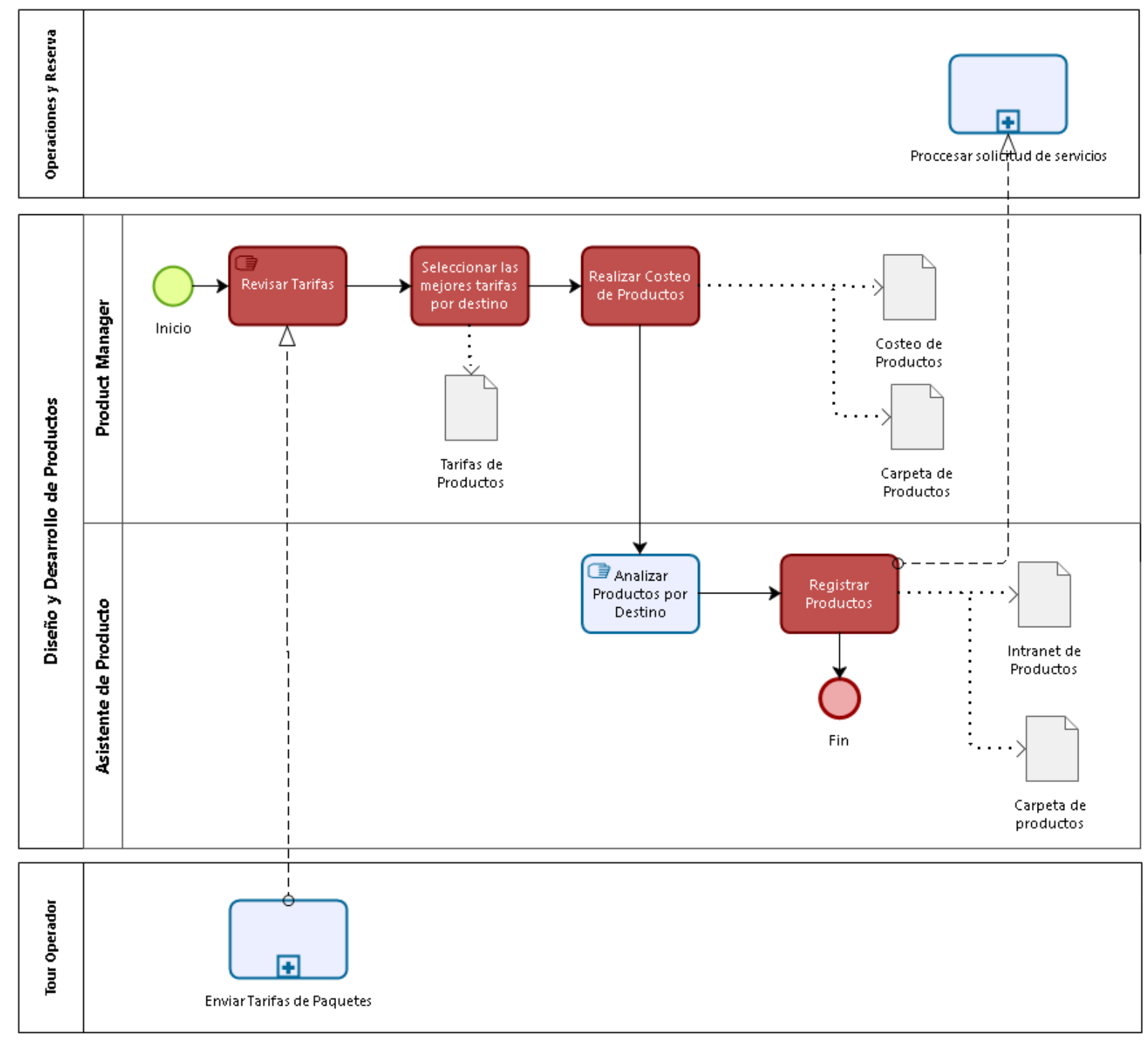

Fuente: Elaboración propia 
En este diagrama se pone foco en las siguientes actividades:

- Revisar tarifas

- Seleccionar las mejores tarifas por destino

- Realizar costeo de productos

- Registrar productos

Según el levantamiento de información realizado con los expertos del negocio y responsables del área de Producto, estas actividades son críticas y definen el comportamiento y resultado de todo el proceso de ventas del Diseño y Desarrollo de producto. 


\section{Caracterización}

Tabla 19. Caracterización AS-IS del proceso Diseño y desarrollo de productos

\section{NOMBRE DEL MACROPROCESO: \\ NOMBRE DEL PROCESO:}

\section{RESPONSABLES DEL PROCESO}

- Product Manager

- Asistente de Producto

\section{OBJETIVO}

- Negociar productos con tarifas competitivas

- Negociar márgenes mayores a 8\%

- Seleccionar los mejores productos

- Gestionar comisiones mayores a $20 \%$

\section{PROVEEDORES:}

\section{ENTRADAS:}

- Operadores Turísticos

- Gerencia General

- Gerencia de Producto

\section{ACTIVIDADES}

\section{Revisar tarifas}

Seleccionar las mejores tarifas por destino

Realizar costeo de productos

Analizar productos por destino

Registrar productos

\section{SALIDAS}

CLIENTES

- Contrato Tarifas Negociadas

- Tarifario de Productos

- Gerencia de Ventas

- Gerencia de Operaciones

- Gerencia de Administración y Finanzas

Fuente: Elaboración propia 


\section{Análisis causa raíz}

Gráfico 18. Análisis causa raíz del proceso Diseño y desarrollo de productos

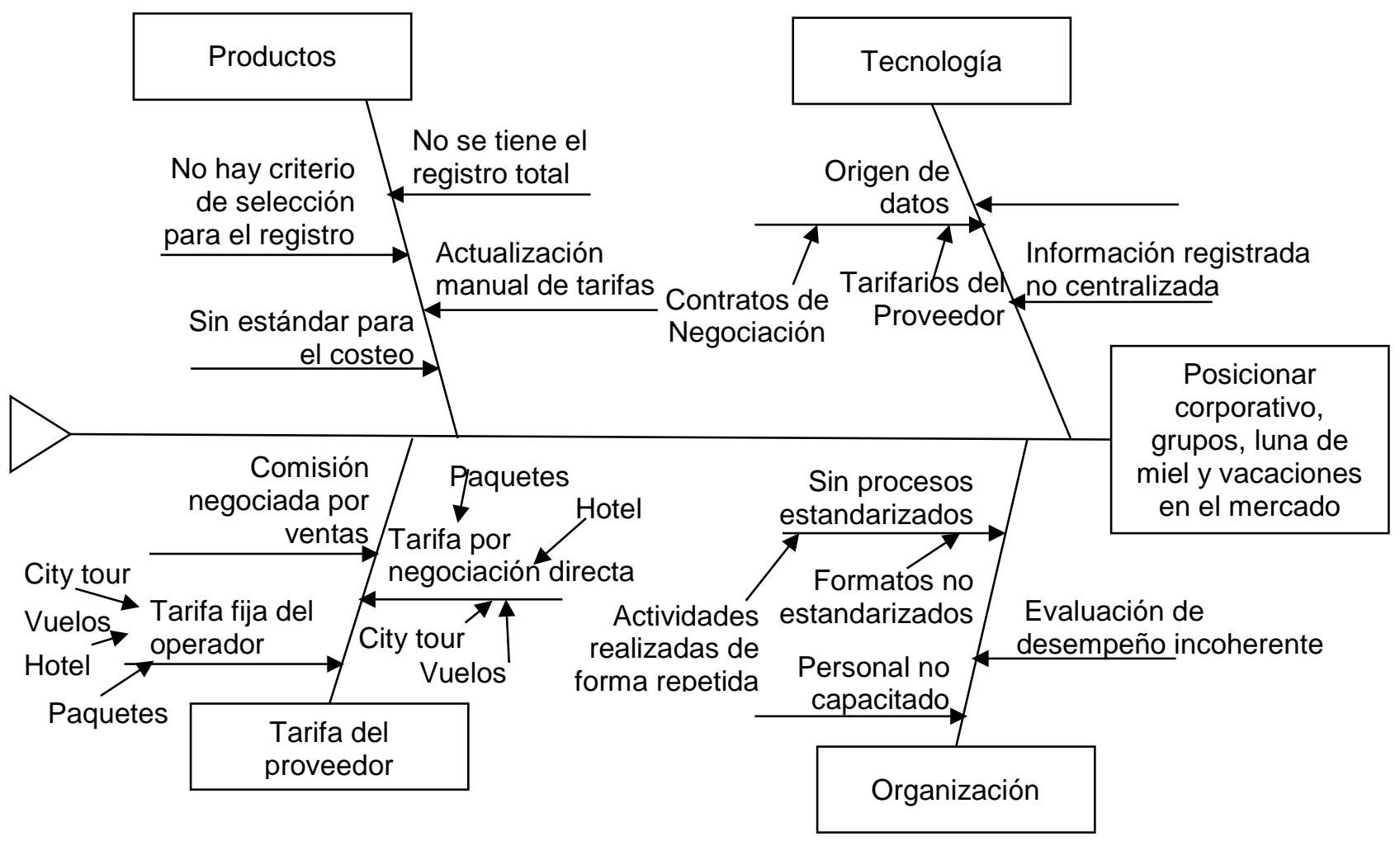

Fuente: Elaboración propia

\section{Caracterización}

Tabla 20. Caracterización AS-IS del proceso Diseño y desarrollo de productos

\begin{tabular}{|l|l|l|l|}
\hline \multicolumn{1}{|c|}{ Entradas } & \multicolumn{1}{|c|}{ Actividad } & \multicolumn{1}{c|}{ Salida } & \multicolumn{1}{c|}{ Responsable } \\
\hline $\begin{array}{l}\text { Requerimiento de } \\
\text { ventas }\end{array}$ & Revisar tarifas & Tarifas revisadas & Product manager \\
\hline Tarifas revisadas & $\begin{array}{l}\text { Seleccionar las mejores } \\
\text { tarifas por destino }\end{array}$ & Tarifas seleccionadas & Product manager \\
\hline Tarifas seleccionadas & $\begin{array}{l}\text { Realizar costeo de } \\
\text { productos }\end{array}$ & $\begin{array}{l}\text { Costeo de productos } \\
\text { realizado }\end{array}$ & Product manager \\
\hline $\begin{array}{l}\text { Costeo de productos } \\
\text { realizado }\end{array}$ & $\begin{array}{l}\text { Analizar productos por } \\
\text { destino }\end{array}$ & $\begin{array}{l}\text { Productos analizados } \\
\text { por destino }\end{array}$ & Asistente de productos \\
\hline
\end{tabular}




\begin{tabular}{|l|l|l|l|}
\hline \multicolumn{1}{|c|}{ Entradas } & \multicolumn{1}{|c|}{ Actividad } & Salida & Responsable \\
\hline $\begin{array}{l}\text { Productos analizados } \\
\text { por destino }\end{array}$ & Registrar productos & Productos registrados & Asistente de productos \\
\hline
\end{tabular}

Fuente: Elaboración propia

\section{Indicadores}

Tabla 21. Indicadores del proceso Diseño y desarrollo de productos

\begin{tabular}{|c|c|c|}
\hline INDICADOR & FORMA DE CÁLCULO & ACTIVIDADES \\
\hline Rentabilidad Producto & $\begin{array}{l}\text { (Tarifa Neta Negociada / Precio venta) * } \\
100\end{array}$ & $\begin{array}{l}\text { Tarifas seleccionadas } \\
\text { Analizar productos por } \\
\text { destino }\end{array}$ \\
\hline $\begin{array}{l}\text { Porcentaje de Paquetes } \\
\text { y Servicios cargados }\end{array}$ & $\begin{array}{l}\text { (Paquetes Servicios cargados / Total de } \\
\text { productos por operador) } * 100\end{array}$ & $\begin{array}{l}\text { Tarifas seleccionadas } \\
\text { Analizar productos por } \\
\text { destino }\end{array}$ \\
\hline Comisión Producto & $\begin{array}{l}\text { (Volumen de venta) } * \text { Porcentaje comisión } \\
\text { negociado }\end{array}$ & $\begin{array}{l}\text { Tarifas seleccionadas } \\
\text { Analizar productos por } \\
\text { destino }\end{array}$ \\
\hline
\end{tabular}

Fuente: Elaboración propia

\subsection{Situación actual de los procesos de Diseño de Productos y Ventas}

En esta fase el objetivo principal es generar una la lista de todos los indicadores que están involucrados en los procesos seleccionados, luego se definirá que tipos de indicadores. Para relevar la información de los indicadores de los procesos detallados en el documento se realizó entrevista de trabajo con los gerentes y jefes de cada área, los cuales son dueños de cada proceso. 
Tabla 22. Matriz de stakeholders

\begin{tabular}{|c|c|}
\hline STAKEHOLDERS & DESCRIPCIÓN \\
\hline Gerencia General & $\begin{array}{l}\text { Persona que evalúa la relación de los } \\
\text { objetivos estratégicos y las metas de } \\
\text { ventas }\end{array}$ \\
\hline Sub Gerente Ventas Retail & $\begin{array}{l}\text { Persona que tiene a cargo a todas a las } \\
\text { áreas de ventas sucursal y Contact Center }\end{array}$ \\
\hline Jefe de Ventas Sucursal & $\begin{array}{l}\text { Persona que tiene a cargo el área de } \\
\text { Ventas Sucursal }\end{array}$ \\
\hline Jefe de Ventas Contact Center & $\begin{array}{l}\text { Persona que tiene a cargo el área de } \\
\text { Contact Center }\end{array}$ \\
\hline Sub Gerente Web & $\begin{array}{l}\text { Persona que tiene a cargo todo lo } \\
\text { relacionado con el canal digital (no } \\
\text { presencial) }\end{array}$ \\
\hline Sub Gerente Diseño de Producto & $\begin{array}{l}\text { Persona que tiene a cargo el área donde } \\
\text { se negocia los productos con los distintos } \\
\text { operadores / líneas aéreas. }\end{array}$ \\
\hline Jefe de Producto & $\begin{array}{l}\text { Persona que tiene a cargo a todo el staff } \\
\text { de que realizar la verificación y } \\
\text { validación de los márgenes de } \\
\text { comisiones de los productos a vender. }\end{array}$ \\
\hline
\end{tabular}

Fuente: Elaboración propia

En estas entrevistas se definieron los criterios de selección para cada indicador, los cuales fueron puestos en una matriz para poder realizar la evaluación. En base a esto de elaboraron las respectivas matrices de evaluación y priorización.

Para poder empezar a realizar la evaluación definimos la importancia relativa que se usará: 
Tabla 23. Matriz de valor de respuestas

\begin{tabular}{|c|c|}
\hline RESPUESTAS & VALOR \\
\hline Altamente critico & 10 \\
\hline Critico & 7 \\
\hline Moderado & 5 \\
\hline Bajo & 3 \\
\hline
\end{tabular}

Fuente: Elaboración propia

\subsubsection{Elaboración de matriz de prioridad de criterios}

Se procede a elaborar la matriz de priorización de criterios, es decir se estima que tipo de criterio mostrado es el más importante y tiene mayor impacto sobre el negocio. Cabe mencionar que esta evaluación de priorización se hizo con los responsables de cada área de negocio de la empresa que se está realizando el análisis.

Tabla 24. Matriz de prioridad de criterios

\begin{tabular}{|c|c|c|c|c|c|c|}
\hline CRITERIOS & 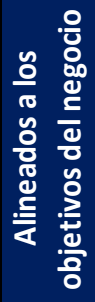 & 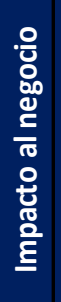 & 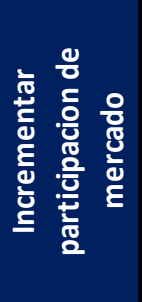 & 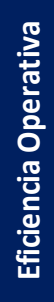 & Suma & Ponderacion \\
\hline Alineados a los objetivos del negocio & & 5 & 10 & 5 & 20 & 0.22 \\
\hline Impacto al negocio & 10 & & 10 & 7 & 27 & 0.29 \\
\hline Incrementar participacion de mercado & 5 & 5 & & 10 & 20 & 0.22 \\
\hline Eficiencia Operativa & 10 & 5 & 10 & & 25 & 0.27 \\
\hline Total & 25 & 15 & 30 & 22 & 92 & 1 \\
\hline
\end{tabular}

Fuente: Elaboración propia 
En base a la evaluación tenemos el siguiente orden de prioridad:

Tabla 25. Tabla de orden de priorización de criterios

\begin{tabular}{|l|r|}
\hline \multicolumn{1}{|c|}{ CRITERIOS } & Ponderacion \\
\hline Impacto al negocio & 0.29 \\
\hline Eficiencia Operativa & 0.27 \\
\hline Alineados a los objetivos del negocio & 0.22 \\
\hline Incrementar participacion de mercado & 0.22 \\
\hline
\end{tabular}

Fuente: Elaboración propia

\subsubsection{Elaboración de matriz de prioridad de indicadores}

\section{Proceso de Ventas sucursales}

Se procede a elaborar la matriz de priorización de indicadores del sub proceso de Ventas Sucursales por cada tipo de criterio definido, es decir se estima que tipo de indicador mostrado es el más importante y tiene mayor impacto sobre el negocio. Cabe mencionar que esta evaluación de priorización se hizo con los responsables de cada área de negocio de la empresa que se está realizando el análisis.

Tabla 26. Matriz de prioridades del proceso Ventas sucursales

\begin{tabular}{|c|c|c|c|c|c|c|c|c|}
\hline $\begin{array}{l}\text { CRITERIO: ALINEADOS A LOS OBJETIVOS DEL } \\
\text { NEGOCIO }\end{array}$ & 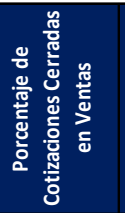 & 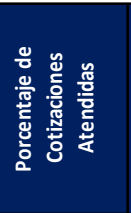 & 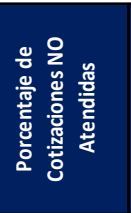 & 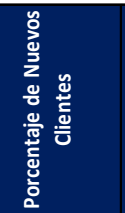 & 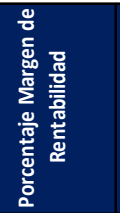 & 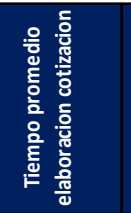 & Suma & Ponderacion \\
\hline Porcentaje de Cotizaciones Cerradas en Ventas & & 7 & 7 & 10 & 5 & 7 & 36 & 0.20 \\
\hline Porcentaje de Cotizaciones Atendidas & 5 & & 5 & 7 & 3 & 5 & 25 & 0.14 \\
\hline Porcentaje de Cotizaciones NO Atendidas & 7 & 7 & & 7 & 3 & 7 & 31 & 0.17 \\
\hline Porcentaje de Nuevos Clientes & 3 & 3 & 3 & & 3 & 3 & 15 & 0.08 \\
\hline Porcentaje Margen de Rentabilidad & 10 & 10 & 10 & 10 & & 10 & 50 & 0.28 \\
\hline Tiempo promedio elaboracion cotizacion & 3 & 5 & 5 & 5 & 3 & & 21 & 0.12 \\
\hline Total & 28 & 32 & 30 & 39 & 17 & 32 & 178 & \\
\hline
\end{tabular}

Fuente: Elaboración propia 
Tabla 27. Matriz de prioridades del proceso Ventas sucursales

\begin{tabular}{|c|c|c|c|c|c|c|c|c|}
\hline CRITERIO: IMPACTO AL NEGOCIO & 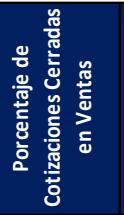 & 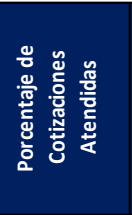 & 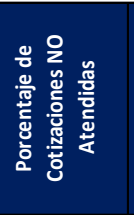 & 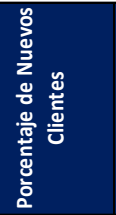 & 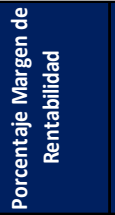 & 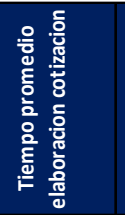 & Suma & Ponderacion \\
\hline Porcentaje de Cotizaciones Cerradas en Ventas & & 7 & 5 & 10 & 5 & 7 & 34 & 0.20 \\
\hline Porcentaje de Cotizaciones Atendidas & 5 & & 3 & 7 & 3 & 5 & 23 & 0.14 \\
\hline Porcentaje de Cotizaciones NO Atendidas & 5 & 5 & & 7 & 3 & 7 & 27 & 0.16 \\
\hline Porcentaje de Nuevos Clientes & 3 & 3 & 3 & & 3 & 3 & 15 & 0.09 \\
\hline Porcentaje Margen de Rentabilidad & 10 & 10 & 10 & 10 & & 10 & 50 & 0.29 \\
\hline Tiempo promedio elaboracion cotizacion & 3 & 5 & 5 & 5 & 3 & & 21 & 0.12 \\
\hline Total & 26 & 30 & 26 & 39 & 17 & 32 & 170 & 1 \\
\hline
\end{tabular}

Fuente: Elaboración propia

Tabla 28. Matriz de prioridades del proceso Ventas sucursales

\begin{tabular}{|c|c|c|c|c|c|c|c|c|}
\hline $\begin{array}{l}\text { CRITERIO: INCREMENTAR PARTICIPACION DE } \\
\text { MERCADO }\end{array}$ & 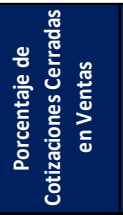 & 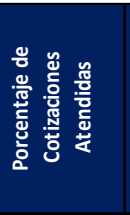 & 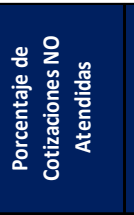 & 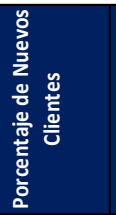 & 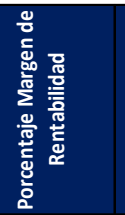 & 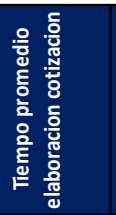 & Suma & Ponderacion \\
\hline Porcentaje de Cotizaciones Cerradas en Ventas & & 7 & 7 & 5 & 5 & 7 & 31 & 0.17 \\
\hline Porcentaje de Cotizaciones Atendidas & 5 & & 7 & 7 & 3 & 5 & 27 & 0.14 \\
\hline Porcentaje de Cotizaciones NO Atendidas & 7 & 7 & & 7 & 5 & 7 & 33 & 0.18 \\
\hline Porcentaje de Nuevos Clientes & 5 & 5 & 5 & & 3 & 5 & 23 & 0.12 \\
\hline Porcentaje Margen de Rentabilidad & 10 & 10 & 10 & 10 & & 10 & 50 & 0.27 \\
\hline Tiempo promedio elaboracion cotizacion & 5 & 5 & 5 & 5 & 3 & & 23 & 0.12 \\
\hline Total & 32 & 34 & 34 & 34 & \begin{tabular}{l|l}
19 \\
\end{tabular} & 34 & 187 & 1 \\
\hline
\end{tabular}

Fuente: Elaboración propia

Tabla 29. Matriz de prioridades del proceso Ventas sucursales

\begin{tabular}{|c|c|c|c|c|c|c|c|c|}
\hline CRITERIO: EFICIENCIA OPERATIVA & 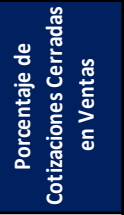 & 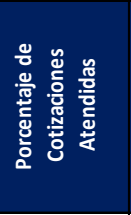 & 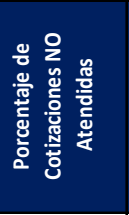 & 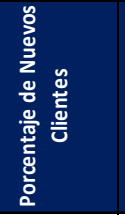 & 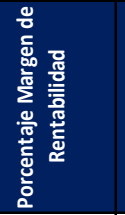 & 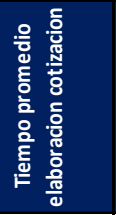 & Suma & Ponderacion \\
\hline Porcentaje de Cotizaciones Cerradas en Ventas & & 10 & 10 & 10 & 5 & 7 & 42 & 0.23 \\
\hline Porcentaje de Cotizaciones Atendidas & 5 & & 7 & 7 & 5 & 5 & 29 & 0.16 \\
\hline Porcentaje de Cotizaciones NO Atendidas & 3 & 3 & & 7 & 5 & 10 & 28 & 0.15 \\
\hline Porcentaje de Nuevos Clientes & 5 & 5 & 5 & & 5 & 5 & 25 & 0.14 \\
\hline \begin{tabular}{|l|} 
Porcentaje Margen de Rentabilidad \\
\end{tabular} & 5 & 5 & 5 & 5 & & 5 & 25 & 0.14 \\
\hline Tiempo promedio elaboracion cotizacion & 7 & 7 & 10 & 5 & 5 & & 34 & 0.19 \\
\hline Total & 25 & 30 & 37 & 34 & 25 & 32 & 183 & 1 \\
\hline
\end{tabular}

Fuente: Elaboración propia 
Se procede a realizar la una matriz donde se visualizan todas las ponderaciones de los indicadores versus los criterios de selección:

Tabla 30. Matriz de prioridades del proceso Ventas sucursales

\begin{tabular}{|c|c|c|c|c|}
\hline CRITERIOS / OPCIONES & $\begin{array}{c}\text { Alineados a los } \\
\text { objetivos del negocio }\end{array}$ & $\begin{array}{l}\text { Impacto al } \\
\text { negocio }\end{array}$ & $\begin{array}{c}\text { Incrementar } \\
\text { participacion de } \\
\text { mercado }\end{array}$ & $\begin{array}{l}\text { Eficiencia } \\
\text { Operativa }\end{array}$ \\
\hline Porcentaje de Cotizaciones Cerradas en Ventas & 0.20 & 0.20 & 0.17 & 0.23 \\
\hline Porcentaje de Cotizaciones Atendidas & 0.14 & 0.14 & 0.14 & 0.16 \\
\hline Porcentaje de Cotizaciones NO Atendidas & 0.17 & 0.16 & 0.18 & 0.15 \\
\hline Porcentaje de Nuevos Clientes & 0.08 & 0.09 & 0.12 & 0.14 \\
\hline Porcentaje Margen de Rentabilidad & 0.28 & 0.29 & 0.27 & 0.14 \\
\hline Tiempo promedio elaboracion cotizacion & 0.12 & 0.12 & 0.12 & 0.19 \\
\hline
\end{tabular}

Fuente: Elaboración propia

Una vez que se tiene el detalle de estas matrices consolidadas se procede a realizar la matriz final donde se procede a multiplicar estos valores por los valores ponderados de los criterios de selección (ver Tabla 31) y se obtiene la siguiente matriz.

Tabla 31. Matriz de prioridades del proceso Ventas sucursales

\begin{tabular}{|c|c|c|c|c|c|}
\hline CRITERIOS / OPCIONES & $\begin{array}{c}\text { Alineados a los } \\
\text { objetivos del negocio }\end{array}$ & $\begin{array}{l}\text { Impacto al } \\
\text { negocio }\end{array}$ & $\begin{array}{l}\text { Incrementar } \\
\text { participacion de } \\
\text { mercado }\end{array}$ & $\begin{array}{l}\text { Eficiencia } \\
\text { Operativa }\end{array}$ & Total \\
\hline Porcentaje de Cotizaciones Cerradas en Ventas & 0.05 & 0.06 & 0.04 & 0.07 & 0.22 \\
\hline Porcentaje de Cotizaciones Atendidas & 0.03 & 0.04 & 0.03 & 0.05 & 0.15 \\
\hline Porcentaje de Cotizaciones NO Atendidas & 0.04 & 0.05 & 0.04 & 0.05 & 0.17 \\
\hline Porcentaje de Nuevos Clientes & 0.02 & 0.03 & 0.03 & 0.02 & 0.10 \\
\hline Porcentaje Margen de Rentabilidad & 0.06 & 0.09 & 0.06 & 0.04 & 0.25 \\
\hline Tiempo promedio elaboracion cotizacion & 0.02 & 0.03 & 0.02 & 0.04 & 0.11 \\
\hline Total & 0.22 & 0.29 & 0.22 & 0.27 & 1.00 \\
\hline
\end{tabular}

Fuente: Elaboración propia

Donde se puede obtener que los indicadores para el sub proceso de Ventas Sucursal que tienen el total y por ende son los más relevantes son:

- Porcentaje de Margen de Rentabilidad.

- Porcentaje de Cotizaciones Cerradas en Ventas. 


\section{Proceso de Ventas contact center}

Se procede a elaborar la matriz de priorización de indicadores del sub proceso de Ventas Contact Center por cada tipo de criterio definido, es decir se estima que tipo de indicador mostrado es el más importante y tiene mayor impacto sobre el negocio. Cabe mencionar que esta evaluación de priorización se hizo con los responsables de cada área de negocio de la empresa que se está realizando el análisis.

Tabla 32. Matriz de prioridades del proceso Ventas contact center

\begin{tabular}{|c|c|c|c|c|c|c|c|c|c|c|}
\hline $\begin{array}{l}\text { CRITERIO: ALINEADOS A LOS OBJETIVOS DEL } \\
\text { NEGOCIO }\end{array}$ & 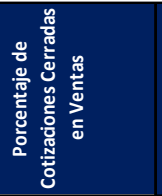 & 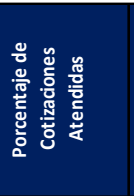 & 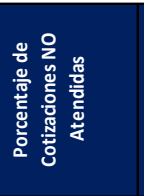 & 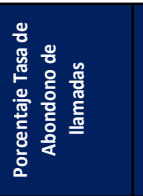 & 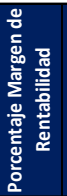 & 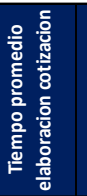 & 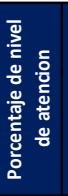 & 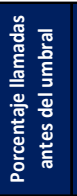 & Suma & Ponderacion \\
\hline Porcentaje de Cotizaciones Cerradas en Ventas & & 7 & 7 & 5 & 5 & 7 & 7 & 7 & 45 & 0.14 \\
\hline Porcentaje de Cotizaciones Atendidas & 5 & & 5 & 7 & 5 & 7 & 5 & 7 & 41 & 0.13 \\
\hline Porcentaje de Cotizaciones NO Atendidas & 5 & 5 & & 5 & 3 & 7 & 5 & 7 & 37 & 0.12 \\
\hline Porcentaje Tasa de Abondono de llamadas & 5 & 5 & 5 & & 3 & 7 & 5 & 5 & 35 & 0.11 \\
\hline Porcentaje Margen de Rentabilidad & 10 & 10 & 10 & 10 & & 10 & 10 & 10 & 70 & 0.22 \\
\hline Tiempo promedio elaboracion cotizacion & 3 & 3 & 3 & 3 & 3 & & 3 & 3 & 21 & 0.07 \\
\hline Porcentaje de nivel de atencion & 5 & 5 & 5 & 5 & 3 & 7 & & 5 & 35 & 0.11 \\
\hline Porcentaje llamadas antes del umbral & 3 & 3 & 3 & 7 & 3 & 7 & 7 & & 33 & 0.10 \\
\hline Total & 36 & 38 & 38 & \begin{tabular}{l|l}
42 \\
\end{tabular} & 25 & \begin{tabular}{l|l}
52 \\
\end{tabular} & 42 & 44 & 317 & 1 \\
\hline
\end{tabular}

Fuente: Elaboración propia

Tabla 33. Matriz de prioridades del proceso Ventas contact center

\begin{tabular}{|c|c|c|c|c|c|c|c|c|c|c|}
\hline CRITERIO: IMPACTO AL NEGOCIO & 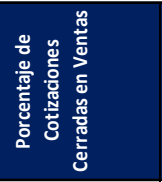 & 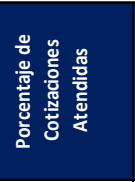 & 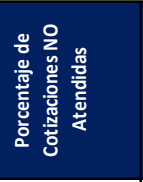 & 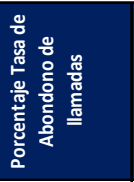 & 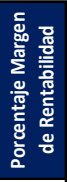 & 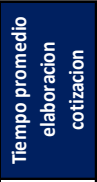 & 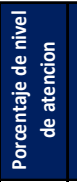 & 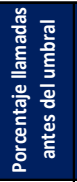 & Suma & Ponderacion \\
\hline Porcentaje de Cotizaciones Cerradas en Ventas & & 7 & 7 & 5 & 5 & 7 & 7 & 7 & 45 & 0.14 \\
\hline Porcentaje de Cotizaciones Atendidas & 5 & & 5 & 5 & 5 & 5 & 5 & 5 & 35 & 0.11 \\
\hline \begin{tabular}{|l|} 
Porcentaje de Cotizaciones NO Atendidas \\
\end{tabular} & 5 & 5 & & 5 & 3 & 7 & 5 & 7 & 37 & 0.12 \\
\hline Porcentaje Tasa de Abondono de llamadas & 3 & 3 & 5 & & 3 & 5 & 5 & 5 & 29 & 0.09 \\
\hline Porcentaje Margen de Rentabilidad & 10 & 10 & 10 & 10 & & 10 & 10 & 10 & 70 & 0.22 \\
\hline Tiempo promedio elaboracion cotizacion & 5 & 5 & 5 & 5 & 3 & & 5 & 5 & 33 & 0.11 \\
\hline Porcentaje de nivel de atencion & 5 & 5 & 5 & 5 & 3 & 10 & & 7 & 40 & 0.13 \\
\hline \begin{tabular}{|l|} 
Porcentaje llamadas antes del umbral \\
\end{tabular} & 3 & 3 & 3 & 3 & 3 & 5 & 5 & & 25 & 0.08 \\
\hline Total & 36 & 38 & 40 & 38 & 25 & 49 & \begin{tabular}{l|l|}
42 & \\
\end{tabular} & 46 & 314 & 1 \\
\hline
\end{tabular}

Fuente: Elaboración propia 
Tabla 34. Matriz de prioridades del proceso Ventas contact center

\begin{tabular}{|c|c|c|c|c|c|c|c|c|c|c|}
\hline $\begin{array}{l}\text { CRITERIO: INCREMENTAR PARTICIPACION DE } \\
\text { MERCADO }\end{array}$ & 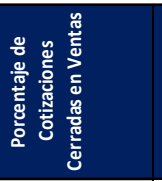 & 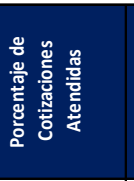 & 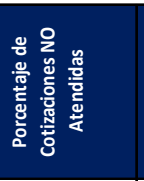 & 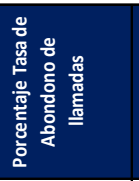 & 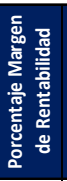 & 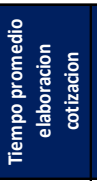 & 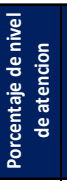 & 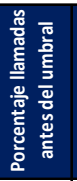 & Suma & Ponderacion \\
\hline Porcentaje de Cotizaciones Cerradas en Ventas & & 7 & 7 & 7 & 5 & 7 & 7 & 7 & 47 & 0.15 \\
\hline Porcentaje de Cotizaciones Atendidas & 5 & & 7 & 5 & 5 & 7 & 5 & 7 & 41 & 0.13 \\
\hline Porcentaje de Cotizaciones NO Atendidas & 5 & 5 & & 5 & 3 & 7 & 5 & 7 & 37 & 0.12 \\
\hline Porcentaje Tasa de Abondono de llamadas & 5 & 5 & 5 & & 3 & 7 & 5 & 5 & 35 & 0.11 \\
\hline Porcentaje Margen de Rentabilidad & 10 & 10 & 10 & 10 & & 10 & 10 & 10 & 70 & 0.22 \\
\hline Tiempo promedio elaboracion cotizacion & 3 & 3 & 3 & 3 & 3 & & 3 & 3 & 21 & 0.07 \\
\hline Porcentaje de nivel de atencion & 5 年 & 5 & 5 & 5 & 3 & 7 & & 5 & 35 & 0.11 \\
\hline Porcentaje llamadas antes del umbral & 3 & 3 & 3 & 7 & 3 & 7 & 7 & & 33 & 0.10 \\
\hline Total & 36 & 38 & 40 & 42 & 25 & 52 & 42 & 44 & 319 & 1 \\
\hline
\end{tabular}

Fuente: Elaboración propia

Tabla 35. Matriz de prioridades del proceso Ventas contact center

\begin{tabular}{|c|c|c|c|c|c|c|c|c|c|c|}
\hline CRITERIO: EFICIENCIA OPERATIVA & 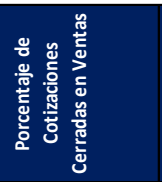 & 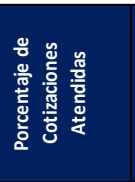 & 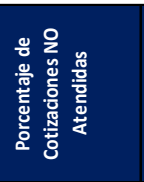 & 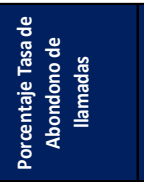 & 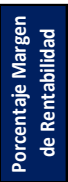 & 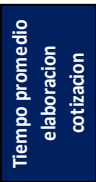 & 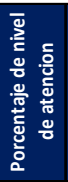 & 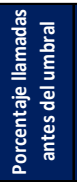 & Suma & Ponderacion \\
\hline Porcentaje de Cotizaciones Cerradas en Ventas & & 7 & 7 & 5 & 5 & 7 & 7 & 7 & 45 & 0.14 \\
\hline Porcentaje de Cotizaciones Atendidas & 5 & & 7 & 5 & 5 & 7 & 5 & 5 & 39 & 0.12 \\
\hline \begin{tabular}{|l} 
Porcentaje de Cotizaciones NO Atendidas \\
\end{tabular} & 5 & 5 & & 5 & 3 & 7 & 5 & 5 & 35 & 0.11 \\
\hline Porcentaje Tasa de Abondono de llamadas & 5 & 5 & 7 & & 3 & 7 & 5 & 7 & 39 & 0.12 \\
\hline Porcentaje Margen de Rentabilidad & 10 & 10 & 10 & 10 & & 10 & 10 & 10 & 70 & 0.22 \\
\hline Tiempo promedio elaboracion cotizacion & 5 & 5 & 5 & 3 & 3 & & 3 & 3 & 27 & 0.08 \\
\hline Porcentaje de nivel de atencion & 5 & 5 & 5 & 5 & 3 & 7 & & 5 & 35 & 0.11 \\
\hline Porcentaje llamadas antes del umbral & 3 & 3 & 3 & 7 & 3 & 7 & 7 & & 33 & 0.10 \\
\hline Total & 38 & 40 & 44 & 40 & 25 & 52 & 42 & 42 & 323 & 1 \\
\hline
\end{tabular}

Fuente: Elaboración propia

Se procede a realizar la una matriz donde se visualizan todas las ponderaciones de los indicadores versus los criterios de selección

Tabla 36. Matriz de prioridades del proceso Ventas contact center

\begin{tabular}{|l|c|c|c|c|}
\hline \multicolumn{1}{|c|}{ CRITERIOS / OPCIONES } & $\begin{array}{c}\text { Alineados a los } \\
\text { objetivos del negocio }\end{array}$ & $\begin{array}{c}\text { Impacto al } \\
\text { negocio }\end{array}$ & $\begin{array}{c}\text { Incrementar } \\
\text { participacion de } \\
\text { mercado }\end{array}$ & $\begin{array}{c}\text { Eficiencia } \\
\text { Operativa }\end{array}$ \\
\hline Porcentaje de Cotizaciones Cerradas en Ventas & 0.14 & 0.14 & 0.15 & 0.14 \\
\hline Porcentaje de Cotizaciones Atendidas & 0.13 & 0.11 & 0.13 & 0.12 \\
\hline Porcentaje de Cotizaciones NO Atendidas & 0.12 & 0.12 & 0.12 & 0.11 \\
\hline Porcentaje Tasa de Abondono de llamadas & 0.11 & 0.09 & 0.11 & 0.12 \\
\hline Porcentaje Margen de Rentabilidad & 0.22 & 0.22 & 0.22 & 0.22 \\
\hline Tiempo promedio elaboracion cotizacion & 0.07 & 0.11 & 0.07 & 0.08 \\
\hline Porcentaje de nivel de atencion & 0.11 & 0.13 & 0.11 & 0.11 \\
\hline Porcentaje llamadas antes del umbral & 0.10 & 0.08 & 0.10 & 0.10 \\
\hline
\end{tabular}

Fuente: Elaboración propia 
Una vez que se tiene el detalle de estas matrices consolidadas se procede a realizar la matriz final donde se procede a multiplicar estos valores por los valores ponderados de los criterios de selección (ver Tabla 37) y se obtiene la siguiente matriz.

Tabla 37. Matriz de prioridades del proceso Ventas contact center

\begin{tabular}{|c|c|c|c|c|c|}
\hline CRITERIOS / OPCIONES & $\begin{array}{c}\text { Alineados a los } \\
\text { objetivos del negocio }\end{array}$ & $\begin{array}{l}\text { Impacto al } \\
\text { negocio }\end{array}$ & $\begin{array}{c}\text { Incrementar } \\
\text { participacion de } \\
\text { mercado }\end{array}$ & $\begin{array}{l}\text { Eficiencia } \\
\text { Operativa }\end{array}$ & Total \\
\hline Porcentaje de Cotizaciones Cerradas en Ventas & 0.03 & 0.04 & 0.03 & 0.04 & 0.14 \\
\hline Porcentaje de Cotizaciones Atendidas & 0.03 & 0.03 & 0.03 & 0.03 & 0.12 \\
\hline Porcentaje de Cotizaciones NO Atendidas & 0.03 & 0.03 & 0.03 & 0.03 & 0.11 \\
\hline Porcentaje Tasa de Abondono de Ilamadas & 0.02 & 0.03 & 0.02 & 0.03 & 0.11 \\
\hline Porcentaje Margen de Rentabilidad & 0.05 & 0.06 & 0.05 & 0.06 & 0.22 \\
\hline Tiempo promedio elaboracion cotizacion & 0.01 & 0.03 & 0.01 & 0.02 & 0.08 \\
\hline Porcentaje de nivel de atencion & 0.02 & 0.04 & 0.02 & 0.03 & 0.11 \\
\hline Porcentaje llamadas antes del umbral & 0.02 & 0.02 & 0.02 & 0.03 & 0.10 \\
\hline Total & 0.22 & 0.29 & 0.22 & 0.27 & 1.00 \\
\hline
\end{tabular}

Fuente: Elaboración propia

Donde se puede obtener que los indicadores para el sub proceso de Ventas Contact Center que tienen el total y por ende son los más relevantes son:

- Porcentaje de Margen de Rentabilidad.

- Porcentaje de Cotizaciones Cerradas en Ventas.

- Porcentaje de Cotizaciones Atendidas.

\section{Proceso de Ventas web}

Se procede a elaborar la matriz de priorización de indicadores del sub proceso de Ventas Web, es decir se estima que tipo de indicador mostrado es el más importante y tiene mayor impacto sobre el negocio. Cabe mencionar que esta evaluación de priorización se hizo con los responsables de cada área de negocio de la empresa que se está realizando el análisis. 
Tabla 38. Matriz de prioridades del proceso Ventas web

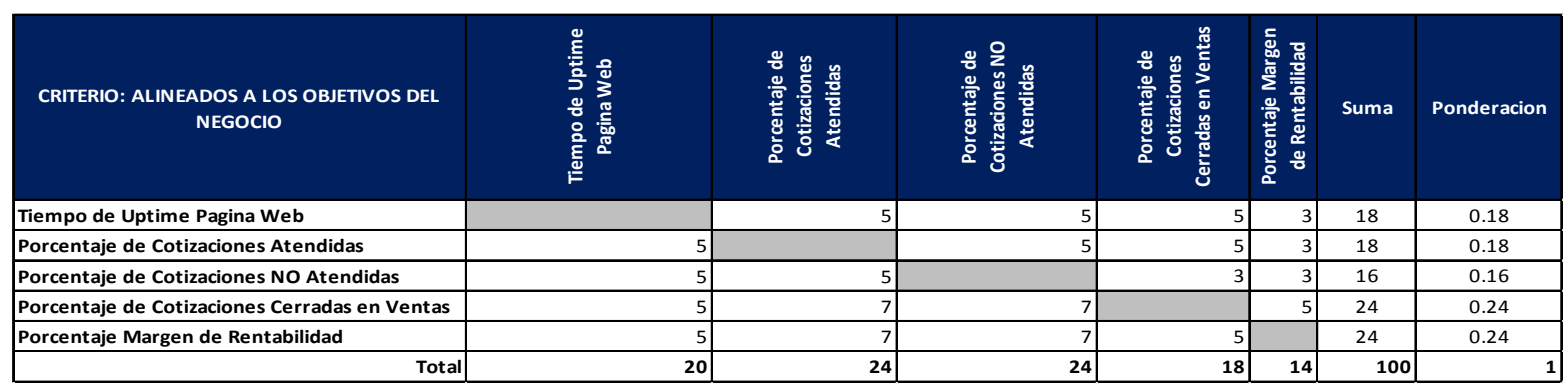

Fuente: Elaboración propia

Tabla 39. Matriz de prioridades del proceso Ventas web

\begin{tabular}{|c|c|c|c|c|c|c|c|}
\hline CRITERIO: IMPACTO AL NEGOCIO & 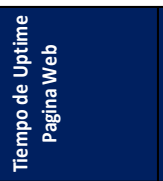 & 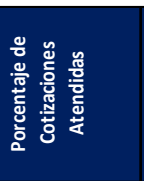 & 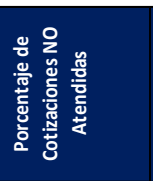 & 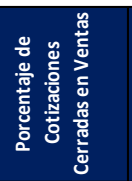 & 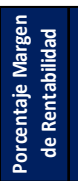 & Suma & Ponderacion \\
\hline Tiempo de Uptime Pagina Web & & 7 & 7 & 7 & 5 & 26 & 0.23 \\
\hline Porcentaje de Cotizaciones Atendidas & 5 & & 5 & 5 & 3 & 18 & 0.16 \\
\hline Porcentaje de Cotizaciones NO Atendidas & 5 & 5 & & 7 & 3 & 20 & 0.18 \\
\hline Porcentaje de Cotizaciones Cerradas en Ventas & 5 & 7 & 7 & & 5 & 24 & 0.21 \\
\hline Porcentaje Margen de Rentabilidad & 5 & 7 & 7 & 5 & & 24 & 0.21 \\
\hline Total & 20 & 26 & 26 & 24 & 16 & 112 & 1 \\
\hline
\end{tabular}

Fuente: Elaboración propia

Tabla 40. Matriz de prioridades del proceso Ventas web

\begin{tabular}{|c|c|c|c|c|c|c|c|}
\hline $\begin{array}{l}\text { CRITERIO: INCREMENTAR PARTICIPACION DE } \\
\text { MERCADO }\end{array}$ & 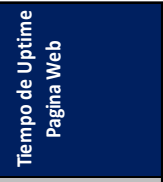 & 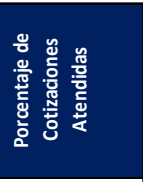 & 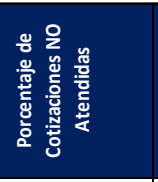 & 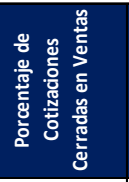 & 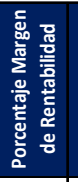 & Suma & Ponderacion \\
\hline Tiempo de Uptime Pagina Web & & 5 & 5 & 5 & 5 & 20 & 0.19 \\
\hline Porcentaje de Cotizaciones Atendidas & 5 & & 5 & 5 & 3 & 18 & 0.17 \\
\hline Porcentaje de Cotizaciones NO Atendidas & 5 & 5 & & 3 & 3 & 16 & 0.15 \\
\hline Porcentaje de Cotizaciones Cerradas en Ventas & 7 & 7 & 7 & & 5 & 26 & 0.25 \\
\hline Porcentaje Margen de Rentabilidad & 7 & 7 & 7 & 5 & & 26 & 0.25 \\
\hline 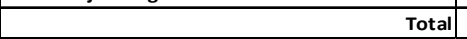 & 24 & 24 & 24 & 18 & 16 & 106 & ${ }^{-}$ \\
\hline
\end{tabular}

Fuente: Elaboración propia 
Tabla 41. Matriz de prioridades del proceso Ventas web

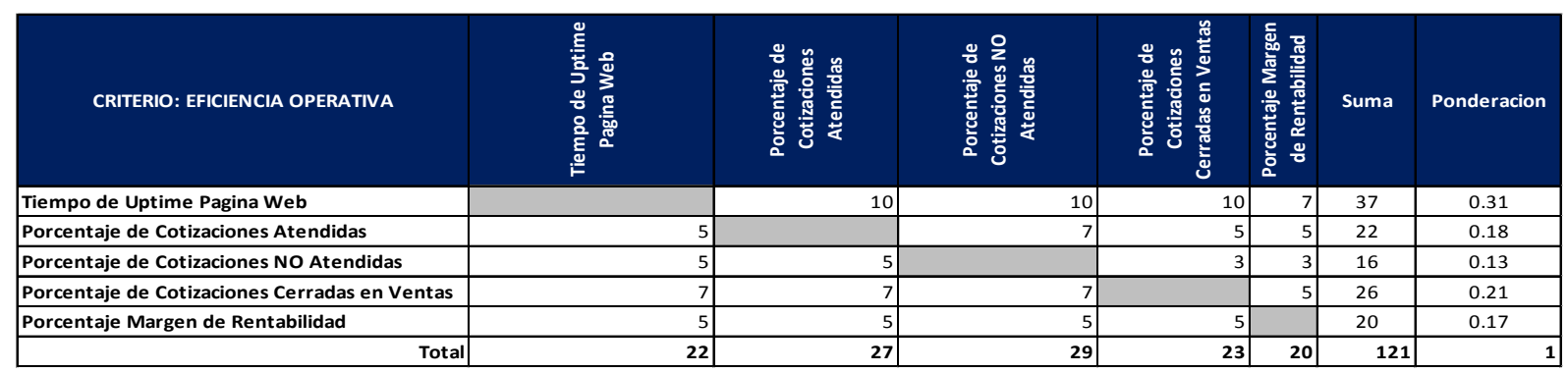

Fuente: Elaboración propia

Se procede a realizar la una matriz donde se visualizan todas las ponderaciones de los indicadores versus los criterios de selección

Tabla 42. Matriz de prioridades del proceso Ventas web

\begin{tabular}{|l|c|c|c|c|}
\hline \multicolumn{1}{|c|}{ CRITERIOS / OPCIONES } & $\begin{array}{c}\text { Alineados a los objetivos } \\
\text { del negocio }\end{array}$ & Impacto al negocio & $\begin{array}{c}\text { Incrementar } \\
\text { participacion de } \\
\text { mercado }\end{array}$ & $\begin{array}{c}\text { Eficiencia } \\
\text { Operativa }\end{array}$ \\
\hline Tiempo de Uptime Pagina Web & 0.18 & 0.23 & 0.19 & 0.31 \\
\hline Porcentaje de Cotizaciones Atendidas & 0.18 & 0.16 & 0.17 & 0.18 \\
\hline Porcentaje de Cotizaciones NO Atendidas & 0.16 & 0.18 & 0.15 & 0.13 \\
\hline Porcentaje de Cotizaciones Cerradas en Ventas & 0.24 & 0.21 & 0.25 & 0.21 \\
\hline Porcentaje Margen de Rentabilidad & 0.24 & 0.21 & 0.25 & 0.17 \\
\hline
\end{tabular}

Fuente: Elaboración propia

Una vez que se tiene el detalle de estas matrices consolidadas se procede a realizar la matriz final donde se procede a multiplicar estos valores por los valores ponderados de los criterios de selección (ver Tabla 43) y se obtiene la siguiente matriz.

Tabla 43. Matriz de prioridades del proceso Ventas web

\begin{tabular}{|c|c|c|c|c|c|}
\hline CRITERIOS / OPCIONES & $\begin{array}{c}\text { Alineados a los objetivos } \\
\text { del negocio }\end{array}$ & Impacto al negocio & $\begin{array}{c}\text { Incrementar } \\
\text { participacion de } \\
\text { mercado }\end{array}$ & $\begin{array}{l}\text { Eficiencia } \\
\text { Operativa }\end{array}$ & Total \\
\hline Tiempo de Uptime Pagina Web & 0.04 & 0.07 & 0.04 & 0.08 & 0.23 \\
\hline Porcentaje de Cotizaciones Atendidas & 0.04 & 0.05 & 0.04 & 0.05 & 0.17 \\
\hline Porcentaje de Cotizaciones NO Atendidas & 0.04 & 0.05 & 0.03 & 0.04 & 0.16 \\
\hline Porcentaje de Cotizaciones Cerradas en Ventas & 0.05 & 0.06 & 0.05 & 0.06 & 0.23 \\
\hline Porcentaje Margen de Rentabilidad & 0.05 & 0.06 & 0.05 & 0.04 & 0.21 \\
\hline Total & 0.22 & 0.29 & 0.22 & 0.27 & 1.00 \\
\hline
\end{tabular}

Fuente: Elaboración propia

Donde se puede obtener que los indicadores para el sub proceso de Ventas Web que tienen el total y por ende son los más relevantes son: 
- Tiempo de Uptime Pagina Web.

- Porcentaje de Cotizaciones Cerradas en Ventas.

- Porcentaje de Margen de Rentabilidad.

\section{Proceso Diseño y desarrollo de productos}

Se procede a elaborar la matriz de priorización de indicadores del sub proceso de Diseño y Desarrollo de Productos, es decir se estima que tipo de indicador mostrado es el más importante y tiene mayor impacto sobre el negocio. Cabe mencionar que esta evaluación de priorización se hizo con los responsables de cada área de negocio de la empresa que se está realizando el análisis.

Tabla 44. Matriz de prioridades del proceso Diseño y desarrollo de productos

\begin{tabular}{|c|c|c|c|c|c|}
\hline $\begin{array}{l}\text { CRITERIO: ALINEADOS A LOS OBJETIVOS DEL } \\
\text { NEGOCIO }\end{array}$ & 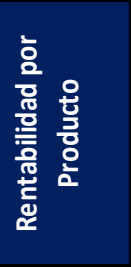 & 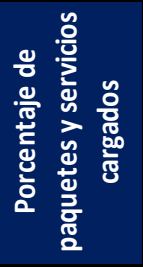 & 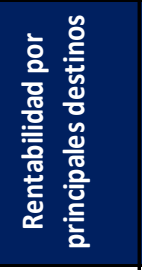 & Suma & Ponderacion \\
\hline Rentabilidad por Producto & & 10 & 7 & 17 & 0.43 \\
\hline Porcentaje de paquetes y servicios cargados & 3 & & 5 & 8 & 0.20 \\
\hline Rentabilidad por principales destinos & 5 & 10 & & 15 & 0.38 \\
\hline Total & 8 & 20 & 12 & 40 & 1 \\
\hline
\end{tabular}

Fuente: Elaboración propia

Tabla 45. Matriz de prioridades del proceso Diseño y desarrollo de productos

\begin{tabular}{|c|c|c|c|c|c|}
\hline CRITERIO: IMPACTO AL NEGOCIO & 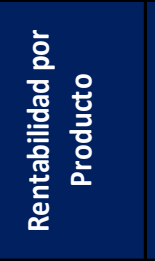 & 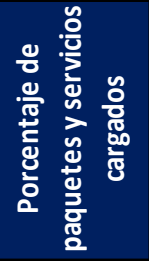 & 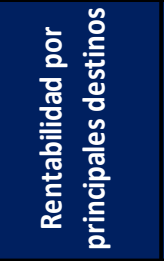 & Suma & Ponderacion \\
\hline Rentabilidad por Producto & & 10 & 7 & 17 & 0.44 \\
\hline Porcentaje de paquetes y servicios cargados & 5 & & 5 & 10 & 0.26 \\
\hline Rentabilidad por principales destinos & 5 & 7 & & 12 & 0.31 \\
\hline Total & 10 & 17 & 12 & 39 & 1 \\
\hline
\end{tabular}

Fuente: Elaboración propia 
Tabla 46. Matriz de prioridades del proceso Diseño y desarrollo de productos

\begin{tabular}{|c|c|c|c|c|c|}
\hline $\begin{array}{l}\text { CRITERIO: INCREMENTAR PARTICIPACION DE } \\
\text { MERCADO }\end{array}$ & 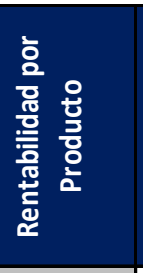 & 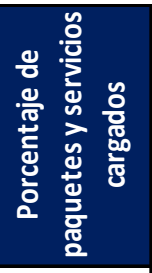 & 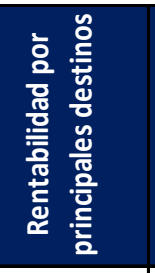 & Suma & Ponderacion \\
\hline Rentabilidad por Producto & & 5 & 5 & 10 & 0.29 \\
\hline Porcentaje de paquetes y servicios cargados & 7 & & 7 & 14 & 0.41 \\
\hline Rentabilidad por principales destinos & 5 & 5 & & 10 & 0.29 \\
\hline Total & 12 & 10 & 12 & 34 & 1 \\
\hline
\end{tabular}

Fuente: Elaboración propia

Tabla 47. Matriz de prioridades del proceso Diseño y desarrollo de productos

\begin{tabular}{|c|c|c|c|c|c|}
\hline CRITERIO: EFICIENCIA OPERATIVA & 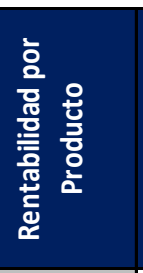 & 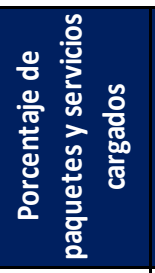 & 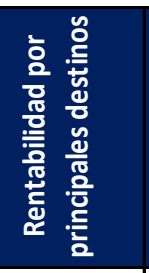 & Suma & Ponderacion \\
\hline Rentabilidad por Producto & & 5 & 5 & 10 & 0.29 \\
\hline Porcentaje de paquetes y servicios cargados & 7 & & 7 & 14 & 0.41 \\
\hline Rentabilidad por principales destinos & 5 & 5 & & 10 & 0.29 \\
\hline Total & 12 & 10 & 12 & 34 & \\
\hline
\end{tabular}

Fuente: Elaboración propia

Se procede a realizar la una matriz donde se visualizan todas las ponderaciones de los indicadores versus los criterios de selección

Tabla 48. Matriz de prioridades del proceso Diseño y desarrollo de productos

\begin{tabular}{|l|c|c|c|c|}
\hline \multicolumn{1}{|c|}{ CRITERIOS / OPCIONES } & $\begin{array}{c}\text { Alineados a los } \\
\text { objetivos del negocio }\end{array}$ & $\begin{array}{c}\text { Impacto al } \\
\text { negocio }\end{array}$ & $\begin{array}{c}\text { Incrementar } \\
\text { participacion de } \\
\text { mercado }\end{array}$ & $\begin{array}{c}\text { Eficiencia } \\
\text { Operativa }\end{array}$ \\
\hline Rentabilidad por Producto & 0.43 & 0.44 & 0.29 & 0.29 \\
\hline Porcentaje de paquetes y servicios cargados & 0.20 & 0.26 & 0.41 & 0.41 \\
\hline Rentabilidad por principales destinos & 0.38 & 0.31 & 0.29 & 0.29 \\
\hline
\end{tabular}

Fuente: Elaboración propia 
Una vez que se tiene el detalle de estas matrices consolidadas se procede a realizar la matriz final donde se procede a multiplicar estos valores por los valores ponderados de los criterios de selección (ver Tabla 49) y se obtiene la siguiente matriz.

Tabla 49. Matriz de prioridades del proceso Diseño y desarrollo de productos

\begin{tabular}{|l|c|r|r|r|r|}
\hline \multicolumn{1}{|c|}{ CRITERIOS / OPCIONES } & $\begin{array}{c}\text { Alineados a los } \\
\text { objetivos del negocio }\end{array}$ & $\begin{array}{c}\text { Impacto al } \\
\text { negocio }\end{array}$ & $\begin{array}{c}\text { Incrementar participacion } \\
\text { de mercado }\end{array}$ & $\begin{array}{c}\text { Eficiencia } \\
\text { Operativa }\end{array}$ & \multicolumn{1}{c|}{ Total } \\
\hline Rentabilidad por Producto & 0.09 & 0.13 & 0.06 & 0.08 & 0.36 \\
\hline Porcentaje de paquetes y servicios cargados & 0.04 & 0.07 & 0.09 & 0.11 & 0.32 \\
\hline Rentabilidad por principales destinos & 0.08 & 0.09 & 0.06 & 0.08 & 0.32 \\
\hline Total & $\mathbf{0 . 2 2}$ & $\mathbf{0 . 2 9}$ & $\mathbf{0 . 2 2}$ & $\mathbf{0 . 2 7}$ & $\mathbf{1}$ \\
\hline
\end{tabular}

Fuente: Elaboración propia

Donde se puede obtener que los indicadores para el proceso de Diseño y Desarrollo de Porducto que tienen el total y por ende son los más relevantes son:

- Rentabilidad por Producto.

- Rentabilidad por principales destinos.

- Porcentaje de paquetes y servicios cargados.

\section{Análisis de datos}

De los indicadores obtenidos, y en base a las encuestas, entrevistas con los expertos e información financiera y de gestión de Viajes Falabella, se han obtenido los siguientes datos: 
Figura 30. Margen sobre las ventas

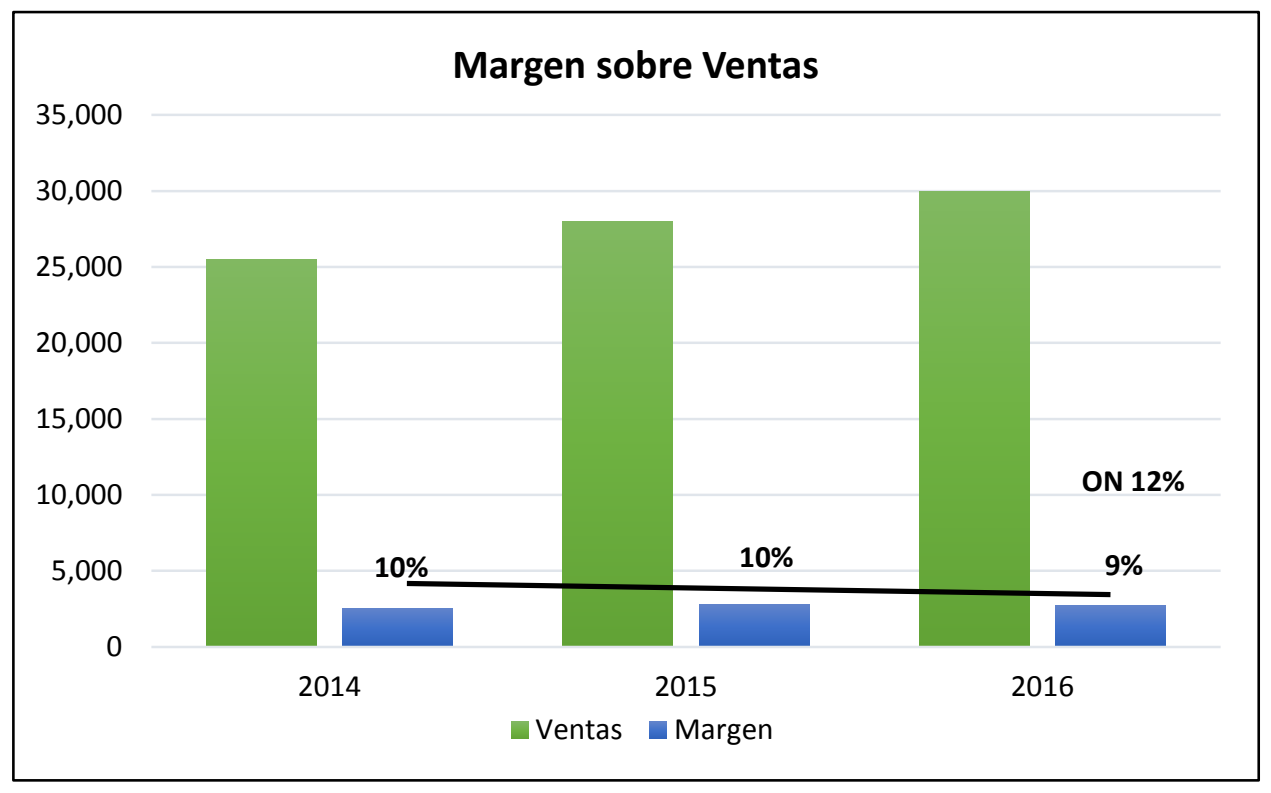

Fuente: Elaboración propia

En la Figura 30, se puede apreciar que, si bien las ventas han tenido un aumento a lo largo de los años, y el margen se ha mantenido y caído en 1\%, no se llegó al objetivo de margen de 12\% como lo precisaba el Plan Estratégico.

Y, en la Figura 31, la venta de productos con el medio de negociación directa da mayor rentabilidad para la empresa, sin embargo, las ventas en mayor proporción son de Tour Operado (se paga una comisión por venta) dado que los asesores de ventas no tienen la información de los productos en un solo repositorio de consulta, por lo que consultan la información de la intranet que no necesariamente es la más rentable

Figura 31. Ventas por Tipo de Producto

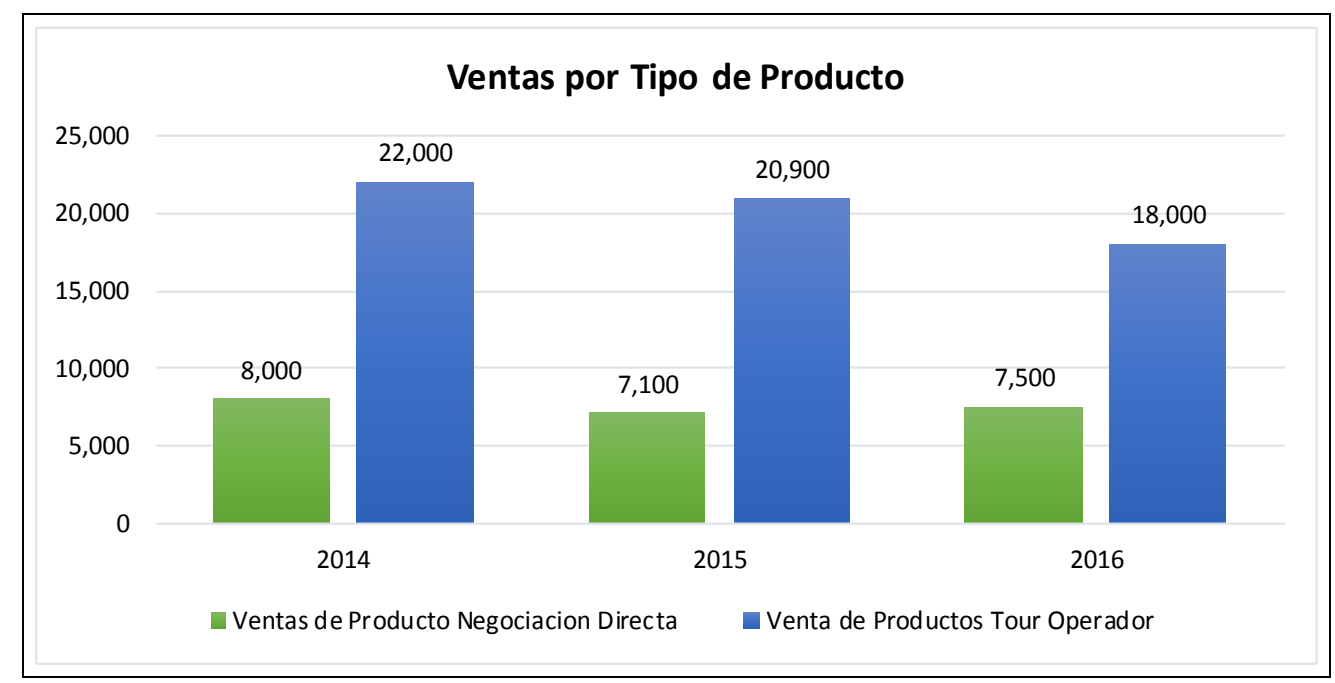


Fuente: Elaboración propia

Cuadro 8. Ventas por Tipo de Producto

\begin{tabular}{|r|r|r|r|}
\hline & $\mathbf{2 0 1 4}$ & $\mathbf{2 0 1 5}$ & $\mathbf{2 0 1 6}$ \\
\hline Ventas de Producto Negociacion Directa & 8,000 & 7,100 & 7,500 \\
\hline Venta de Productos Tour Operador & 22,000 & 20,900 & 18,000 \\
\hline TOTAL & $\mathbf{3 0 , 0 0 0}$ & $\mathbf{2 8 , 0 0 0}$ & $\mathbf{2 5 , 5 0 0}$ \\
\hline
\end{tabular}

Fuente: Elaboración propia

Y, respecto a los productos registrados por fuente de datos utilizados por los asesores de viajes para la realización de las ventas por cualquier unidad de negocio, el criterio de selección para la carga de productos no está definido por la gerencia de producto, por lo que los asistentes de producto registran la información bajo su propio criterio y no por la rentabilidad que ésta pueda generar.

Figura 32. Productos registrados por fuente de datos

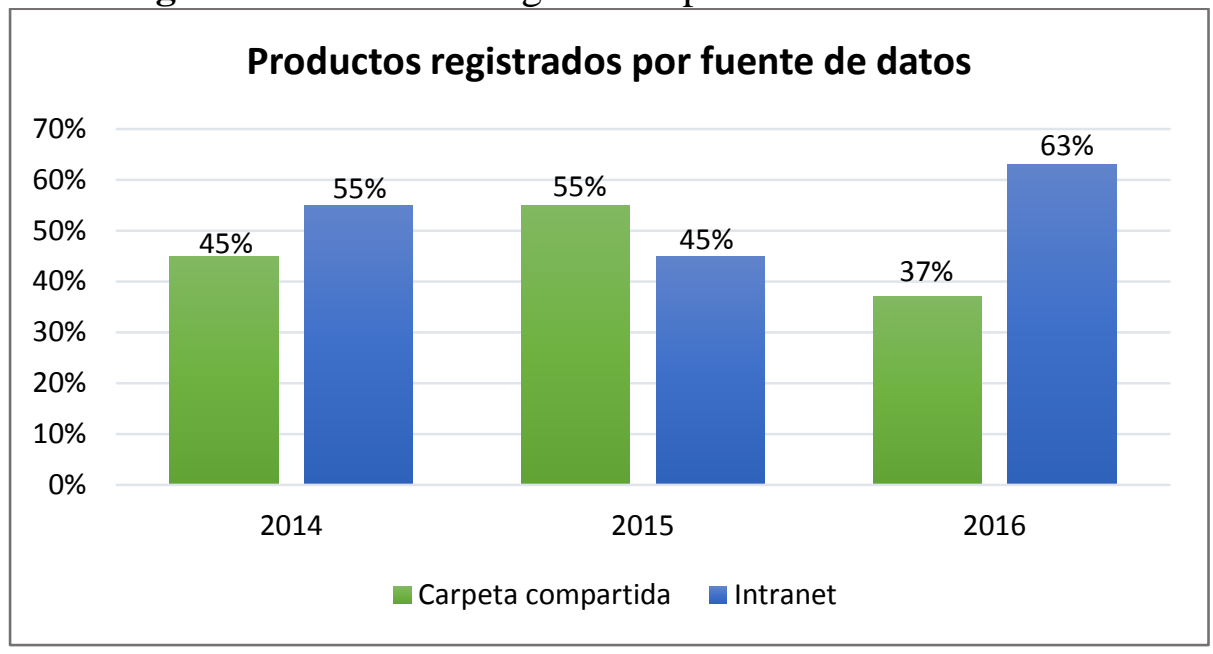

Fuente: Elaboración propia

En la Figura 33, se puede evidenciar que el registro de los datos del producto se realiza 3 veces con la misma información en los siguientes documentos: Formatos de productos, cotización, formato de pago; generando pérdida de tiempo al transcribir la información en un medio físico o digital.

Figura 33. Retrabajo 


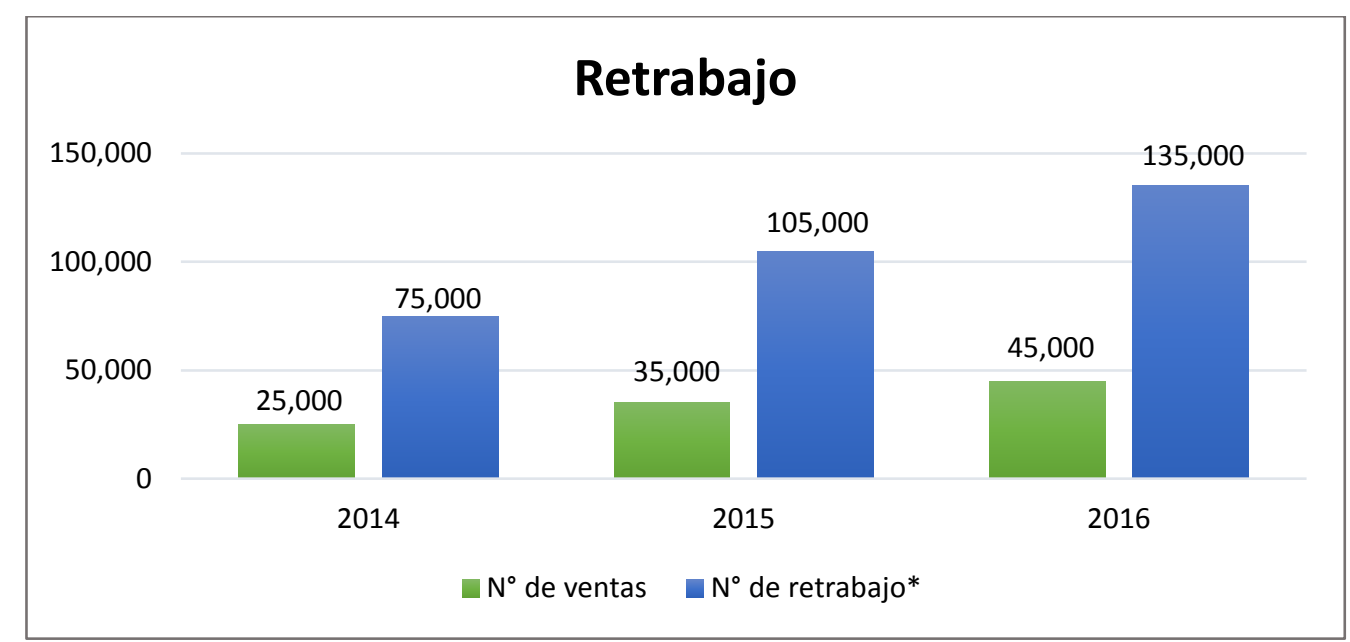

Fuente: Elaboración propia

*Cantidad de veces en los que el producto ha sido registrado en el mismo proceso

La rentabilidad por destino top Caribe ha ido bajando del 2014 al 2016, dado que los asesores de ventas no tienen la información de los productos en un solo repositorio de consulta, por lo que consultan la información de la intranet que no necesariamente es la más rentable, Figura 34.

Figura 34. Rentabilidad por destino

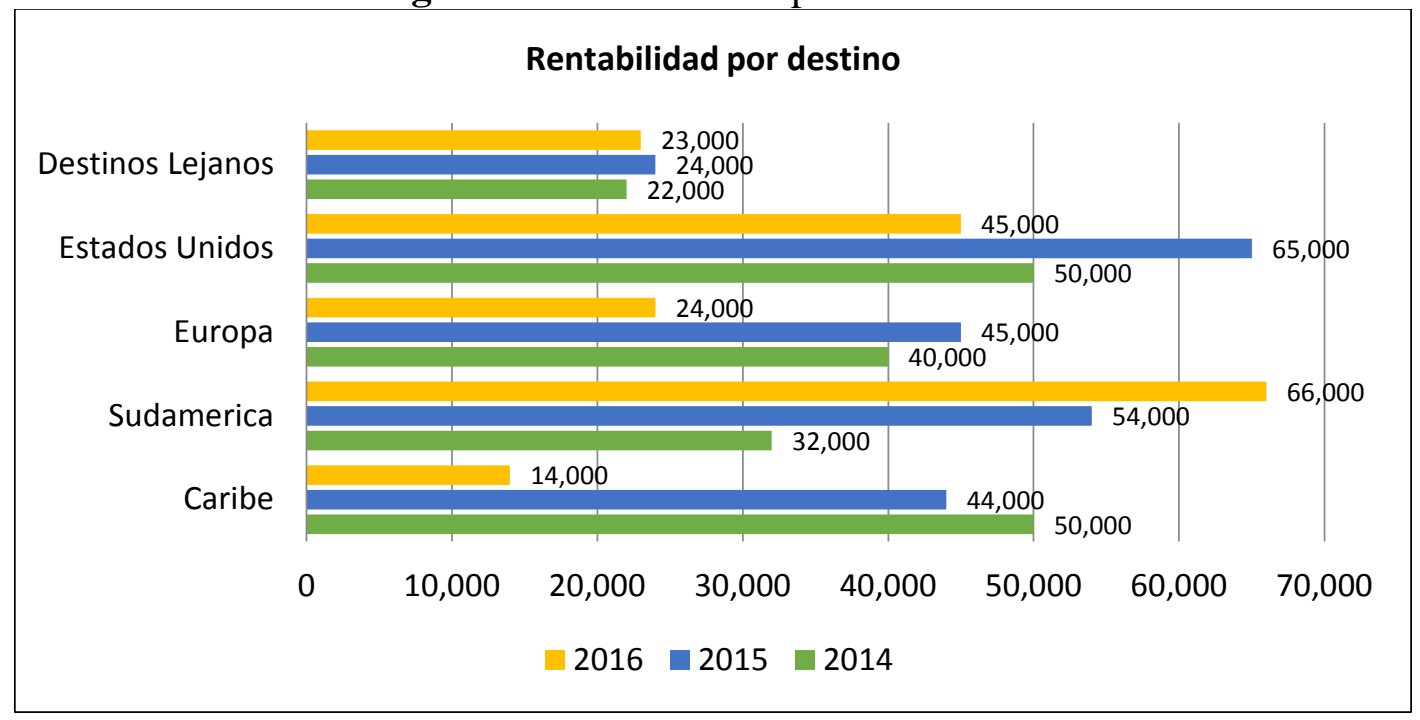

Fuente: Elaboración propia

\subsection{Planteamiento del problema}

El Área de Producto, a través del Product Manager, realiza el costeo de productos (hoteles, vuelos, paquetes) en función a los datos proporcionados por los proveedores y establece el margen para cada uno, el cual es completado de manera manual en archivos en Excel. Las cifras 
asociadas a los márgenes son establecidas de acuerdo a los objetivos de negocio y son proporcionadas de acuerdo a cada producto. La información del costeo de productos se lleva a cabo de manera descentralizada, no se cuenta con información a la que se pueda acceder en un determinado momento, si se desea un dato especifico se debe consultar con el Product Manager para que pueda brindar el dato respectivo.

El asistente de producto realiza la carga de cada archivo en Excel con los datos de los productos (hoteles, servicios, cruceros, seguros) en la intranet de la empresa; para ello genera una ficha con la descripción del producto, el precio, las características y la vigencia respectiva, esta ficha es elaborada en dreamwaver y es incluida en la intranet. Estos registros son generados de manera manual uno por uno. Los datos no son incluidos en su totalidad en la intranet, por lo que se emplea una carpeta compartida para colocar los archivos. Hasta este punto el asistente de producto cuenta con dos entradas para colocar la información: intranet y carpeta compartida.

El área de ventas a través de los ejecutivos de ventas consulta sobre los productos (hoteles, servicios, seguros, cruceros) a través de la intranet y carpetas compartidas. Cada vez que un cliente necesita información o solicita un producto, el ejecutivo de ventas ingresa a la intranet y busca la opción respectiva, ingresa a la página del producto requerido y obtiene datos como el precio, características y vigencia. Si el cliente necesita realizar una combinación de productos (hoteles, vuelos, seguros, etc.), el ejecutivo de ventas debe ingresar a cada página generada en la intranet copiar la descripción en un archivo en Excel y generar manualmente la cotización requerida. Estas acciones las realiza para cada cotización o solicitud que el cliente requiera.

Las actualizaciones de los paquetes son ingresadas por los asistentes de producto, los cuales actualizan las páginas web pero no comunican los cambios requeridos, si hay modificaciones en la vigencia de los paquetes, el ejecutivo de ventas no se entera y puede brindar opciones que no están disponibles. Para ello el ejecutivo de ventas debe ingresar y verificar la descripción de cada producto, de tal manera que cuente con información disponible y se asegure de datos correctos al momento de realizar una cotización.

Al ejecutar las actividades correspondientes al proceso de ventas, el ejecutivo de ventas no tiene visibilidad de las cotizaciones generadas, las que se convirtieron en ventas o las que se perdieron. Estos datos no se obtienen de manera directa, ya que la información que se tiene está distribuida en más de una fuente: Intranet y carpetas compartidas. 
Las cotizaciones ganadas con un alto margen pueden brindar información sobre la atención al cliente, la elaboración de los paquetes y los precios asociados. Actualmente esta figura no es posible y no se puede plantear una estrategia para seguir esta tendencia. De la misma manera las cotizaciones que no se convierten en ventas pueden brindar datos sobre lo que no se debe considerar en la elaboración de paquetes y atención al cliente.

Cada fin de mes se tiene la necesidad de obtener la información de los márgenes para cada venta, estos datos no son visibles durante el proceso, de ventas o producto, incluso posterior a la venta. Lo que dificulta el establecimiento de una estrategia clara para la empresa.

El trabajo manual realizado en el proceso de desarrollo de productos al elaborar archivos en Excel para los costos y luego publicar páginas en la intranet, dificulta la integración y no permite establecer un estándar en la forma de trabajo. Las diversas fuentes de información empleadas generan retrasos en el acceso a los paquetes, servicios, hoteles, etc. Ocasionando que las cotizaciones en la parte de ventas no sean las adecuadas. Todo esto tiene como consecuencia que el margen para cada producto no sea reconocido hasta el final o incluso en instancias posteriores. 


\section{CAPITULO 3}

\section{PROPUESTA DE SOLUCIÓN}

En el presente capítulo se presenta el desarrollo de la propuesta de solución, contemplando los diagramas TO-BE, impacto en la organización y la evaluación de los proyectos de mejora.

Los diagramas TO-BE desarrollados indicarán las mejoras sobre el estado actual de los procesos.

El análisis de impacto permite identificar los riesgos y establecer las medidas de control para mitigar el daño 


\section{Propuesta de solución}

\subsection{Mejora de procesos}

\subsubsection{Ventas sucursales}

En el diagrama AS-IS (ver Figura 11. Diagrama AS IS del proceso Ventas sucursales) se observa que el proceso cuenta con actividades manuales y sin el apoyo de una herramienta para la gestión de información.

La propuesta va por el lado de optimizar el proceso y para ello se han identificado las actividades que causan retraso en la atención del cliente y que esto genera que las ventas no puedan cerrarse. 
Figura 15. Diagrama TO-BE del proceso Ventas sucursales

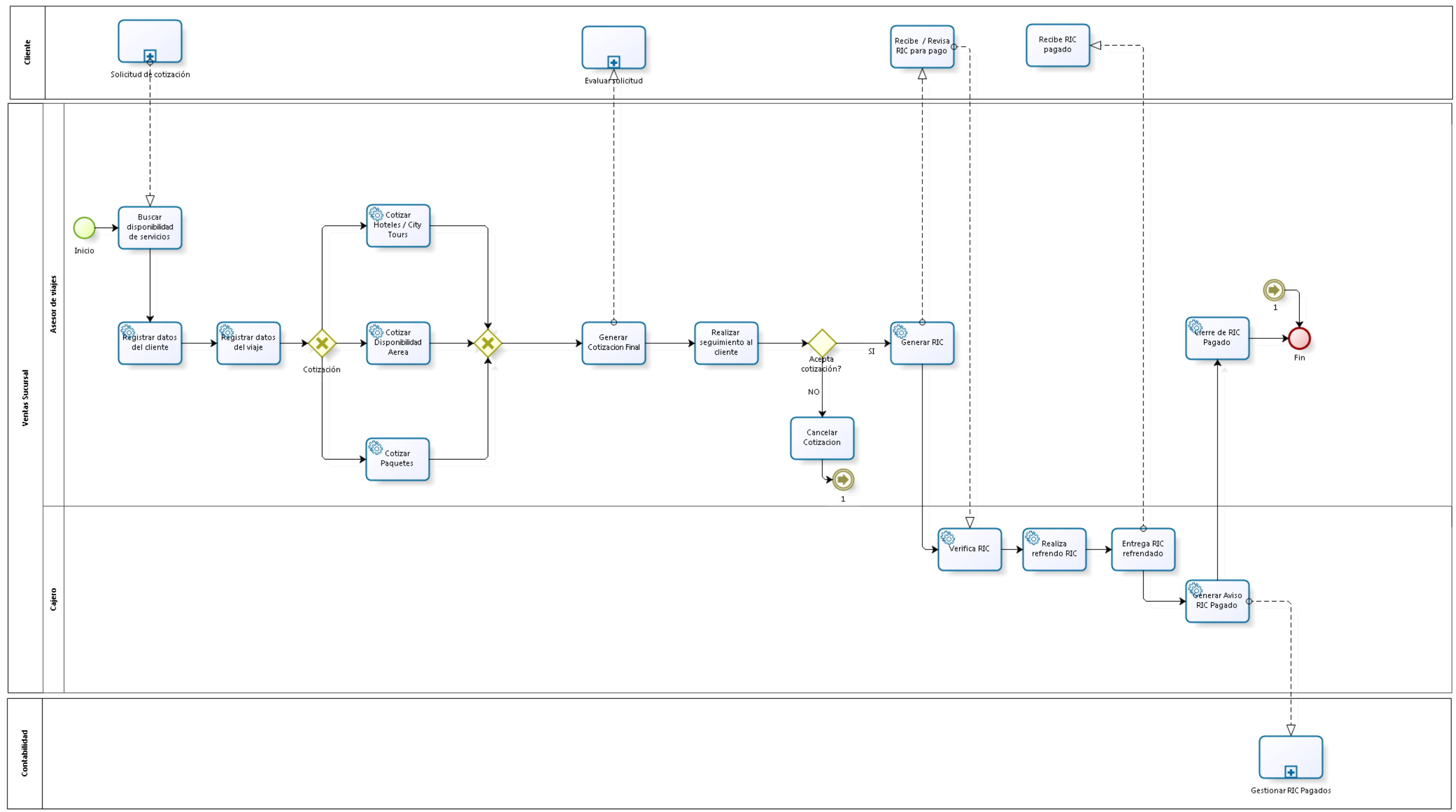

Fuente: Elaboración propia 


\section{Brecha del proceso AS-IS con el TO-BE}

Tabla 50. Matriz de brecha del proceso AS-IS con el TO-BE

\begin{tabular}{|c|c|c|}
\hline PROCESO & AS IS & TO BE \\
\hline Ventas sucursales & Buscar disponibilidad de servicios & $\begin{array}{l}\text { Buscar disponibilidad de } \\
\text { servicios }\end{array}$ \\
\hline Ventas sucursales & Registrar datos del cliente & Registrar datos del cliente \\
\hline Ventas sucursales & Registrar datos del viaje & Registrar datos del viaje \\
\hline Ventas sucursales & $\begin{array}{l}\text { Revisar disponibilidad en intranet de } \\
\text { cityTours }\end{array}$ & \multirow{5}{*}{ Cotizar city tours } \\
\hline Ventas sucursales & Revisar disponibilidad con operador & \\
\hline Ventas sucursales & Buscar alternativas & \\
\hline Ventas sucursales & Tomar información & \\
\hline Ventas sucursales & Realizar pre reserva & \\
\hline Ventas sucursales & Revisar disponibilidad de vuelos & \multirow{3}{*}{ Cotizar disponibilidad aérea } \\
\hline Ventas sucursales & Buscar alternativas & \\
\hline Ventas sucursales & Tomar información & \\
\hline Ventas sucursales & Revisar disponibilidad en intranet de hoteles & \multirow{5}{*}{ Cotizar paquetes } \\
\hline Ventas sucursales & Revisar disponibilidad con hoteles & \\
\hline Ventas sucursales & Buscar alternativas & \\
\hline Ventas sucursales & Realizar pre reserva & \\
\hline Ventas sucursales & Tomar información & \\
\hline Ventas sucursales & Realizar cotización final & Generar cotización final \\
\hline Ventas sucursales & Realizar seguimiento al cliente & Realizar seguimiento al cliente \\
\hline Ventas sucursales & Cancelar & Cancelar \\
\hline Ventas sucursales & Generar RIC & Generar RIC \\
\hline Ventas sucursales & Verifica RIC & Verifica RIC \\
\hline Ventas sucursales & Realiza refrendo & Realiza refrendo \\
\hline
\end{tabular}




\begin{tabular}{|l|l|l|}
\hline \multicolumn{1}{|c|}{ PROCESO } & \multicolumn{1}{|c|}{ AS IS } & \multicolumn{1}{c|}{ TO BE } \\
\hline Ventas sucursales & Entrega RIC con refrendo & Entrega RIC con refrendo \\
\hline & Entrega RIC con refrendo & Generar aviso RIC pagado \\
\hline Ventas sucursales & Cerrar RIC & Cierre de RIC pagado \\
\hline
\end{tabular}

Fuente: Elaboración propia

\begin{tabular}{|l|l|l|}
\hline 25 & 15 & $40 \%$ \\
\hline
\end{tabular}

Índice de reducción de actividades

\subsubsection{Ventas contact center}

En el diagrama AS-IS (ver Figura 12. Diagrama AS IS del proceso Ventas contact center) se observa que el proceso cuenta con actividades manuales y sin el apoyo de una herramienta para la gestión de información.

La propuesta va por el lado de optimizar el proceso y para ello se han identificado las actividades que causan retraso en la atención del cliente y que esto genera que las ventas no puedan cerrarse 
Figura 16. Diagrama TO-BE del proceso Ventas contact center

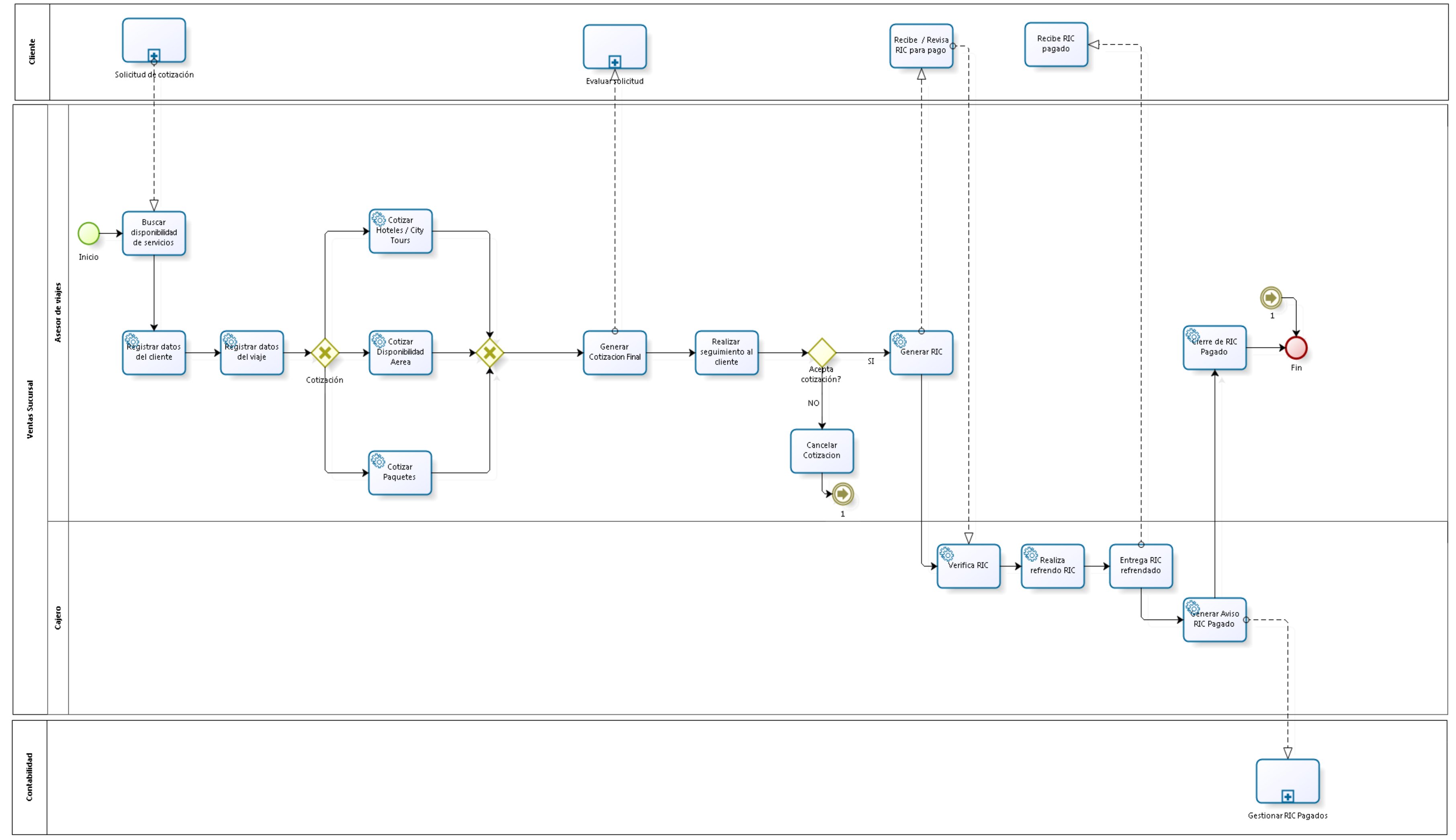

Fuente: Elaboración propia 


\section{Brecha del proceso AS-IS con el TO-BE}

Tabla 51. Matriz de brecha del proceso AS-IS con el TO-BE

\begin{tabular}{|c|c|c|}
\hline PROCESO & AS IS & TO BE \\
\hline Ventas Contact center & Recibir llamada & \multirow{2}{*}{$\begin{array}{l}\text { Buscar disponibilidad de } \\
\text { servicios }\end{array}$} \\
\hline Ventas Contact center & Buscar disponibilidad de servicios & \\
\hline Ventas Contact center & Registrar datos del cliente & Registrar datos del cliente \\
\hline Ventas Contact center & Registrar datos del viaje & Registrar datos del viaje \\
\hline Ventas Contact center & $\begin{array}{l}\text { Revisar disponibilidad en intranet de } \\
\text { cityTours }\end{array}$ & \multirow{5}{*}{ Cotizar city tours } \\
\hline Ventas Contact center & Revisar disponibilidad con operador & \\
\hline Ventas Contact center & Buscar alternativas & \\
\hline Ventas Contact center & Tomar información & \\
\hline Ventas Contact center & Realizar pre reserva & \\
\hline Ventas Contact center & Revisar disponibilidad de vuelos & \multirow{3}{*}{ Cotizar disponibilidad aérea } \\
\hline Ventas Contact center & Buscar alternativas & \\
\hline Ventas Contact center & Tomar información & \\
\hline Ventas Contact center & $\begin{array}{l}\text { Revisar disponibilidad en intranet de } \\
\text { hoteles }\end{array}$ & \multirow{5}{*}{ Cotizar paquetes } \\
\hline Ventas Contact center & Revisar disponibilidad con hoteles & \\
\hline Ventas Contact center & Buscar alternativas & \\
\hline Ventas Contact center & Realizar pre reserva & \\
\hline Ventas Contact center & Tomar información & \\
\hline
\end{tabular}




\begin{tabular}{|c|c|c|}
\hline PROCESO & AS IS & TO BE \\
\hline Ventas Contact center & Realizar cotización final & Generar cotización final \\
\hline Ventas Contact center & Confirmar vía telefónica & $\begin{array}{lll}\text { Realizar } & \text { seguimiento al } \\
\text { cliente } & & \end{array}$ \\
\hline Ventas Contact center & Cancelar & Cancelar \\
\hline Ventas Contact center & Enviar URL de POS Visa & \multirow{5}{*}{ Generar RIC } \\
\hline Ventas Contact center & Revisa constancia de pago & \\
\hline Ventas Contact center & Genera RIC validado & \\
\hline Ventas Contact center & Entrega RIC validado & \\
\hline Ventas Contact center & Generar RIC & \\
\hline Ventas Contact center & Verifica RIC & Verifica RIC \\
\hline Ventas Contact center & Realiza refrendo & Realiza refrendo \\
\hline \multirow[t]{2}{*}{ Ventas Contact center } & Entrega RIC con refrendo & Entrega RIC con refrendo \\
\hline & Cerrar RIC & Genera aviso RIC pagado \\
\hline Ventas Contact center & Cerrar RIC & Cerrar RIC \\
\hline
\end{tabular}

Fuente: Elaboración propia

\begin{tabular}{|l|l|l|}
\hline 30 & 15 & $50 \%$ \\
\hline
\end{tabular}

Índice de reducción de actividades. 


\subsubsection{Ventas web}

En el diagrama AS-IS (ver Figura 13. Diagrama AS IS del proceso Ventas web) se observa que el proceso cuenta con actividades manuales y sin el apoyo de una herramienta para la gestión de información.

La propuesta va por el lado de optimizar el proceso y para ello se han identificado las actividades que no son relevantes y que podrían omitirse o sustituirse en pos de que el proceso tenga mayor nivel de automatización y pueda entregar un valor agregado al cliente. 
Figura 17. Diagrama TO-BE del proceso Ventas web

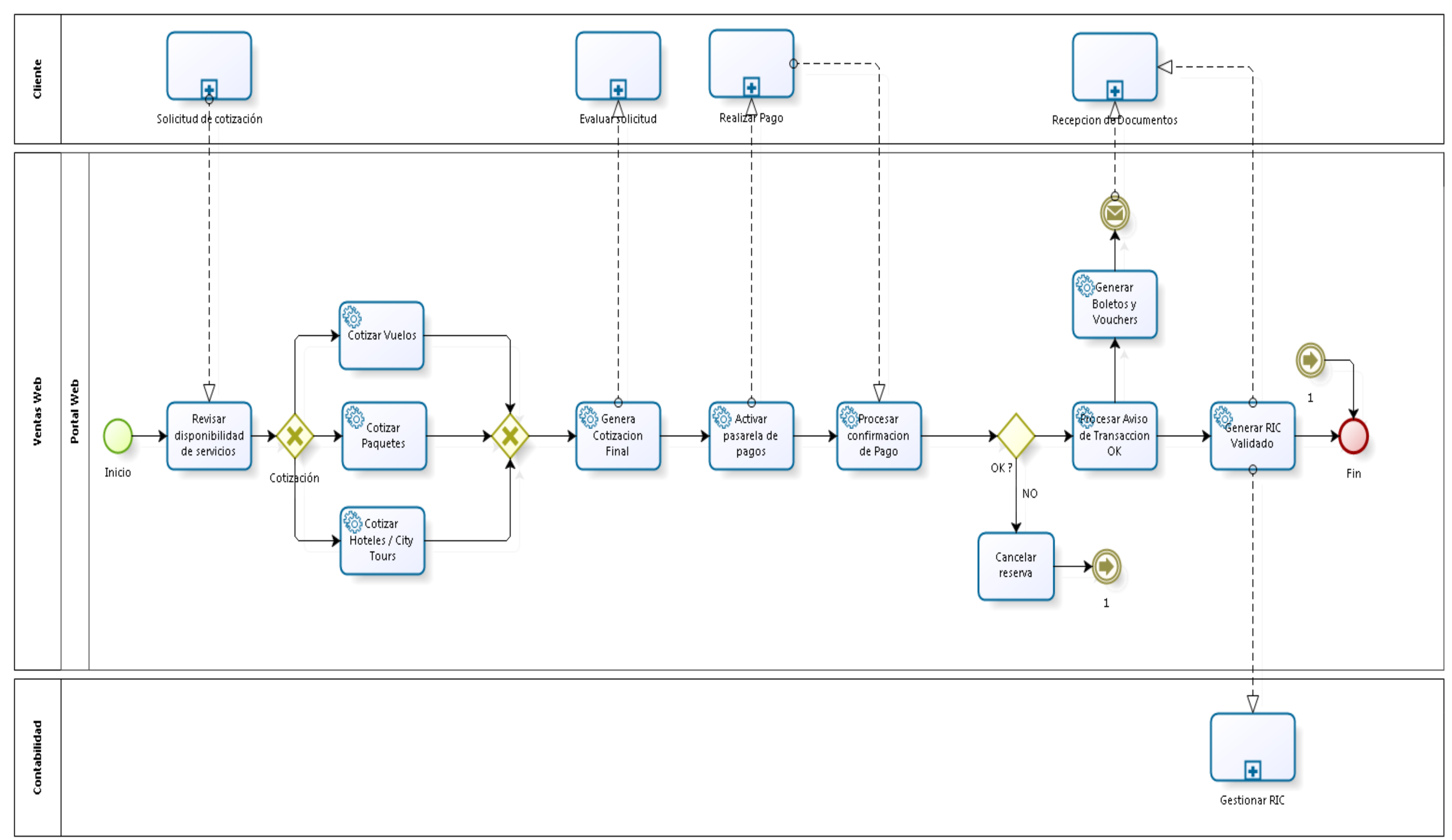

Fuente: Elaboración propia 


\section{Brecha del proceso AS-IS con el TO-BE}

Tabla 52. Matriz de brecha del proceso AS-IS con el TO-BE

\begin{tabular}{|c|c|c|}
\hline PROCESO & AS IS & TO BE \\
\hline Ventas Web & Revisar disponibilidad de productos & $\begin{array}{l}\text { Revisar disponibilidad de } \\
\text { servicios }\end{array}$ \\
\hline Ventas Web & Realizar búsqueda de vuelos & \multirow{2}{*}{ Cotizar vuelos } \\
\hline Ventas Web & Seleccionar vuelos & \\
\hline Ventas Web & Activar pasarela de pagos & Activar pasarela de pagos \\
\hline Ventas Web & Emitir aviso de transacción & $\begin{array}{l}\text { Procesar confirmacion de } \\
\text { pagos }\end{array}$ \\
\hline Ventas Web & Cancelar reserva & Cancelar reserva \\
\hline Ventas Web & Emitir boleto & $\begin{array}{l}\text { Procesar aviso de transaccion } \\
\text { OK }\end{array}$ \\
\hline Ventas Web & Realizar búsqueda de paquetes & \multirow{2}{*}{ Cotizar paquetes } \\
\hline Ventas Web & Seleccionar paquetes & \\
\hline Ventas Web & Realizar búsqueda de citytours & \multirow{2}{*}{ Cotizar hoteles/city tours } \\
\hline Ventas Web & Seleccionar citytours & \\
\hline Ventas Web & Realizar cotización final & Generar cotizacion final \\
\hline Ventas Web & Emitir aviso & \multirow{4}{*}{$\begin{array}{l}\text { Procesar aviso de transaccion } \\
\text { OK }\end{array}$} \\
\hline Ventas Web & Recibir cotización & \\
\hline Ventas Web & Gestionar reserva & \\
\hline Ventas Web & Enviar reserva & \\
\hline
\end{tabular}




\begin{tabular}{|c|c|c|}
\hline PROCESO & AS IS & TO BE \\
\hline Ventas Web & Realizar seguimiento & \\
\hline Ventas Web & Enviar URL POS Visa & \multirow{2}{*}{ Generar boletos y vouchers } \\
\hline Ventas Web & Revisar pago & \\
\hline Ventas Web & Generar RIC validado & \multirow{5}{*}{ Generar RIC validado } \\
\hline Ventas Web & Verificar RIC & \\
\hline Ventas Web & Realizar refrendo & \\
\hline Ventas Web & Entregar RIC con refrendo & \\
\hline Ventas Web & Cerrar RIC & \\
\hline
\end{tabular}

Fuente: Elaboración propia

\begin{tabular}{|l|l|l|}
\hline 24 & 12 & $50 \%$ \\
\hline
\end{tabular}

Índice de reducción de actividades 


\subsubsection{Diseño y desarrollo y de productos}

En el diagrama AS-IS (ver Figura 14. Diagrama AS IS del proceso Diseño y desarrollo y de productos) se observa que el proceso cuenta con actividades manuales y sin el apoyo de una herramienta para la gestión de información.

La propuesta va por el lado de optimizar el proceso y para ello se han identificado las actividades que causan retraso en el registro de un producto.

Figura 18. Diagrama TO-BE del proceso Diseño y desarrollo y de productos

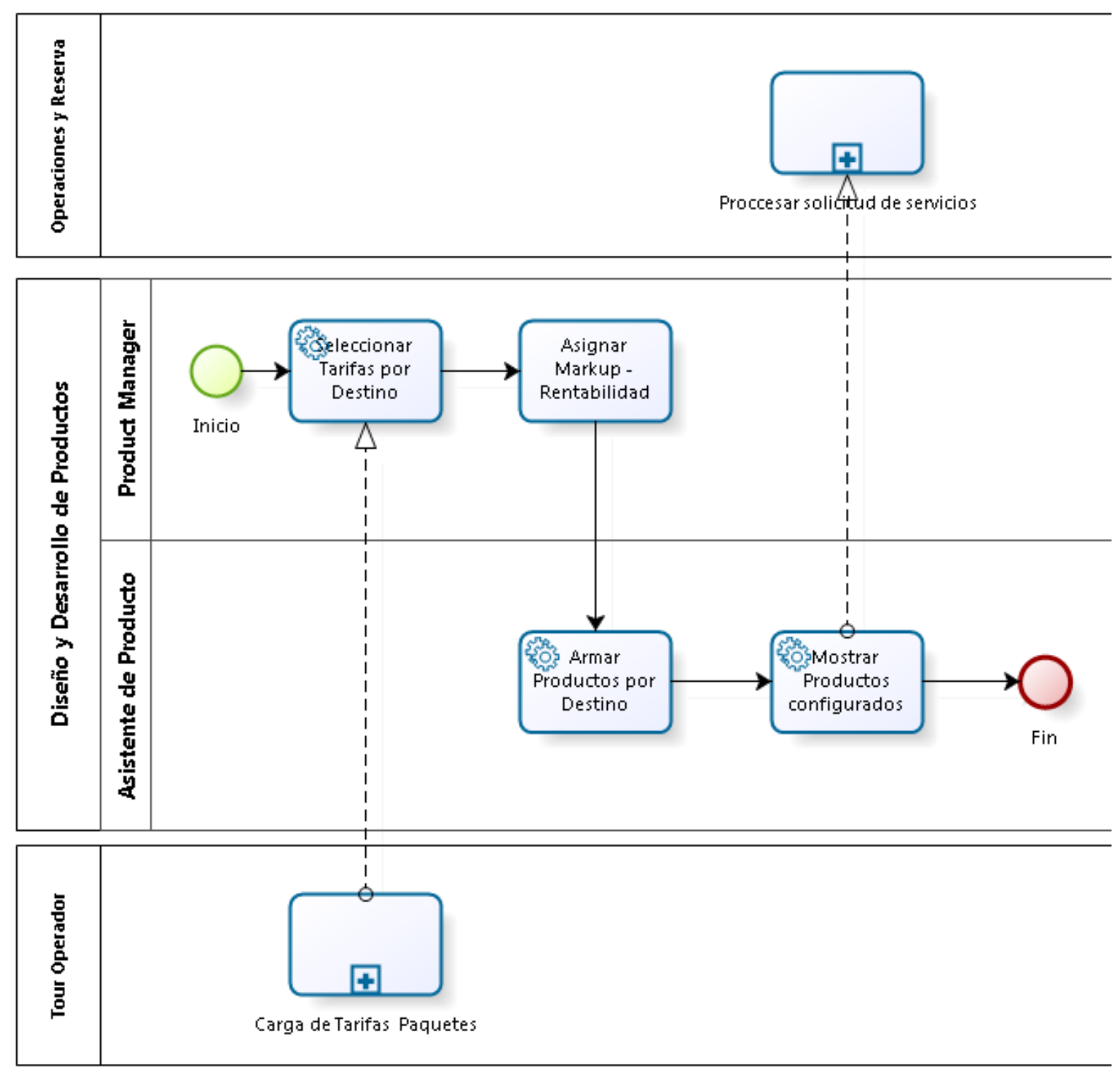

Fuente: Elaboración propia 


\section{Brecha del proceso AS-IS con el TO-BE}

Tabla 53. Matriz de brecha del proceso AS-IS con el TO-BE

\begin{tabular}{|l|l|l|}
\hline \multicolumn{1}{|c|}{ PROCESO } & \multicolumn{1}{|c|}{ AS IS } & \multicolumn{1}{c|}{ TO BE } \\
\hline Desarrollo de Productos & Revisar tarifas & $\begin{array}{l}\text { Seleccionar tarifas por } \\
\text { destino }\end{array}$ \\
\hline Desarrollo de Productos & Seleccionar las mejores tarifas & Asignar Mark Up \\
Desarrollo de Productos & Realizar costeo de productos & rentabilidad \\
\hline Desarrollo de Productos & Analizar productos por destino & Armar productos por destino \\
\hline Desarrollo de Productos & Registrar productos & Mostrar productos \\
\hline Desarrollo de Productos & Registrar productos & configurados \\
\hline
\end{tabular}

Fuente: Elaboración propia

\begin{tabular}{|l|l|l|}
\hline 6 & 4 & $33 \%$ \\
\hline
\end{tabular}

Índice de reducción de actividades. 


\subsection{Proyectos propuestos}

De acuerdo a lo desarrollado en el punto 3.1. Mejora de procesos, se proponen los siguientes proyectos a implementarse que permitirán pasar del AS-IS al TO-BE:

\section{P1: Implementación Front de Ventas (Juniper)}

\section{Propósito}

El proyecto brindará una herramienta de ventas y reservas con el objetivo de fortalecer el canal de venta retail convirtiéndolo en un pilar estratégico multicanal, integrando todos los productos ofertados en Viajes Falabella tales como: Paquete Dinámico, Hoteles, Cruceros, Tarjetas de Asistencia. También se podrá tener un conocimiento y unificación de clientes que nos compraron y nos cotizaron, un seguimiento oportuno de posibles ventas.

\section{Beneficios}

- Incremento de ventas retail, por contar con la información centralizada de los productos.

- Ahorro en disminución de multas, por contar con la información centralizada de las ventas de los clientes.

- Ahorro en compensación a clientes, por atención oportuna con ayuda de su información centralizada de los productos vendidos.

\section{Tiempo}

Tabla 54. Tiempo de implementación del P1

\begin{tabular}{|r|c|}
\hline \multicolumn{1}{|c|}{ Actividad } & Duración \\
\hline Análisis y Diseñol & 4 meses \\
\hline Personalización & 6 meses \\
\hline Certificación de la Calidad & 2 meses \\
\hline TOTAL & $\mathbf{1 2}$ meses \\
\hline
\end{tabular}

Fuente: Elaboración propia 


\section{P2: Implementación BackOffice (Pythagoras)}

\section{Propósito}

El proyecto brindará una herramienta administrativa con el objetivo de optimizar el proceso de facturación y poder gestionar de manera ágil los indicadores de negocio tanto a nivel operativo como contable.

\section{Beneficios}

- Incremento Eficiencia Operativa, por contar con información centralizada y obtenida del sistema Juniper (P1) como input para el proceso de facturación.

- Ahorro en costos de documentación, por estar sistematizado en el sistema y solo imprimir si es necesario para los procesos de auditoría financiera o si lo requiere el cliente.

- Incremento de la productividad del personal, dado que ya no invertirá tiempo en validar información del productos y reservas, pues será automático al culminar el proceso de pago.

\section{Tiempo}

Tabla 55. Tiempo de implementación del P2

\begin{tabular}{|r|c|}
\hline \multicolumn{1}{|c|}{ Actividad } & Duración \\
\hline Análisis y Diseñol & 3 meses \\
\hline Personalización & 5 meses \\
\hline Certificación de la Calidad & 2 meses \\
\hline TOTAL & $\mathbf{1 0}$ meses \\
\hline
\end{tabular}

Fuente: Elaboración propia 


\section{Propósito}

El proyecto brindará una herramienta que servirá como pasarela de pago dentro de la página web de Viajes Falabella, con esta pasarela de pago, el cliente final podrá compra en línea productos y servicios con las tarjetas del Banco Falabella, ya que ésta pasarela es propiedad del Banco Falabella.

\section{Beneficios}

- Incremento de la venta web, por contar con los productos y su detalle al alcance del cliente con el beneficio del pago en línea.

- Aumento de tráfico en la web, por que el cliente tendrá que realizar cualquier pago a través de la web que permitirá además ser un canal donde ofrezca publicidad de la variedad de ofertas que Viajes Falabella puede ofrecerle y que puede elegir de acuerdo a su necesidad.

\section{Tiempo}

Tabla 56. Tiempo de implementación del P3

\begin{tabular}{|r|c|}
\hline \multicolumn{1}{|c|}{ Actividad } & Duración \\
\hline Análisis y Diseñol & 4 meses \\
\hline Personalización & 2 meses \\
\hline Certificación de la Calidad & 4 meses \\
\hline TOTAL & $\mathbf{1 0}$ meses \\
\hline
\end{tabular}

Fuente: Elaboración propia

\section{Roadmap de proyectos}

Los proyectos podrán ejecutarse en paralelo, dado que se conocen los inputs y salidas. 
Gráfico 19. Roadmap de proyectos

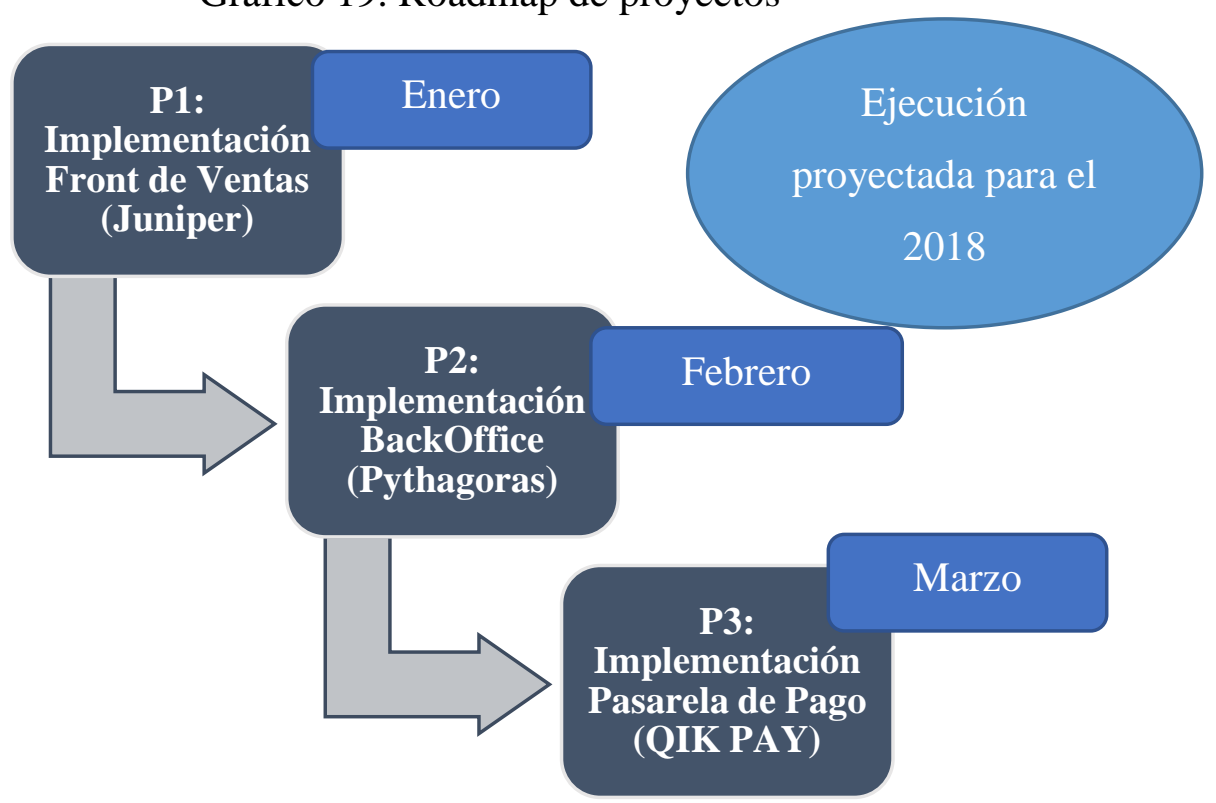

Fuente: Elaboración propia

\subsection{Análisis de Impacto}

Para la identificación y clasificación de riesgos se sigue la metodología aplicada en el PMBOK 5ta edición de acuerdo a los proyectos descritos en el punto 3.2. Proyectos Propuestos. Para ello, se tiene la tabla 57 en la cual se indican la probabilidad de impacto.

Tabla 57. Probabilidad de impacto

\begin{tabular}{|c|c|c|c|c|c|}
\hline Probabilidad & \multicolumn{5}{|c|}{ Amenazas } \\
\hline 0.9 & 0.05 & 0.09 & 0.18 & 0.36 & 0.72 \\
\hline 0.7 & 0.04 & 0.07 & 0.14 & 0.28 & 0.56 \\
\hline 0.5 & 0.03 & 0.05 & 0.10 & 0.20 & 0.40 \\
\hline 0.3 & 0.02 & 0.03 & 0.06 & 0.12 & 0.24 \\
\hline 0.1 & 0.01 & 0.01 & 0.02 & 0.04 & 0.08 \\
\hline & 0.05 & 0.1 & 0.2 & 0.4 & 0.8 \\
\hline & Muy bajo & Bajo & Moderado & Alto & Muy Alto \\
\hline
\end{tabular}

Fuente: Elaboración propia

\section{Escala de probabilidad}


En la escala de probabilidad se indica que tan probable es que un evento ocurra:

Tabla 58. Escala de probabilidad

\begin{tabular}{|c|l|}
\hline Probabilidad & \multicolumn{1}{|c|}{ Escala } \\
\hline 0.9 & Muy probable \\
\hline 0.7 & Bastante probable \\
\hline 0.5 & Medianamente probable \\
\hline 0.3 & Poco probable \\
\hline 0.1 & Nada probable \\
\hline
\end{tabular}

Fuente: Elaboración propia

\section{Escala de impacto}

En la escala de impacto se indica los efectos que se producen:

Tabla 59. Escala de impacto

\begin{tabular}{|c|l|}
\hline Impacto & \multicolumn{1}{|c|}{ Escala } \\
\hline 0.80 & Muy alto \\
\hline 0.40 & Alto \\
\hline 0.20 & Moderado \\
\hline 0.10 & Bajo \\
\hline 0.05 & Muy bajo \\
\hline
\end{tabular}

Fuente: Elaboración propia

\section{Escala de importancia}


La escala de importancia indica que tan probable es que un evento ocurra

Tabla 60. Escala de importancia

\begin{tabular}{|l|l|}
\hline Probabilidad & \multicolumn{1}{|c|}{ Escala } \\
\hline & Alto \\
\hline & Moderado \\
\hline & Bajo \\
\hline
\end{tabular}

Fuente: Elaboración propia

\section{Riesgos identificados}

Tabla 61. Riesgos identificados

\begin{tabular}{|c|c|c|c|c|c|c|}
\hline $\mathrm{N}^{\circ}$ & Riesgo & Descripción & Prob. & Imp. & Res. & Estrategia de mitigación \\
\hline 1 & $\begin{array}{l}\text { Acceso a } \\
\text { información no } \\
\text { integrada }\end{array}$ & $\begin{array}{l}\text { La falta de integración en } \\
\text { las aplicaciones puede } \\
\text { ocasionar problemas al } \\
\text { momento de consultar } \\
\text { información más precisa. }\end{array}$ & 0.5 & 0.4 & 0.2 & $\begin{array}{l}\text { Identificar aplicaciones } \\
\text { base y seleccionar la } \\
\text { información crítica a } \\
\text { considerar. }\end{array}$ \\
\hline 2 & $\begin{array}{l}\text { Resistencia al } \\
\text { cambio }\end{array}$ & $\begin{array}{l}\text { El estilo y forma de } \\
\text { trabajo vigente en la } \\
\text { empresa, principalmente } \\
\text { de los líderes, puede } \\
\text { afectar el desarrollo de la } \\
\text { propuesta impidiendo } \\
\text { identificar las mejoras o } \\
\text { proporcionando } \\
\text { información errónea. }\end{array}$ & 0.5 & 0.2 & 0.10 & $\begin{array}{l}\text { Seleccionar personal } \\
\text { clave en cada unidad de } \\
\text { negocio que permita } \\
\text { llegar a los demás } \\
\text { integrantes de las áreas y } \\
\text { proporcionarles } \\
\text { información sobre las } \\
\text { mejoras en reuniones de } \\
\text { trabajo. }\end{array}$ \\
\hline
\end{tabular}




\begin{tabular}{|c|c|c|c|c|c|c|}
\hline $\mathrm{N}^{\circ}$ & Riesgo & Descripción & Prob. & Imp. & Res. & Estrategia de mitigación \\
\hline 3 & $\begin{array}{l}\text { Falta de } \\
\text { establecimiento } \\
\text { para la línea } \\
\text { base del análisis } \\
\text { de brechas }\end{array}$ & $\begin{array}{l}\text { El no establecimiento de } \\
\text { una línea base sobre la } \\
\text { cual empezar (situación } \\
\text { actual AS-IS) se podría } \\
\text { tener propuestas que no } \\
\text { están asociadas a los } \\
\text { objetivos estratégicos y no } \\
\text { reflejarían la realidad. }\end{array}$ & 0.3 & 0.8 & 0.24 & $\begin{array}{l}\text { Identificar las actividades } \\
\text { correspondientes a la } \\
\text { situación actual, } \\
\text { incluyendo responsables } \\
\text { y tareas, de tal manera } \\
\text { que el trabajo sobre las } \\
\text { mejoras tenga un enlace } \\
\text { directo con los objetivos } \\
\text { vigentes. }\end{array}$ \\
\hline 4 & $\begin{array}{l}\text { Disponibilidad } \\
\text { de recursos para } \\
\text { el proyecto }\end{array}$ & $\begin{array}{l}\text { Si los recursos destinados } \\
\text { al proyecto no se } \\
\text { encuentran disponibles } \\
\text { (internos y externo) con } \\
\text { una asignación de mínimo } \\
80 \% \text { el proyecto puede } \\
\text { retrasarse. }\end{array}$ & 0.3 & 0.4 & 0.12 & $\begin{array}{l}\text { Identificar recursos } \\
\text { críticos y establecer } \\
\text { tiempos para cada } \\
\text { actividad a realizar. }\end{array}$ \\
\hline 5 & $\begin{array}{l}\text { Postergación de } \\
\text { reuniones }\end{array}$ & $\begin{array}{l}\text { Debido a la postergación } \\
\text { de reuniones se pueden } \\
\text { omitir o no considerar } \\
\text { actividades para los } \\
\text { diferentes procesos. }\end{array}$ & 0.3 & 0.4 & 0.12 & $\begin{array}{l}\text { Establecer fechas para } \\
\text { las reuniones a realizarse } \\
\text { con los involucrados del } \\
\text { proyecto y la realización } \\
\text { de entrevistas para } \\
\text { recopilar los datos } \\
\text { necesarios. }\end{array}$ \\
\hline
\end{tabular}




\begin{tabular}{|l|l|l|l|l|l|l|}
\hline \multicolumn{1}{|c|}{ Riesgo } & \multicolumn{1}{|c|}{ Descripción } & Prob. & Imp. & Res. & Estrategia de mitigación \\
\hline Cambios en el & $\begin{array}{l}\text { Modificaciones en el } \\
\text { alcance del proyecto } \\
\text { pueden generar retrasos } \\
\text { alcance del } \\
\text { proyecto }\end{array}$ & $\begin{array}{l}\text { en el cronograma o } \\
\text { incumplimiento de } \\
\text { actividades previamente } \\
\text { definidas. }\end{array}$ & 0.1 & 0.8 & 0.08 & $\begin{array}{l}\text { Realizar un análisis de } \\
\text { toda propuesta de cambio } \\
\text { y evaluar el impacto en } \\
\text { el proyecto. }\end{array}$ \\
\hline $\begin{array}{l}\text { Disponibilidad } \\
\text { de usuarios } \\
\text { clave }\end{array}$ & $\begin{array}{l}\text { Debido a la rotación de } \\
\text { personal en Viajes } \\
\text { femolla se puede generar en el desarrollo de } \\
\text { las entrevistas o } \\
\text { recopilación de } \\
\text { información. }\end{array}$ & 0.3 & 0.4 & 0.12 & $\begin{array}{l}\text { Establecer mecanismos } \\
\text { de control como actas de } \\
\text { reunión para llevar el } \\
\text { registro de las } \\
\text { actividades. }\end{array}$ \\
\hline
\end{tabular}

Fuente: Elaboración propia 


\subsection{Evaluación Financiera}

\section{INVERSIÓN}

Se muestra de forma detallada todos los puntos en los que se tendrá que invertir, para poder empezar con las distintas implementaciones propuestas.

\begin{tabular}{|l|r|l|r|r|}
\hline & \multicolumn{1}{c}{ Cantidad } & \multicolumn{1}{c|}{ Unidad } & 233 & 35,000 \\
\hline Liciencias Pythagoras & 150 & personas & 40.00 & 16,000 \\
\hline Desarrollo GAP - Pythagoras & 400 & horas & 250 & 60,000 \\
\hline Licencias Juniper & 240 & personas & 70 & 21,000 \\
\hline Desarrollo GAP - Juniper & 300 & horas & 4,000 & 20,000 \\
\hline Infraestructura CLOUD & 5 & servidores & 5,500 & 5,500 \\
\hline Implementación IVR & 1 & producto & 25,000 & 25,000 \\
\hline Implementación de red entre Chile y Perú & 1 & producto & & 182,500 \\
\hline
\end{tabular}

Fuente: Elaboración propia

\section{GASTOS INTERNOS}

Se muestra de forma detallada como está construido la línea de Gastos Internos.

\begin{tabular}{|c|c|c|c|c|c|c|}
\hline Actividad & Costo & Etapa Proyecto & Personas & Dias & Veces & Totales \\
\hline Vuelo & 350 & Planificación & 2 & 5 & 1 & 2,400 \\
\hline Hotel & 100 & Desarrollo & 1 & 10 & 3 & 5,200 \\
\hline Viatico & 60 & Puesta en Marcha & 1 & 10 & 2 & 3,600 \\
\hline Traslados & 50 & Producción & 1 & 5 & 1 & 1,200 \\
\hline & & Seguimiento & 1 & 2 & 3 & 1,360 \\
\hline & & Proveedor & 1 & 30 & 5 & 24,400 \\
\hline & & & & & Total 1er Año & 38,160 \\
\hline
\end{tabular}

Fuente: Elaboración propia 


\section{GASTOS EXTERNOS}

Se muestra de forma detallada todos los puntos en los que se convertirán en gastos recurrentes.

\begin{tabular}{|l|r|r|r|}
\hline & \multicolumn{1}{|c}{ Mensual } & \multicolumn{1}{c|}{$\mathbf{2 0 1 9}$} & \multicolumn{1}{c|}{2020} \\
\hline Mantención Pythagoras & 2,000 & 24,000 & 24,000 \\
\hline Mantención Jniper & 1,500 & 18,000 & 18,000 \\
\hline Mantenimiento de Infraestructura CLOUD & 500 & 6,000 & 6,000 \\
\hline Servicio IVR & 300 & 3,600 & 3,600 \\
\hline & Total & $\mathbf{5 1 , 6 0 0}$ & $\mathbf{5 1 , 6 0 0}$ \\
\hline
\end{tabular}

Fuente: Elaboración propia

\section{REDUCCIÓN PERDIDAS / AHORROS}

Se muestra de forma detallada todos los puntos que se convierten en beneficios para el negocio.

\begin{tabular}{|c|c|c|c|}
\hline & Disminucion de compensacion a los clientes & $-20 \%$ & $-30 \%$ \\
\hline & Disminucion en Pago de Multas & $-20 \%$ & $-30 \%$ \\
\hline & Crecimiento Rentabilidad & $3 \%$ & $5 \%$ \\
\hline BENEFICIOS & ForeCast 2018 & 2019 & 2020 \\
\hline Aumento del Margen Rentabilidad & 210,000 & 216,300 & 227,115 \\
\hline Ahorro en pago de horas extras & 6,000 & 2,000 & 3,000 \\
\hline Disminucion en Pago de Multas & 20,000 & 4,000 & 6,000 \\
\hline Disminucion de compensacion a los clientes & 30,000 & 6,000 & 9,000 \\
\hline Eliminacion Mantenimiento BackOffice Actual & 10,000 & 24,000 & 24,000 \\
\hline Desarticulacion cuarto de computo & - & 12,000 & 12,000 \\
\hline Venta servidores actuales & - & 7,000 & - \\
\hline TOTAL & 276,000 & 271,300 & 281,115 \\
\hline
\end{tabular}

Fuente: Elaboración propia

\section{CASO NEGOCIO (USD)}




\begin{tabular}{|c|c|c|c|c|}
\hline & 2018 & 2019 & 2020 & Total \\
\hline \multicolumn{5}{|l|}{ Inversión US\$ } \\
\hline Liciencias Pythagoras & 35,000 & & & 35,000 \\
\hline Desarrollo GAP - Pythagoras & 16,000 & & & 16,000 \\
\hline Licencias Juniper & 60,000 & & & 60,000 \\
\hline Desarrollo GAP - Juniper & 21,000 & & & 21,000 \\
\hline Infraestructura Cloud & 20,000 & & & 20,000 \\
\hline Implementación IVR & 5,500 & & & 5,500 \\
\hline Implementación de red entre Chile y Perú & 25,000 & & & 25,000 \\
\hline Total Inversión & 182,500 & & & 182,500 \\
\hline \multicolumn{5}{|l|}{ Gastos Internos US\$ } \\
\hline Costos de Viajes de coordinación & 38,160 & & & 38,160 \\
\hline Total Gastos Internos & 38,160 & & & 38,160 \\
\hline \multicolumn{5}{|l|}{ Gastos Externos US\$ } \\
\hline Mantención Pythagoras & - & 24,000 & 24,000 & 48,000 \\
\hline Mantención Juniper & & 18,000 & 18,000 & 36,000 \\
\hline Mantenimiento Infraestructura CLOUD & - & 6,000 & 6,000 & 143,726 \\
\hline Servicio IVR & - & 3,600 & 3,600 & 7,200 \\
\hline Total Gastos Externos & - & 51,600 & 51,600 & 234,926 \\
\hline Flujos Negativos US\$ & 220,660 & 51,600 & 51,600 & 323,860 \\
\hline \multicolumn{5}{|l|}{ Reducción Pérdidas/Ahorros US\$ } \\
\hline Aumento del Margen Rentabilidad & & 216,300 & 227,115 & 443,415 \\
\hline Ahorro en pago de horas extras & & 2,000 & 3,000 & 5,000 \\
\hline Dismuinución Multas & & 4,000 & 6,000 & 10,000 \\
\hline Disminución Compensaciones Clientes & & 6,000 & 9,000 & 15,000 \\
\hline Eliminación Chiabra Sistemas & & 24,000 & 24,000 & 48,000 \\
\hline Desarticulacion del Cuarto de Computo & & 12,000 & 12,000 & 24,000 \\
\hline Venta de servidores antiguos & & 7,000 & - & 7,000 \\
\hline Total Beneficios & - & 271,300 & 281,115 & 552,415 \\
\hline Flujos Positivos US\$ & - & 271,300 & 281,115 & 552,415 \\
\hline Flujos Totales Us\$ & 220,660 & 219,700 & 229,515 & 228,556 \\
\hline
\end{tabular}

Fuente: Elaboración propia

\section{RESUMEN FLUJO CAJA (USD)}




\begin{tabular}{|c|c|c|c|c|c|c|c|}
\hline Año & Ingresos & Egresos & $\begin{array}{l}\text { Flujo } \\
\text { Anual }\end{array}$ & $\begin{array}{c}\text { Acum } \\
\text { Egresos }\end{array}$ & $\begin{array}{c}\text { Acum } \\
\text { Ingreso }\end{array}$ & $\begin{array}{l}\text { Flujo } \\
\text { Acum }\end{array}$ & Payback \\
\hline Año 0 & - & 220,660 & $-\quad 220,660$ & 220,660 & - & $-\quad 220,660$ & 0.00 \\
\hline Año 1 & 271,300 & 51,600 & 219,700 & 272,260 & 271,300 & 960 & 0.00 \\
\hline \multirow[t]{2}{*}{ Año 2} & 281,115 & 51,600 & 229,515 & 323,860 & 552,415 & 228,556 & 1.59 \\
\hline & 552,415 & 323,860 & 228,556 & & & & \\
\hline
\end{tabular}

\begin{tabular}{|l|r|}
\hline Tasa Interés & $9 \%$ \\
\hline VAN & 174,078 \\
\hline TIR & $63 \%$ \\
\hline PayBack & 1.59 \\
\hline ROI & $71 \%$ \\
\hline
\end{tabular}

Fuente: Elaboración propia

Después de analizar el caso de negocio y realizar el flujo de caja respectivo podemos apreciar que el proyecto es viable financieramente ya que nos da una VAN de USD 174,078 positiva, lo cual indica que el proyecto nos propondrá una ganancia significativa. Así mismo podemos observar que el proyecto tiene una rentabilidad de 63\% por año lo cual se puede apreciar a través del indicador financiero TIR. También se muestra el indicador del ROI que indica 71\% de retorno de la inversión durante los dos periodos calculados. Y como último indicador calculado tenemos el PayBack de 1.59 que indica que, para poder tener retorno de la inversión, esta se realiza en 1 año y 6 meses aproximadamente. Cabe mencionar que el periodo utilizado para la evaluación financiera será del 2018-2020 y está orientado al desarrollo de los proyectos descritos en el punto 3.2. Proyectos Propuestos, con ello se podrá implementar la arquitectura de negocio con un retorno de la inversión a partir del 2020 con una tasa de interés anual de 9\%. 


\section{CAPITULO 4}

\section{CONCLUSIONES}

En el presente capítulo se presenta para finiquitar el trabajo de investigación con las conclusiones a las que se ha llegado. 


\section{Conclusiones}

El aporte de la presente propuesta, contribuye favorablemente a la mejora de procesos del área de Ventas y Productos de la Agencia de Viajes “Viajes Falabella”

Las empresas requieren de instrumentos que les permitan una mayor agilidad empresarial, la cual es posible si se facilita la implantación de nuevos modelos de negocio de forma rápida y la obtención de una mejora en la eficiencia empresarial derivada de unos procesos mejor orquestados, vía una integración más natural, confiable y oportuna, y que, en el ámbito operativo de TI, estén representados principalmente en reducción de costos, facilidad de la escalabilidad, flexibilidad y oportunidad, y mejor administración de la seguridad, entre otros.

El desarrollo de la Arquitectura de Negocio se debe entender como la descripción integral y estructurada de los diferentes elementos que conforman la empresa, que es realizada por equipos interdisciplinarios que conocen muy bien la empresa, sus procesos, las líneas de negocio y la forma en que la empresa evoluciona, que se acogen a las reglas y principios corporativos, que aplican las técnicas y metodologías establecidas, que se arriesgan a proponer, a innovar y a disfrutar del proceso de construcción de diferentes procesos y proyectos que apoyan el desarrollo del negocio, y que tienen la capacidad de percibir, pensar y proyectar la empresa con una visión global e integral, sin perder de vista el contexto en que ésta se desenvuelve.

El proceso de construcción de la Arquitectura de Negocio no debe ser visto solamente como el ejercicio de “desarrollar o crear la arquitectura”; la importancia real radica en el hecho de que ésta realmente sea útil para quien la utiliza, que se mantenga actualizada y que genere valor al negocio al ser aplicada en la ejecución de los proyectos. 


\section{BIBLIOGRAFÍA}

Monserrat de Gregorio Pachon (2014) “Impacto de las TICs en el Sector Turístico”

Diario Gestion - $\quad$ Articulo "Estadisticas de Turismo" (2016) http://gestion.pe/economia/2015-35-millones-turistas-internacionales-visitaronperu-senala-mincetur-2154616

Revista de Turismo \& Tecnologia - Articulo "Uso de las TICs en Turismo, nuevas tecnologías al servicio del viajero" (2014) http://www.turismoytecnologia.com/todos-los-articulos-detecnologia/item/3617-uso-de-tics-en-turismo-nuevas-tecnologias-al-servicio-del-

viajero

Starcom - Reporte de Competencia (2017)

Viceministerio de Turismo - PENTUR - Plan Estrategico Nacional de Turismo (2012-2021)

Ministerio de Comercio Exterior y Turismo - Reporte Estadistico de Turismo (2016)

Norma Fuller - Polticas Publicas de Turismo en el Peru (2012)

Rafael Castillo Santos, Hernando Castillo García (2014). Arquitectura Empresarial y las Organizaciones Estatales.

Annette Malleuve Martínez, Daniel Alfonso Robaina, Mavis Lis Stuart Cárdenas (2015). Una aproximación hacia la evaluación del nivel de madurez de la arquitectura empresarial.

Cesar Esquetini Cáceres, Oswaldo Moscoso Zea (2014). Propuesta de un marco de referencia de gestión de organizaciones usando Arquitectura Empresarial. 
Arango S., Londoño S. y Branch B. (2015). Enfoque de arquitectura de solución, mecanismo para reducir la brecha entre la arquitectura empresarial y la implementación de soluciones tecnológicas. Dyna, 82(193), 117-126.

CIO@gov (2013). Un Estado integrado: La meta de la Arquitectura Empresarial para Colombia. Publicación del Ministerio TIC para los CIO públicos de Colombia, 2, 4-9.

Fatemeh N., Binti A., Darvish R. y Naz'ri M. (2016). An effective Enterprise Architecture Implementation Methodology. Springer-Verlag, 3-29. doi: 10.1007/s10257-016-0336-5

Gartner., IT glossary gartner research, [En línea]. [Fecha de referencia Febrero de 2017]. Recuperado de http://www.gartner.com/it-glossary/solution-architecture

The Open Group., The Open Group Architectural Framework (TOGAF) Version 9.1, Capitulo 3.65 [En línea], [Fecha de referencia Febrero de 2017]. Recuperado de http://www.opengroup.org/subjectareas/enterprise/togaf

Viajes Falabella (2015). Plan Estratégico 2015 - 2016. 